\title{
Modelling and interpreting the isotopic composition of water vapour in convective updrafts
}

\author{
M. Bolot ${ }^{1}$, B. Legras ${ }^{1}$, and E. J. Moyer ${ }^{2}$ \\ ${ }^{1}$ Laboratoire de Météorologie Dynamique, IPSL, UPMC/CNRS/ENS/Ecole Polytechnique, UMR8539, Paris, France \\ ${ }^{2}$ Department of the Geophysical Sciences, University of Chicago, Chicago, USA \\ Correspondence to: M. Bolot (bolot@1md.ens.fr)
}

Received: 10 May 2012 - Published in Atmos. Chem. Phys. Discuss.: 31 August 2012

Revised: 4 July 2013 - Accepted: 10 July 2013 - Published: 16 August 2013

\begin{abstract}
The isotopic compositions of water vapour and its condensates have long been used as tracers of the global hydrological cycle, but may also be useful for understanding processes within individual convective clouds. We review here the representation of processes that alter water isotopic compositions during processing of air in convective updrafts and present a unified model for water vapour isotopic evolution within undiluted deep convective cores, with a special focus on the out-of-equilibrium conditions of mixed-phase zones where metastable liquid water and ice coexist. We use our model to show that a combination of water isotopologue measurements can constrain critical convective parameters, including degree of supersaturation, supercooled water content and glaciation temperature. Important isotopic processes in updrafts include kinetic effects that are a consequence of diffusive growth or decay of cloud particles within a supersaturated or subsaturated environment; isotopic re-equilibration between vapour and supercooled droplets, which buffers isotopic distillation; and differing mechanisms of glaciation (droplet freezing vs. the Wegener-Bergeron-Findeisen process). As all of these processes are related to updraft strength, particle size distribution and the retention of supercooled water, isotopic measurements can serve as a probe of in-cloud conditions of importance to convective processes. We study the sensitivity of the profile of water vapour isotopic composition to differing model assumptions and show how measurements of isotopic composition at cloud base and cloud top alone may be sufficient to retrieve key cloud parameters.
\end{abstract}

\section{Introduction}

Because the relative abundances of the stable isotopologues of water - $\mathrm{HDO}, \mathrm{H}_{2}{ }^{18} \mathrm{O}$, and $\mathrm{H}_{2} \mathrm{O}-$ are sensitive to phase changes that occur within air masses, water isotopic ratios have long been used as tracers of the atmospheric water cycle (since pioneering works in the 1950s; see Dansgaard, 1964 for review). Although the primary motivation for isotopic studies in the past has been the interpretation of paleoclimatic measurements (Jouzel and Merlivat, 1984, and references herewith), a second motivation is to obtain otherwise irretrievable information about convective processes (Jouzel et al., 1975; Risi et al., 2008; Lee et al., 2009; Kurita et al., 2011). Constraining convective processes has been a major incentive for recent efforts to include water isotopologues in atmospheric general circulation models (AGCMs) (Joussaume et al., 1984; Jouzel et al., 1987; Schmidt et al., 2005; Bony et al., 2008). These modelling studies, along with the recent availability of spaceborne observations of the isotopic composition of water vapour (Moyer et al., 1996; Kuang et al., 2003; Nassar et al., 2007; Steinwagner et al., 2007; Worden et al., 2011), have shown the potential of using water isotopologues to test our understanding of large-scale atmospheric processes (Risi et al., 2008; Lee et al., 2009). At smaller scales, in situ measurements and inclusion of water isotopologues in cloud-resolving models may bring insight into the deep convective transport of water to the tropical tropopause layer (TTL) (Smith et al., 2006; Hanisco et al., 2007; Blossey et al., 2010; Sayres et al., 2010).

In the tropics, convective clouds provide the only mechanism for transporting vapour and condensates across isentropes in the free troposphere, and most air parcels, dried 
out within the convective cells, eventually sink back to the surface owing to radiational heat loss once they reach beyond the confines of convective anvils (Folkins and Martin, 2005). Fast large-scale stirring also redistributes air parcels towards the subtropics, moving upward in a quasi-isentropic way (Pierrehumbert and Roca, 1998; Couhert et al., 2010) and providing further dehydration (Galewsky et al., 2005). While moisture is fixed by the last dehydration within or outside the clouds, the water isotopic signature depends on the whole history of the air parcel since its last contact with the boundary layer. The isotopic signature of free tropospheric water vapour in the tropics and subtropics is therefore largely determined by processes within convective clouds and by the evaporation of condensates formed by convection (Wright et al., 2009; Risi et al., 2012).

Our ability to model the convective transport of water isotopologues depends on how well we account for the relevant physical processes in convective clouds. In that regard, some current assumptions about water isotopologues made in AGCMs may need to be revisited. The need to reproduce the observed isotopic content of precipitations over very cold regions (Greenland, Antarctica) was the main incentive to include kinetic isotope effects (i.e. the fact that isotope fractionation is limited by diffusion of water vapour and heat) in AGCMs (Jouzel and Merlivat, 1984; Ciais and Jouzel, 1994). As clouds and precipitations are parametrised rather than explicitly represented in AGCMs, supersaturation over ice has been commonly represented as a simple function of temperature with the dependence chosen to reproduce isotopic signatures in polar regions (Jouzel et al., 1987; Hoffmann et al., 1998). Temperatures as low as those over the poles are also found at the top of convective towers, but the conditions within vertically-rising convective air parcels are very different from those associated with transport of moisture from evaporation to deposition zones at polar latitudes. Convective towers, unlike stratiform clouds, are characterised by a high amount of condensed phase retained in the cloud and supercooled droplets may persist to temperatures as low as $-40^{\circ} \mathrm{C}$ level. Supersaturation in convective clouds depends on updraft velocity, on the size distribution of liquid and ice particles, and on the retention of supercooled water. The distribution of stable isotopologues is therefore expected to be sensitive to the representation of convective processes.

Much of the material discussed in this paper has already been treated in the literature, and the basic physics of isotopologues is not new. Studies of isotopologues in the context of convection can be traced back to the pioneering works of Jouzel et al. (1975) and Federer et al. (1982). Further contributions to the field include Gedzelman and Arnold (1994); Moyer et al. (1996); Bony et al. (2008); Lee et al. (2009) and Blossey et al. (2010). Our aim here is to provide a consistent picture of how isotopic distributions are linked to cloud microphysics and thermodynamics, incorporating elements that are spread across several studies. As stated above, we will revisit some current assumptions on the representation of microphysics. In particular, we are interested in the effects related to saturation and glaciation on the distribution of isotopologues within deep convective clouds, which may open a way to retrieve quantitative information on these key processes from isotopic observations. This work is motivated by the recent surge of field and satellite measurements in the upper troposphere (Sayres et al., 2009; Nassar et al., 2007; Steinwagner et al., 2007; Randel et al., 2012) and by rising interest in using isotopologues to diagnose cloud processes and their impact on tropical variability. For example, water isotopologues have recently been used to study the origin of water and circulations around clouds in hurricanes (Fudeyasu et al., 2008; Lawrence and Gedzelman, 1996, 2003) and the Madden-Julian oscillation (Kurita et al., 2011; Berkelhammer et al., 2012). A consistent model can aid interpretation of measurements and can be useful in helping to design measurement programs.

In this paper, we describe and discuss a minimal model that predicts the isotopic composition of water vapour within convective clouds. We restrict the model based on two assumptions. First, we omit any interaction between precipitating species and the environment they descend through, and include only transformations between vapour, cloud water, and cloud ice. This assumption does not invalidate treatment of water vapour in updrafts, since precipitating condensates tend to be collected in convective-scale downdrafts that are spatially distinct from updrafts (see, e.g. LeMone and Zipser, 1980; Kirkpatrick et al., 2009). Second, we assume that those transformations are adiabatic (i.e. that entrainment is negligible). The modelling framework we present therefore best represents undiluted deep convection that reaches the upper troposphere (i.e. tropical hot towers, Riehl and Malkus, 1958; Fierro et al., 2009). These limitations seem legitimate for a first step and do not hamper our ability to investigate how variations in updraft physics produce variations in the distribution of vapour isotopologues within clouds.

In the sections that follow, Sect. 2 reviews the physics of fractionation and the kinetic effects induced by the diffusional growth of droplets and crystals; Sect. 3 describes the bulk approach to modelling and derives the equation governing the water vapour isotopic profile; and Sect. 4 discusses model results for the distillation of water vapour as an air parcel ascends and its sensitivity to saturation and other microphysical processes. Section 5 discusses the comparative evolution of the $\mathrm{H}_{2} \mathrm{O} / \mathrm{HDO}$ and $\mathrm{H}_{2} \mathrm{O} / \mathrm{H}_{2}{ }^{18} \mathrm{O}$ systems; Sect. 6 evaluates the use of combined observation of HDO and $\mathrm{H}_{2}{ }^{18} \mathrm{O}$ to retrieve key convective parameters; and Sect. 7 summarises and offers further discussion.

\section{Fractionation physics}

Before presenting model equations, it is useful to review the basic physics of isotopes partitioning at microphysical scales and its connection with the macroscopic description 
of cloud physics. We describe notation (Sect. 2.1) and review both equilibrium isotopic partitioning (Sect. 2.2) and the additional fractionation induced by the kinetics of particle growth/decay (Sect. 2.3). Additional material on kinetic effects is included in appendices: Appendix A reviews the growth and loss rates of droplets and ice crystals that is the basis of the isotopic kinetic effects and Appendix B provides the full derivation of kinetic fractionation factors. We follow closely the derivations of Jouzel et al. (1975) and Jouzel and Merlivat (1984), but emphasize the differences between fractionation of ice and liquid water and highlight interpretations that are specific to the context of deep convection. Reviews covering similar material include Gedzelman and Arnold (1994) and Blossey et al. (2010).

\subsection{Isotopic notation}

Isotopic abundances are typically described in terms of isotopic ratios, e.g. for the deuterated water $R=[\mathrm{D}] /[\mathrm{H}]$ (or $\left.R=\frac{1}{2}[\mathrm{HDO}] /\left[\mathrm{H}_{2} \mathrm{O}\right]\right)$. These isotopic ratios are themselves typically reported as per mil deviations from a standard: $\delta=1000\left(\frac{R}{R_{0}}-1\right)$, where $R_{0}$ is the isotopic ratio of the standard (the symbols $\delta \mathrm{D}$ and $\delta^{18} \mathrm{O}$ are used for the isotopic abundances of deuterium and oxygen 18 in water vapour, respectively). For water isotopologues, the reference standard is generally the Vienna Sea Mean Ocean Water (VSMOW) (Hagemann et al., 1970; Gonfiantini, 1978; Stichler et al., 1995). In this work, we have found it convenient to define isotopic ratio as the ratio of isotopologue masses rather than as the ratio of their abundances. That is, $R=\rho_{\mathrm{HDO}} / \rho_{\mathrm{H}_{2} \mathrm{O}}=$ $2 \rho_{\mathrm{D}} / \rho_{\mathrm{H}}$ or $R=\rho_{\mathrm{H}_{2}{ }^{18} \mathrm{O}} / \rho_{\mathrm{H}_{2} \mathrm{O}}=\rho_{18} \mathrm{O} / \rho_{16} \mathrm{O}$, where the $\rho_{[\ldots]} \mathrm{S}$ represent densities of heavy and light isotopologues. Our definition leaves $\delta$ s unaffected, given an adjustment of the definition of $R_{0}$ (see Appendix D2). Fractionation factors (defined below) are also unaffected by our definition. Throughout this work, we represent the heavy isotopologue quantity (HDO or $\mathrm{H}_{2}{ }^{18} \mathrm{O}$ ) by a prime letter, e.g. $R=\rho^{\prime} / \rho$.

\subsection{Equilibrium fractionation}

The vapour pressure isotope effect is a quantum phenomenon that results from a lowering of vibrational energies upon substitution of an atom by its heavy isotope equivalent (Herzfeld and Teller, 1938; Urey, 1947; Bigeleisen, 1961; Van Hook, 1968). At phase equilibrium between liquid and solid, or vapour and solid, the condensed phase is then relatively enriched in heavy isotopologues. This equilibrium partitioning is described by the equilibrium fractionation factors $\alpha_{1, \mathrm{i}}=$ $R_{1, \mathrm{i}} / R_{\mathrm{V}} \geqslant 1$ where $R_{\mathrm{v}}, R_{1}$ and $R_{\mathrm{i}}$ are the isotopic ratios of vapour, liquid and ice, respectively (the double index $1, \mathrm{i}$ is used throughout as a shorthand notation for relations which are valid for both liquid water and ice). The fractionation factor $\alpha_{1, \mathrm{i}}$ is a physical parameter that depends only on temperature, and is larger at colder temperatures (see Fig. 1 and Appendix D3).
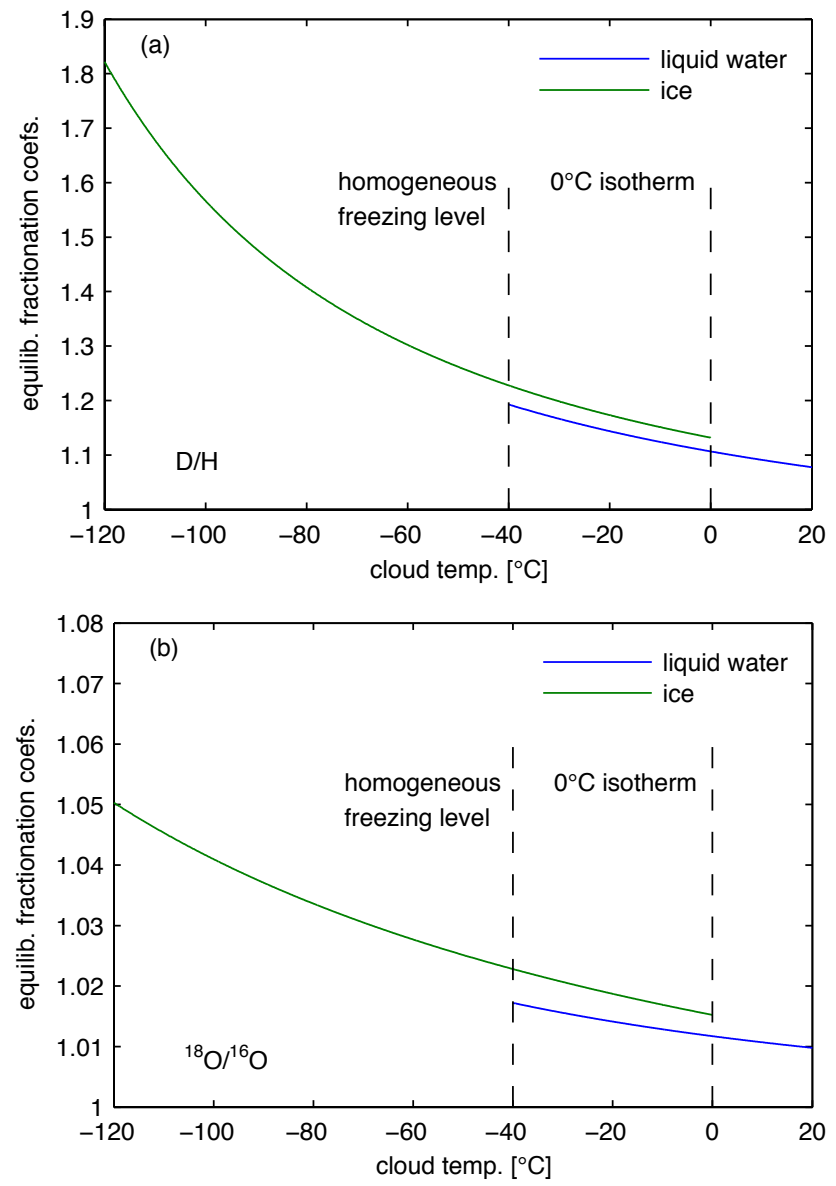

Fig. 1. Equilibrium fractionation factors for vapour-liquid (blue) and vapour-ice (green) phase transition as a function of temperature. (a) $\mathrm{HDO} / \mathrm{H}_{2} \mathrm{O}$; (b) $\mathrm{H}_{2}{ }^{18} \mathrm{O} / \mathrm{H}_{2} \mathrm{O}$. Notice that fractionation over ice is higher than fractionation over liquid in the mixed-phase zone. This equilibrium behaviour is eventually reversed when kinetic effects and droplet evaporation are considered (WBF process).

Achieving this thermodynamic equilibrium fractionation requires that vapour surrounding cloud droplets or crystals be exactly at saturation, with no temperature contrast between environment vapour and condensates. In real-world cloud conditions, these conditions are unlikely to hold. First, condensates grow and evaporate under supersaturated or subsaturated environments. Second, growth and evaporation typically occur rapidly enough that condensate surfaces are not in thermodynamic equilibrium with their environments. Isotopic models must therefore be built on a broader kinetic theory in which thermal equilibrium behaviour applies only at the surface of droplets or ice crystals, which interacts with ambient air through a diffusive boundary layer. Under stationary conditions, this combination yields a pseudoequilibrium between condensates and the environment. We describe this pseudo-equilibrium in the next section. 


\subsection{Kinetic fractionation and isotopic relaxation in droplets and ice}

Kinetic modifications to fractionation factors occur whenever phase transformations take place in conditions other than thermodynamic equilibrium, i.e. whenever ambient water vapour is super- or subsaturated. Such effects were first discussed for ocean evaporation by Dansgaard (1964) and Craig and Gordon (1965), and were later investigated in the context of cloud physics by Gedzelman and Lawrence (1982) and Jouzel and Merlivat (1984).

Phase changes in super- or subsaturated environments are common in nature. Cloud droplets and crystals may grow in a supersaturated environment when the surrounding vapour field cannot adjust to saturation over liquid water or ice (as may happen when temperature and pressure drop is rapid and nuclei are limited; see, e.g. Korolev and Mazin, 2003). Conversely, supercooled droplets may evaporate in a subsaturated environment in mixed-phase conditions, where vapour pressure is intermediate between saturation over liquid and that over ice. In supersaturated (subsaturated) conditions, heavy and light vapour molecules diffuse toward (away from) the condensate across a boundary layer that connects the condensate surface to the far field environment, and the latent heat of phase transformation is extracted from (imported to) the condensate through a corresponding thermal boundary layer. (See Appendix A for a more detailed review).

As a result of diffusive exchanges, gradients in temperature and both light and heavy water vapour isotopologues develop across the boundary layer. That is, the surface values of vapour density $\rho_{\mathrm{v}}^{(\mathrm{s})}$, temperature $T^{(\mathrm{s})}$ and vapour isotopic ratio $R_{\mathrm{v}}^{(\mathrm{s})}=\rho_{\mathrm{v}}^{\prime(\mathrm{s})} / \rho_{\mathrm{v}}^{(\mathrm{s})}$ differ from those in the far field environment $\left(\rho_{\mathrm{v}}^{(\infty)}, T^{(\infty)} \text { and } R_{\mathrm{v}}^{(\infty)}=\rho_{\mathrm{v}}^{\prime(\infty)} / \rho_{\mathrm{v}}^{(\infty)}\right)^{1}$. Gradients in isotopologue vapour density necessarily differ because of both the preferential condensation and the lower diffusivity of heavy isotopologues (Merlivat, 1978), meaning that gradients also develop in isotopic composition: $R_{\mathrm{v}}^{(\infty)}<R_{\mathrm{v}}^{(\mathrm{s})}$ at droplet evaporation, and $R_{\mathrm{v}}^{(\infty)}>R_{\mathrm{v}}^{(\mathrm{s})}$ at droplet condensation or ice deposition (Figs. 2 and 3). It is conventional to capture these effects by defining kinetic fractionation factors between condensate surface and far field vapour $\left(\alpha_{\mathrm{k} \mid l, \mathrm{i}}=R_{1, \mathrm{i}}^{(\mathrm{s})} / R_{\mathrm{v}}^{(\infty)}\right)$ that differ from the equilibrium fractionation factors that actually govern partitioning at the surface $\left(\alpha_{1, \mathrm{i}}=R_{\mathrm{l}, \mathrm{i}}^{(\mathrm{s})} / R_{\mathrm{v}}^{(\mathrm{s})}\right)$.

The kinetic fractionation factors for liquid-vapour and ice-vapour phase transitions are obtained by coupling the laws of diffusion for heat and for light and heavy vapour (full derivation is performed in Appendix B; see also Jouzel and Merlivat, 1984 and Ciais and Jouzel, 1994). The resulting

\footnotetext{
${ }^{1}$ The environment beyond the diffusive boundary layer is also the far field from the point of view of diffusive theory (see Appendix A), hence the superscript $(\infty)$.
}

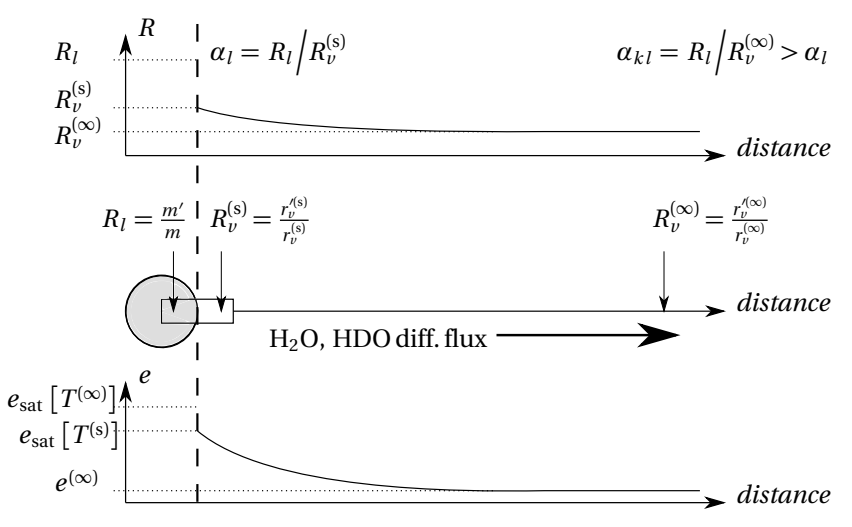

Fig. 2. Sketch of the evaporation of a droplet in a subsaturated environment. The lower panel displays the radial variation of water vapour partial pressure. The upper panel displays the radial variation of vapour isotopic ratios. The superscripts $(s)$ and $(\infty)$ denote values at droplet surface and outside the diffusive boundary layer, respectively. Vapour partial pressure decreases across the boundary layer in a way that depends on thermal and molecular diffusivity. Note that $e_{\mathrm{sat}}\left[T^{(\mathrm{s})}\right]<e_{\mathrm{sat}}\left[T^{(\infty)}\right]$ since the droplet surface is cooled below environmental temperature at evaporation $\left(e_{\mathrm{sat}}=\right.$ liquid saturation here). Thus, thermal impedance limits subsaturation at droplet surface compared to what it would be if $T^{(\mathrm{s})}$ were equal to $T^{(\infty)}$, and consequently limits isotopic kinetic effects. The decrease of vapour isotopic ratio across the boundary layer explains why the kinetic fractionation factor is enhanced over its equilibrium value. Note also that the whole droplet is assumed to equilibrate with its surrounding vapour field (grey shaded area = water actively exchanging with vapour) if its isotopic relaxation time is sufficiently small.

common expression for $\alpha_{\mathrm{kl}}$ and $\alpha_{\mathrm{ki}}$ is

$\alpha_{\mathrm{k} \mid 1, \mathrm{i}} \equiv \frac{R_{1, \mathrm{i}}^{(\mathrm{s})}}{R_{\mathrm{v}}^{(\infty)}}=\frac{\alpha_{1, \mathrm{i}}}{1+\left(\beta_{1, \mathrm{i}}-1\right)\left(1-\left(S_{1, \mathrm{i}}^{(\mathrm{eff})}\right)^{-1}\right)}$,

where

$S_{1, \mathrm{i}}^{(\mathrm{eff})}=\left(1-A_{1, \mathrm{i}}\left(1-S_{1, \mathrm{i}}^{-1}\right)\right)^{-1}$

is the effective saturation of vapour over liquid or ice measured at surface temperature $\rho_{\mathrm{v}}^{(\infty)} / \rho_{\mathrm{sat}}^{1, \mathrm{i}}\left[T^{(\mathrm{s})}\right], S_{\mathrm{l}, \mathrm{i}}$ is vapour saturation at far field temperature $\rho_{\mathrm{v}}^{(\infty)} / \rho_{\text {sat }}^{1, \mathrm{i}}\left[T^{(\infty)}\right], A_{1, \mathrm{i}}$ are coefficients that represent the thermal impedance to condensate growth or evaporation (see Appendix A and Eq. (A6) for definition of $A_{1, i}$ ) and $\beta_{1, i}$ are coefficients defined in the next paragraph. A crucial distinction in deriving $\alpha_{\mathrm{kl}}$ and $\alpha_{\mathrm{ki}}$ is the fact that small droplets are assumed to fully re-equilibrate isotopically with the surrounding vapour, but the migration of molecules within the crystal lattice of ice is too slow to support such an equilibration assumption. For the liquid case, we therefore write $\alpha_{\mathrm{kl}}=R_{\mathrm{l}} / R_{\mathrm{v}}^{(\infty)}$, and assume that the droplet surface is identical in composition to the bulk composition 

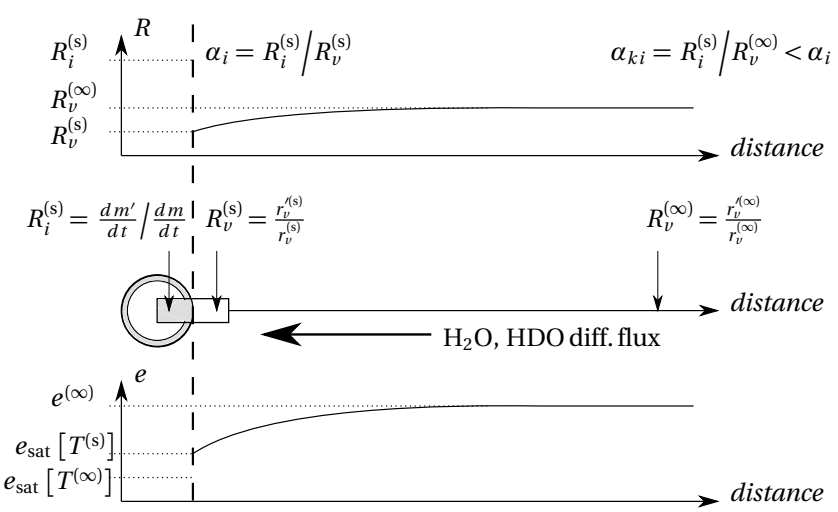

Fig. 3. Same as Fig. 2 but for ice deposition in a supersaturated environment. Vapour pressure is now increasing across the diffusive boundary layer surrounding the crystal, and $e_{\mathrm{sat}}\left[T^{(\mathrm{s})}\right]>$ $e_{\text {sat }}\left[T^{(\infty)}\right]$, owing to the surface being heated above environmental temperature at deposition ( $e_{\text {sat }}=$ ice saturation here $)$. Thus, thermal impedance reduces supersaturation compared to what it would be if $T^{(\mathrm{s})}$ were equal to $T^{(\infty)}$, and limits kinetic effects at deposition too. The increase of vapour isotopic ratio across the boundary layer explains why the kinetic fractionation factor is reduced compared to its equilibrium value. Note that isotopic equilibration with vapour is restricted to the surface layer of the crystal (grey shaded area). This is the main difference with the droplet case.

$R_{1}$. For ice, we assume that fractionation occurs only between ice surface and vapour: $\alpha_{\mathrm{ki}}=R_{\mathrm{i}}^{(\mathrm{s})} / R_{\mathrm{v}}^{(\infty)}$.

The coefficients $\beta_{1, \mathrm{i}}$ combine three factors that are responsible for a gradient in isotopic composition between particle surface and its environment: the equilibrium fractionation factors $\alpha_{1, i}$, the ratio of light to heavy isotopologue molecular diffusivities $K_{\mathrm{v}} / K_{\mathrm{v}}^{\prime}$, and the ratio of light to heavy isotopologue ventilation coefficients $f_{\mathrm{v}} / f_{\mathrm{v}}^{\prime}$, i.e.

$\beta_{1, \mathrm{i}}=\alpha_{1, \mathrm{i}} \frac{K_{\mathrm{v}}}{K_{\mathrm{v}}^{\prime}} \frac{f_{\mathrm{v}}}{f_{\mathrm{v}}^{\prime}}$.

$\beta_{1, \mathrm{i}}$ is always larger than 1 since the first two factors act in the same direction - heavy isotopes preferentially condense, meaning equilibrium fractionation factors $\alpha_{1, i}$ are always $>1$, and heavy isotopologues have lower diffusivity than light ones, meaning $K_{\mathrm{v}} / K_{\mathrm{v}}^{\prime}>1-$ and the ratio of ventilation coefficients $f_{\mathrm{v}} / f_{\mathrm{v}}^{\prime}$ is close to unity. The result is that in supersaturated conditions, fractionation during droplet growth or ice deposition is reduced relative to the equilibrium scenario and in subsaturated conditions, fractionation is enhanced: the sign of $\alpha_{\mathrm{k} \mid 1, \mathrm{i}}-\alpha_{1, \mathrm{i}}$ is opposite to that of $S_{1, \mathrm{i}}^{\text {(eff }}-1$ (see Appendices D5 and Appendix A for discussion of diffusivities and diffusional growth rates and Online Supplement Sect. 1 for ventilation coefficients).

Mathematically, kinetic isotopic effects arise from the differences in behaviour between isotopologues $\left(\beta_{1, \mathrm{i}} \neq 1\right)$ in conditions of super- or subsaturation $\left(S_{1, \mathrm{i}}^{\text {(eff) }} \neq 1\right)$. If the ambient environment is exactly at effective saturation, there is no diffusion limitation and no kinetic isotope effects occur: the kinetic fractionation factors reduce to $\alpha_{\mathrm{k} \mid 1, \mathrm{i}}=\alpha_{1, \mathrm{i}}$.

It is important to recognise that any factor that causes $\beta_{1, \mathrm{i}} \neq 1$ gives rise to kinetic fractionation effects. Preferential uptake at droplet or ice surface would alone produce an isotopic gradient between particle surface and far field and a kinetic isotope effect even if there were no differences in diffusivity between isotopologues. For $\mathrm{H}_{2} \mathrm{O} / \mathrm{HDO}$, equilibrium fractionation at droplet or ice surface is in fact a larger contributor to kinetic effects than is differential diffusivity since $K_{\mathrm{v}} / K_{\mathrm{v}}^{\prime} \sim 1.03$ and $\alpha_{\mathrm{i}}>\alpha_{1} \sim 1.1$ even at Earth's surface temperatures and increases further with altitude. For $\mathrm{H}_{2} \mathrm{O} / \mathrm{H}_{2}{ }^{18} \mathrm{O}$, both effects contribute more equally: the diffusivity ratio is again $K_{\mathrm{v}} / K_{\mathrm{v}}^{\prime} \sim 1.03$ but equilibrium fractionation is only $\alpha_{1, \mathrm{i}} \sim 1.02-1.05$. This difference makes evolution of the oxygen isotopologue system more sensitive to vapour saturation $S_{1, \mathrm{i}}$.

Kinetic effects on fractionation are somewhat reduced by thermal impedance, i.e. by the fact that particle and droplet surface temperatures differ from ambient temperature (this effect is responsible for the effective saturation $S_{1, \mathrm{i}}^{\text {(eff) }}$ differing from $S_{1, \mathrm{i}}$ ). Thermal impedance effectively reduces both subsaturation and supersaturation because evaporation lowers surface temperature (i.e. $S_{1, \mathrm{i}}<S_{1, \mathrm{i}}^{\text {(eff) }}<1$ ) and deposition raises surface temperature (i.e. $1<S_{1, \mathrm{i}}^{\text {(eff) }}<S_{1, \mathrm{i}}$ ). In all environmental conditions, then, thermal impedance reduces the kinetic modifications to equilibrium fractionation. The effects of thermal impedance decrease as temperature falls and so are less important with altitude (see Appendix A for discussion of the magnitude of thermal impedance effects).

The representation of isotopic fractionation for droplets given above follows most isotopic models in assuming that cloud droplets instantly equilibrate with their surrounding vapour. However, at low temperatures, larger cloud droplets (tens of microns) that are still below the typical size for onset of precipitation (Houze, 1993, chap. 3.1.3) can have equilibration times of a minute or more (see Appendix B and discussion in Sect. 4.1). While small droplets can be considered to fully equilibrate with surrounding vapour as they ascend in updrafts, larger droplets may not do so, especially for high updraft speeds and low temperatures. A full tracking of isotopic exchange between droplets and their surrounding vapour would require integrating a relaxation equation for droplets isotopic ratio (see Eq. B3) over a spectrum of droplet sizes. In the modelling treatment described below, we choose instead a simplified approach. We separate droplets into two classes: "cloud water" that undergo instantaneous exchanges and "passive water" that can be seen as representing either precipitation or any fraction of cloud liquid that does not fully exchange. We impose a simple ad hoc parametrisation in which a constant fraction $C_{1}$ of actively exchanging cloud liquid and ice is auto-converted at each altitude in the uplift.

Several factors pose no significant complications for modelling. Thermal relaxation times in droplets are always 
Table 1. The four free parameters of the isotopic model.

\begin{tabular}{lclc}
\hline Symbol & Unit & Meaning & Reference value \\
\hline$\zeta$ & - & Saturation parameter & 1 \\
$\gamma$ & - & Glaciation parameter & 3.5 \\
$b$ & - & Fraction of liquid water converted to ice via the WBF process & 0 \\
$C_{1}$ & $\mathrm{~m}^{-1}$ & Fractional rate of auto-conversion (deactivation/precipitation) of liquid water & 0 \\
\hline
\end{tabular}

considerably smaller than isotopic relaxation times, justifying the use of a steady-state solution of the heat transfer equation in deriving the evolution of droplet and vapour isotopic ratios (Appendix A, Fig. B1). Droplet freezing is also fast relative to isotopic relaxation, justifying the assumption that freezing does not produce isotopic fractionation (Supplement Sect. 2, Fig. B1).

We note one factor omitted in our framework that may be of importance for ice crystal isotopic evolution. We have assumed conditions of thermodynamic equilibrium at the surface of both droplets and ice crystals (i.e. $\rho_{\mathrm{v}}^{(\mathrm{s})}=\rho_{\mathrm{sat}}^{1, \mathrm{i}}\left[T^{(\mathrm{s})}\right]$, $R_{1}^{(\mathrm{s})}=\alpha_{1} R_{\mathrm{v}}^{(\mathrm{s})}$ and $\left.R_{\mathrm{i}}^{(\mathrm{s})}=\alpha_{\mathrm{i}} R_{\mathrm{v}}^{(\mathrm{s})}\right)$. This assumption is reasonable for droplets of sufficient size such that surface curvature and salt molarity effects are negligible. However, it is less obviously appropriate for ice crystals. Surface kinetic processes are known to be of importance in crystal growth, which cannot be accurately described by simple capacitance models (Kuroda, 1984). Because slight supersaturations at crystal surface appear necessary to overcome surface kinetics, deposition coefficients for heavy and light isotopologues may differ, inducing additional fractionation effects. Theories of isotopic fractionation incorporating surface kinetic effects are only recently under development (DePaolo, 2011; Nelson, 2011) and we cannot include them here. However, ice crystal shapes suggest that at high supersaturations, crystal growth may be compatible with a pure diffusional theory and surface kinetic effects are less important.

\section{Modelling isotopic composition}

In this section, we describe our model. We first describe the various classes of water species involved (Sect. 3.1), then present a simple representation of the microphysics and thermodynamics of rising air parcels, considering light water alone (Sect. 3.2), and finally apply the previously established isotope physics to extract the evolution of the isotopic ratio of water vapour $R_{\mathrm{v}}$ (Sect. 3.3). The model uses only four free parameters, listed in Table 1 (for a full list of all symbols used throughout the manuscript, see Table 3).

\subsection{Bulk approach}

While the previous section described fractionation between vapour and single droplets or ice crystals, modelling vapour isotopic composition requires that we represent the interactions between bulk vapour, cloud liquid and cloud ice. A closed-form solution requires bulk modelling of heavy and light isotopologues in several classes of water species and an expression for conservation of energy. We describe the phases of water and their isotopologue content in terms of mass mixing ratios of vapour, liquid, and ice $\left(r_{\mathrm{v}}, r_{1}, r_{\mathrm{i}}\right)$ and corresponding isotopic ratios $R_{\mathrm{v}}=r_{\mathrm{v}}^{\prime} / r_{\mathrm{v}}, R_{1}=r_{1}^{\prime} / r_{1}$ and $R_{\mathrm{i}}=r_{\mathrm{i}}^{\prime} / r_{\mathrm{i}}$. We assume that the cloud column is stationary in time and therefore time dependence along the path of a given parcel can be replaced by a dependency of all variables on $z$ only. The updraft velocity, which determines the rate of change of pressure and temperature in the air parcel, is not explicitly defined in our model but it implicitly determines a height of relaxation for processes that adjust over a finite time. This relaxation height is the product of the vertical velocity by the process relaxation timescale (the latter is shown in Fig. B1 for a number of processes). If the relaxation height is sufficiently small compared to the spatial resolution of the model, the corresponding process may be considered as adjusted, i.e. it can be modelled as if it had a null intrinsic timescale. Hence, "active" liquid water, as defined in Sect. 2.3, is modelled as if droplets were to instantaneously equilibrate. However, the largest droplets cannot be considered to fully re-equilibrate for high updraft speeds and low temperatures, which could produce variations with height of the size of the "active" liquid water reservoir. This is accounted for in a simple way by our model by specifying an ad hoc conversion of actively exchanging cloud liquid water to passive water, as will be described in Sect. 3.2.3.

Since we use an exact adiabatic assumption for the conservation of energy, our model requires the conservation of total water. In order to satisfy the adiabatic assumption, as discussed above, we track all precipitation as "deactivated" water carried with the air parcel and included in the water budget. Retaining water rather than allowing precipitation to fall out does introduce small differences in entropy and buoyancy, but these do not affect our results significantly. The total light water and heavy isotopologue contents are then

$$
\begin{aligned}
& r_{\mathrm{t}}=r_{\mathrm{v}}+r_{\mathrm{l}}+r_{\mathrm{i}}+r_{1}^{(\mathrm{p})}+r_{\mathrm{i}}^{(\mathrm{p})}, \\
& r_{\mathrm{t}}^{\prime}=r_{\mathrm{v}}^{\prime}+r_{1}^{\prime}+r_{\mathrm{i}}^{\prime}+r_{1}^{\prime(\mathrm{p})}+r_{\mathrm{i}}^{\prime(\mathrm{p})},
\end{aligned}
$$

where deactivated/precipitated species are denoted as $x^{(\mathrm{p})}$. 
The differing kinetic isotope properties of liquid water and ice have important consequences for bulk relationships. In the case of liquid water, the assumed rapid equilibration of the active cloud water with its environment means that the fractionation factor describes partitioning of isotopologues between bulk vapour and bulk liquid of active droplets:

$$
\frac{r_{1}^{\prime}}{r_{1}}=\alpha_{\mathrm{k} 1} \frac{r_{\mathrm{v}}^{\prime}}{r_{\mathrm{v}}} .
$$

Because the kinetic fractionation factors previously defined relate properties of the condensed phase with those of vapour beyond the diffusive boundary layer, we no longer need to distinguish between surface and far field quantities, and can therefore unambiguously remove the parenthesised superscripts $(\infty)$ or (s) introduced in the previous section unless surface quantities are explicitly required.

In the case of ice, we assume that the fractionation factor describes partitioning between isotopologues in the bulk vapour and the surface of ice crystals, with no effect from crystal size or shape, so that

$$
\frac{\left(\mathrm{d} r_{\mathrm{i}}^{\prime} / \mathrm{d} t\right)}{\left(\mathrm{d} r_{\mathrm{i}} / \mathrm{d} t\right)}=\alpha_{\mathrm{ki}} \frac{r_{\mathrm{v}}^{\prime}}{r_{\mathrm{v}}}
$$

Note that the bulk composition $r_{\mathrm{i}}^{\prime} / r_{\mathrm{i}}$ is generally different from the composition of instantaneously deposited ice $\left(\mathrm{d} r_{\mathrm{i}}^{\prime} / \mathrm{d} t\right) /\left(\mathrm{d} r_{\mathrm{i}} / \mathrm{d} t\right)$. The bulk ice composition $r_{\mathrm{i}}^{\prime} / r_{\mathrm{i}}$ depends on the history of the accumulation of ice in each crystal.

\subsection{Microphysics and thermodynamics}

\subsubsection{Thermodynamics}

As mentioned above, we assume that the rising air parcel experiences adiabatic thermodynamics and therefore that its ice-liquid water potential temperature $\theta_{\mathrm{il}}$ is conserved (Tripoli and Cotton, 1981; Bryan and Fritsch, 2004). This assumption is equivalent to assuming perfect conservation of total entropy for dry air and all water species, and therefore precludes any entrainment of environmental air. The utility of the model is therefore limited to the cores of deep convection, which arguably do not entrain, or to cores embedded within mesoscale convective systems that are plausibly somewhat isolated from their broader environment. For strict adiabaticity and conservation of $\theta_{\mathrm{il}}$ to hold, total water must be conserved and transformations must be reversible. As discussed above, total water conservation is enforced by retaining deactivated/precipitated species (the $\left(l^{(\mathrm{p})}\right)$ and $\left(i^{(\mathrm{p})}\right)$ water classes, cf. Sect. 3.1) within the parcel. Because of that, we compute an upper bound on cloud temperature and buoyancy since we do not allow entropy exportation through hydrometeor fallout. Reversibility of the transformations does not strictly hold in our model since condensation and evaporation may happen in non-equilibrium conditions (indeed, $S_{1, \mathrm{i}} \neq 1$ is unavoidable in mixed-phase clouds). However, the tendency in $\theta_{\text {il }}$ arising from irreversibility has only a small effect on the temperature profile (Bryan and Fritsch, 2004), so can be neglected, allowing $\theta_{\mathrm{il}}$ to be treated as a perfectly conservative variable.

Conservation of ice-liquid water potential temperature is written as

$\frac{\mathrm{d} \theta_{\mathrm{il}}}{\mathrm{d} z}=0$,

with $\theta_{\mathrm{il}}$ given by

$$
\begin{aligned}
\theta_{\mathrm{i} 1}= & T\left(\frac{p_{0}}{p}\right)^{\chi}\left(1-\frac{r_{1}+r_{1}^{(\mathrm{p})}+r_{\mathrm{i}}+r_{\mathrm{i}}^{(\mathrm{p})}}{\epsilon+r_{\mathrm{t}}}\right)^{\chi} \\
& \times\left(1-\frac{r_{1}+r_{1}^{(\mathrm{p})}+r_{\mathrm{i}}+r_{\mathrm{i}}^{(\mathrm{p})}}{r_{\mathrm{t}}}\right)^{-\vartheta} \\
& \times \exp \left[\frac{-L_{\mathrm{v}}\left(r_{1}+r_{1}^{(\mathrm{p})}\right)-L_{\mathrm{s}}\left(r_{\mathrm{i}}+r_{\mathrm{i}}^{(\mathrm{p})}\right)}{\left(c_{\mathrm{p}}+c_{\mathrm{pv}} r_{\mathrm{t}}\right) T}\right. \\
& \left.+\frac{R_{\mathrm{v}}^{*}}{c_{\mathrm{p}}+c_{\mathrm{pv}} r_{\mathrm{t}}}\left(\left(r_{1}+r_{1}^{(\mathrm{p})}\right) \ln S_{1}+\left(r_{\mathrm{i}}+r_{\mathrm{i}}^{(\mathrm{p})}\right) \ln S_{\mathrm{i}}\right)\right],
\end{aligned}
$$

with

$\chi=\frac{R_{d}^{*}+R_{\mathrm{v}}^{*} r_{\mathrm{t}}}{c_{\mathrm{p}}+c_{\mathrm{pv}} r_{\mathrm{t}}}$,

and

$\vartheta=\frac{R_{\mathrm{v}}^{*} r_{\mathrm{t}}}{c_{\mathrm{p}}+c_{\mathrm{pv}} r_{\mathrm{t}}}$.

\subsubsection{Vapour pressure adjustment to saturation}

In our simplified model, we do not represent the growth and evaporation/sublimation rates of droplets and ice particles in a prognostic way, but instead specify the evolution of relative humidity in the air parcel and assume that phase changes occur in coherence with that evolution. Our treatment of vapour saturation is necessarily ad hoc but is designed to reproduce expected behaviour in convective clouds (theory of supersaturation in convective clouds is discussed in greater depth in Appendix C).

At temperatures above $0{ }^{\circ} \mathrm{C}$, we assume that clouds are entirely liquid and that vapour is at saturation over liquid water. Supersaturation over liquid water is neglected since it is expected not to exceed a few percentage points (Korolev and Mazin, 2003; see also Appendix C); it would therefore have negligible consequences in our framework as the kinetic isotope effect would not be significant and our model does not explicitly calculate growth rates as a function of supersaturation. 
Table 2. Relation between internal parameters $\zeta, \gamma$ and $C_{1}$ of the model and physical quantities. Row 2: vapour saturation over ice at $T \leq-40^{\circ} \mathrm{C}$ as a function of $\zeta$ obtained from Eq. (8). Rows 4 to 9: glaciation temperature, altitude and pressure (conventionally defined where $r_{1}=10^{-6} \mathrm{~kg} \mathrm{~kg}^{-1}$ ) as a function of $\gamma$ for two extreme values of the auto-conversion coefficient for liquid water $C_{1}$. Temperature is computed from a full integration of the model with cloud base level at $1050 \mathrm{~m}$. Pressure and altitude grids are taken from a mean tropical profile from the ERA-Interim reanalysis (Dee et al., 2011). The saturation parameter $\zeta$ is set to 1 in these computations. Setting it to 0 affects the glaciation temperature by less than $2 \%$ in all cases. Row 11: ratio $r_{1} / r_{1, \text { adiab }}$ at $T=0^{\circ} \mathrm{C}$ between the (active) liquid water content for a given value of $C_{1}$ and the same quantity for $C_{1}=0$ (adiabatic content). This ratio is calculated from a full integration of the model and is not sensitive to glaciation and saturation parameters, which are ineffective at positive temperatures.

\begin{tabular}{|c|c|c|c|c|c|c|c|}
\hline \multicolumn{2}{|c|}{ Saturation parameter $\zeta$} & 0 & 0.2 & 0.4 & 0.6 & 0.8 & 1 \\
\hline \multicolumn{2}{|c|}{$S_{\mathrm{i}}$ at $T \leq-40^{\circ} \mathrm{C}$} & 1 & 1.09 & 1.18 & 1.28 & 1.37 & 1.47 \\
\hline \multicolumn{2}{|c|}{ Glaciation parameter $\gamma$} & 1 & 2 & 3 & 4 & 6 & 9 \\
\hline \multirow{3}{*}{$C_{1}=0$} & $T_{\mathrm{g}}\left({ }^{\circ} \mathrm{C}\right)$ & -13.12 & -23.09 & -29.07 & -32.64 & -35.93 & -38.04 \\
\hline & $z_{\mathrm{g}}(\mathrm{km})$ & 7.70 & 9.20 & 10.00 & 10.45 & 10.85 & 11.10 \\
\hline & $p_{\mathrm{g}}(\mathrm{hPa})$ & 394 & 321 & 286 & 268 & 253 & 244 \\
\hline \multirow{3}{*}{$C_{1}=0.5 \mathrm{~km}^{-1}$} & $T_{\mathrm{g}}\left({ }^{\circ} \mathrm{C}\right)$ & -11.30 & -20.63 & -26.4 & -30.25 & -34.28 & -37.19 \\
\hline & $z_{\mathrm{g}}(\mathrm{km})$ & 7.40 & 8.85 & 9.65 & 10.15 & 10.65 & 11.00 \\
\hline & $p_{\mathrm{g}}(\mathrm{hPa})$ & 410 & 337 & 301 & 280 & 261 & 248 \\
\hline \multicolumn{2}{|c|}{ Auto-conversion coefficient $C_{1}$} & 0 & 0.1 & 0.2 & 0.3 & 0.4 & 0.5 \\
\hline \multicolumn{2}{|c|}{$r_{1} / r_{1, \text { adiab }}$ at $T=0{ }^{\circ} \mathrm{C}(\%)$} & 100 & 80 & 64 & 51 & 40 & 31 \\
\hline
\end{tabular}

Between $0{ }^{\circ} \mathrm{C}$ and $-40^{\circ} \mathrm{C}$, vapour pressure is expected to be constrained to within a few percentage points of liquid water saturation as long as supercooled droplets dominate ice crystals in mixed-phase updrafts, departing from that constraint only when glaciation is sufficiently advanced (Korolev and Mazin, 2003; Korolev and Isaac, 2006). In sufficiently slow updrafts, vapour pressure would fall to saturation over ice $e_{\text {sat }}^{\mathrm{i}}$ as ice becomes dominant, but faster updrafts are expected to retain a higher degree of saturation after full glaciation. In real-world convective systems, the range of possible saturation values is wide, depends on updraft velocity and droplet and ice crystal number densities, and can evolve over the lifetime of an updraft (Korolev and Mazin (2003); see also Appendix C for more extensive discussion of supersaturation in convective clouds). For simplicity, we assume here that fully glaciated updrafts experience some fixed intermediate vapour pressure between the saturated pressure over liquid water and the saturated pressure over ice. The specified degree of supersaturation can be seen as a proxy for those parameters (updraft velocity, particle size distribution) that we do not explicitly model. The intermediate vapour pressure is parametrised down to $-40^{\circ} \mathrm{C}$ as $e_{\text {sat }}^{1} \zeta+e_{\text {sat }}^{\mathrm{i}}(1-\zeta)$, where $\zeta$ is a free parameter of the model. Once temperatures cool below $-40^{\circ} \mathrm{C}$, the degree of supersaturation assigned over ice at $-40^{\circ} \mathrm{C}$ is fixed from that point on. Throughout this manuscript, we use $\zeta$ to describe supersaturation, but see Table 2 to relate $\zeta$ to the final supersaturation over ice. We model the evolution of vapour pressure in mixed-phase updrafts from saturation over liquid to the intermediate vapour pressure as governed by the relative weight of ice among water condensates $f_{\mathrm{i}}=r_{\mathrm{i}} /\left(r_{\mathrm{i}}+r_{1}\right)$.

The parametrization of vapour pressure $e_{\text {adj }}$ over the whole range of temperature is then

$$
\begin{aligned}
& e_{\text {adj }}\left[T>0{ }^{\circ} \mathrm{C}\right]=e_{\text {sat }}^{1}, \\
& e_{\text {adj }}\left[-40^{\circ} \mathrm{C}<T<0^{\circ} \mathrm{C}\right]=\left(1-f_{\mathrm{i}}\right) e_{\text {sat }}^{1} \\
& +f_{\mathrm{i}}\left[e_{\mathrm{sat}}^{1}[T] \zeta+e_{\mathrm{sat}}^{\mathrm{i}}[T](1-\zeta)\right], \\
& e_{\text {adj }}\left[T<-40^{\circ} \mathrm{C}\right]=\left[1-\zeta+\frac{e_{\text {sat }}^{1}\left[T=-40^{\circ} \mathrm{C}\right]}{e_{\text {sat }}^{\mathrm{i}}\left[T=-40^{\circ} \mathrm{C}\right]} \zeta\right] e_{\text {sat }}^{\mathrm{i}}[T] \text {. }
\end{aligned}
$$

\subsubsection{Droplet and cloud ice mass balance}

The change in the amount of liquid water or ice held by a rising parcel can be split into three components: diffusional growth of condensates accommodating changes in ambient saturation, conversion of liquid water to ice, and auto-conversion of condensates to deactivated/precipitated species. Even the simplest isotopic model must represent all three effects.

As an air parcel is lifted adiabatically, condensed phases are assumed to take up vapour to maintain the adjusted vapour pressure specified in Eq. (8). At temperatures above $0^{\circ} \mathrm{C}$, vapour uptake results in the growth of droplets. Below $0^{\circ} \mathrm{C}$, both growth of liquid droplets and deposition onto ice can occur if updraft velocity is sufficiently strong (i.e. if $w_{\text {up }}>w_{\text {up }}^{\star}$; see Korolev and Mazin (2003) and Appendix C). 
Table 3. Unit, meaning, and location of all symbols used in the text. Some symbols which are only local to a single formula are not listed here. In the last column, "Supplt" stands for the Supplement.

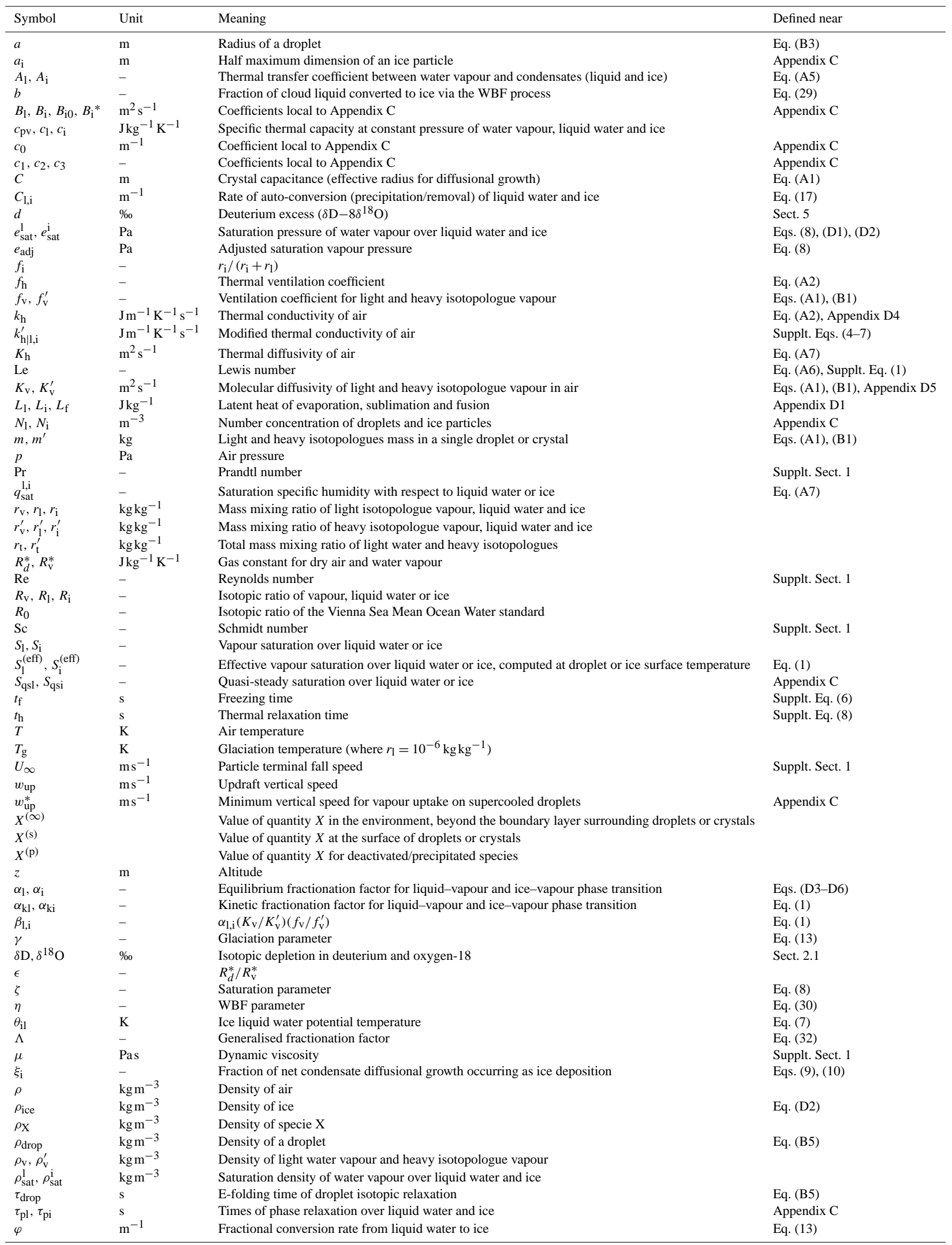


In these conditions, and as long as the number concentration of supercooled droplets dominates that of ice crystals, vapour pressure stays close to liquid saturation (as discussed in the previous section) and most vapour uptake should occur on supercooled droplets. As glaciation proceeds, deposition onto ice eventually dominates over growth of supercooled droplets.

We represent net diffusional growth accommodating changes in vapour saturation by the following set of equations:

$$
\begin{aligned}
& \left.\frac{\mathrm{d} r_{\mathrm{i}}}{\mathrm{d} z}\right|_{\text {ajs }}=-\xi_{\mathrm{i}} \frac{\mathrm{d} r_{\mathrm{v}}}{\mathrm{d} z}, \\
& \left.\frac{\mathrm{d} r_{1}}{\mathrm{~d} z}\right|_{\text {ajs }}=-\left(1-\xi_{\mathrm{i}}\right) \frac{\mathrm{d} r_{\mathrm{v}}}{\mathrm{d} z},
\end{aligned}
$$

where the notation "ajs" refers to "adjustment at saturation" and $\xi_{\mathrm{i}}$ is the fraction of condensate growth resulting in ice deposition. In order to reproduce the expected transition from droplet growth to ice deposition in mixed-phase updrafts, and for the sake of simplicity, we require that the importance of ice deposition positively corresponds with the fraction of ice among condensates. That is, we set $\xi_{\mathrm{i}}=f_{\mathrm{i}}$. Notice that Eqs. (9) and (10) hold for any temperature, $\xi_{\mathrm{i}}$ being equal to 0 in the liquid domain, 1 in the glaciated domain and taking intermediate values in the domain of coexistence of liquid and ice (remaining close to 0 when supercooled liquid water dominates ice).

Supercooled droplets can be converted to ice by two processes: either by freezing of droplets (homogeneous or heterogeneous) or by the Wegener-Bergeron-Findeisen (WBF) process (Wegener, 1911; Bergeron, 1935; Korolev, 2007) in which cloud droplets evaporate to water vapour that then redeposits as ice on growing crystals. Those processes have a complex dependency upon updraft velocity, droplet and ice particle size distributions and aerosols characteristics (Kumjian et al., 2012; Korolev, 2007), which we cannot reproduce in our model. We will instead assume that the conversion from liquid water to ice can be described by a single ad hoc fractional rate of conversion $\varphi$ with a free parameter $b$ describing the fraction of liquid water converted to ice through the WBF process versus droplet freezing. In our representation, the route to cloud glaciation does not matter for liquid water and ice mass balance but it does for vapour isotopic composition because the two processes bear very distinct isotopic signatures.

The conversion of liquid water to ice is thus parametrised as

$$
\begin{aligned}
& \left.\frac{\mathrm{d} r_{\mathrm{i}}}{\mathrm{d} z}\right|_{\mathrm{cli}}=-\left.\frac{\mathrm{d} r_{1}}{\mathrm{~d} z}\right|_{\mathrm{frz}}-\left.\frac{\mathrm{d} r_{1}}{\mathrm{~d} z}\right|_{\mathrm{wbf}}=\varphi(T) r_{1}, \\
& \left.\frac{\mathrm{d} r_{1}}{\mathrm{~d} z}\right|_{\mathrm{cli}}=\left.\frac{\mathrm{d} r_{1}}{\mathrm{~d} z}\right|_{\mathrm{frz}}+\left.\frac{\mathrm{d} r_{1}}{\mathrm{~d} z}\right|_{\mathrm{wbf}}=-\varphi(T) r_{1},
\end{aligned}
$$

where the subscript "cli" refers to liquid-ice conversion and "frz" and "wbf" are self-evident. Notice that our represen- tation of freezing is intended to capture different mechanisms, depending on the temperature range considered. Since the droplets of active liquid water are presumably small, their heterogeneous freezing in immersion-mode is likely promoted at lower temperatures of the mixed-phase zone, while freezing at warmer temperatures should occur mostly in contact-mode via particle interaction (i.e. riming) (Pruppacher and Klett, 1978; Kumjian et al., 2012). The droplets eventually freeze homogeneously if they get in the vicinity of the $-40^{\circ} \mathrm{C}$ level. Our parametrisation of freezing thus contains tendencies due to homogeneous freezing, heterogeneous immersion freezing and riming. Conditions that promote strong updraft (hence high vapour saturation and no WBF) and low riming potential (continental aerosol spectra, shallow warm cloud depth) delay cloud glaciation to lower temperatures.

The temperature dependence of the conversion rate $\varphi$ is chosen to ensure zero conversion at $T=0^{\circ} \mathrm{C}$ and maximum conversion at $T=-40^{\circ} \mathrm{C}$ :

$\varphi(T)=\frac{1}{50}\left(\frac{273.15-T}{40}\right)^{\gamma}$

where $T$ is in Kelvin and $\varphi$ is in $\mathrm{m}^{-1}$. The glaciation parameter $\gamma$ controls the rate of glaciation of the cloud, which in turn sets the effective altitude at which liquid water is fully converted to ice. Higher $\gamma$ produces lower glaciation rates, delaying cloud glaciation and allowing significant amounts of supercooled liquid to persist to higher altitudes. For the sake of illustration, let us assume a constant lapse rate in the mixed-phase region. The falloff in liquid water with altitude in the mixed-phase region, under the sole action of liquid to ice conversion (no auto-conversion), is derived by integrating Eq. (12) over the range of altitude between $0^{\circ} \mathrm{C}$ and $-40^{\circ} \mathrm{C}$, and yields

$$
\begin{aligned}
\ln \left(\frac{r_{1}}{r_{1}\left[0^{\circ} \mathrm{C}\right]}\right) \sim & \frac{z\left[0^{\circ} \mathrm{C}\right]-z\left[-40^{\circ} \mathrm{C}\right]}{50(\gamma+1)} \\
& \times\left(\frac{z\left[0^{\circ} \mathrm{C}\right]-z}{z\left[0^{\circ} \mathrm{C}\right]-z\left[-40^{\circ} \mathrm{C}\right]}\right)^{\gamma+1} .
\end{aligned}
$$

The altitude above which $r_{1}$ drops below some threshold clearly increases with $\gamma$. By convention, we define the glaciation temperature $T_{\mathrm{g}}$ and glaciation altitude $z_{\mathrm{g}}$ as the location where $r_{1}=10^{-6} \mathrm{~kg} \mathrm{~kg}^{-1}$ is reached. Glaciation altitude is mainly a function of $\gamma$, but also depends slightly on the conversion of droplets to deactivated/precipitated species and very slightly on supersaturation. This dependency is illustrated in Table 2. Notice that, with our definitions, any choice of $\gamma$ less than 9 ensures full glaciation before the $-40{ }^{\circ} \mathrm{C}$ level is reached.

As discussed in Sect. 3.1, we represent the auto-conversion of condensates to deactivated/precipitated species as a constant fractional loss of mass from the activated liquid and ice 
water classes:

$$
\begin{aligned}
& \left.\frac{\mathrm{d} r_{\mathrm{i}}}{\mathrm{d} z}\right|_{\mathrm{acv}}=-C_{\mathrm{i}} r_{\mathrm{i}}, \\
& \left.\frac{\mathrm{d} r_{1}}{\mathrm{~d} z}\right|_{\mathrm{acv}}=-C_{1} r_{1}, \\
& \left.\frac{\mathrm{d} r_{\mathrm{i}}^{(\mathrm{p})}}{\mathrm{d} z}\right|_{\mathrm{acv}}=C_{\mathrm{i}} r_{\mathrm{i}}, \\
& \left.\frac{\mathrm{d} r_{1}^{(\mathrm{p})}}{\mathrm{d} z}\right|_{\mathrm{acv}}=C_{1} r_{1},
\end{aligned}
$$

where the subscript "acv" refers to auto-conversion, $C_{1}$ and $C_{\mathrm{i}}$ are fractional auto-conversion coefficients for liquid water and ice, and the superscript (p) refers to deactivated/precipitated species. Our parametrization of autoconversion contains tendencies due to precipitation and growth of droplets to non-fully-exchanging sizes (see Sects. 2.3 and 3.1). Note that $C_{\mathrm{i}}$ is a dummy parameter that is included for completeness of the representation but has no effect on vapour isotopic ratio (see Sect. 3.3).

Saturation adjustment, liquid to ice conversion and deactivation/precipitation can be combined into expressions for the vertical variation of the liquid water and ice mixing ratios:

$$
\begin{aligned}
& \frac{\mathrm{d} r_{\mathrm{i}}}{\mathrm{d} z}=-\xi_{\mathrm{i}} \frac{\mathrm{d} r_{\mathrm{v}}}{\mathrm{d} z}-C_{\mathrm{i}} r_{\mathrm{i}}+\varphi(T) r_{1} \\
& \frac{\mathrm{d} r_{1}}{\mathrm{~d} z}=-\left(1-\xi_{\mathrm{i}}\right) \frac{\mathrm{d} r_{\mathrm{v}}}{\mathrm{d} z}-C_{1} r_{1}-\varphi(T) r_{\mathrm{i}}
\end{aligned}
$$

along with Eqs. (17) and (18) for the deactivated/precipitated components.

The full model of light water transformations in the convective plume then consists of Eq. (2) (water mass balance); Eqs. (17)-(20) (tendencies for the (1), (i), $\left(1^{(\mathrm{p})}\right)$, and $\left(\mathrm{i}^{(\mathrm{p})}\right)$ water classes); Eqs. (6) and (7) (thermodynamics); and Eq. (8) (vapour saturation assignment).

\subsubsection{Model solving}

The full model has $6 z$ dependent variables, the temperature $T$ and the light water mixing ratios $\boldsymbol{r}=\left(r_{\mathrm{v}}, r_{1}, r_{\mathrm{i}}, r_{1}^{(\mathrm{p})}, r_{\mathrm{i}}^{(\mathrm{p})}\right)$. The control parameters $\left(\zeta, \gamma, b, C_{1}\right)$ are fixed (see Table 2 ). Boundary conditions must be provided at cloud base. At cloud base, water vapour is assumed to be saturated, with all condensate water classes set to zero and the ice-liquid potential temperature set at a value $\theta_{\mathrm{il}}=\theta_{\mathrm{il} 0}$, which is then preserved aloft within the convective plume. The stratification in the environment of the cloud is assumed to be hydrostatic.

The set of equations of the model can be reduced to the mixing ratios equation:

$$
\frac{\mathrm{d} \boldsymbol{r}}{\mathrm{d} z}=\mathbf{F}\left(\boldsymbol{r}, \frac{\mathrm{d} T}{\mathrm{~d} z}, T, p\right)
$$

and the thermodynamic equation:

$0=\frac{\mathrm{d} \theta_{\mathrm{il}}}{\mathrm{d} z}\left(T, \frac{\mathrm{d} T}{\mathrm{~d} z}, \boldsymbol{r}, \frac{\mathrm{d} \boldsymbol{r}}{\mathrm{d} z}, p\right)$.

After replacement of $\mathrm{d} \boldsymbol{r} / \mathrm{d} z$ using Eq. (21), Eq. (22) is turned into an implicit equation for $\mathrm{d} T / \mathrm{d} z$ which is solved iteratively after discretisation. This solution is then readily used to make a step of $T$ in the vertical and to make a step for the water classes mixing ratios $\boldsymbol{r}$ in Eq. (21).

The model is solved with a spatial resolution of $50 \mathrm{~m}$. Updraft velocities ranging from $10 \mathrm{~m} \mathrm{~s}^{-1}$ to $50 \mathrm{~m} \mathrm{~s}^{-1}$ thus correspond to implicit time steps of $1 \mathrm{~s}$ to $5 \mathrm{~s}$. As shown by Fig. B1, such time steps essentially support an equilibration assumption for all processes except for phase relaxation over ice and isotopic equilibration of large droplets at low temperatures (below $-20^{\circ} \mathrm{C}$ ). This is consistent with our modelling choices.

\subsection{Vapour isotopic composition}

The tendency in $R_{\mathrm{V}}$ may be derived from the conservation of heavy isotopologues:

$\frac{\mathrm{d}}{\mathrm{d} z}\left(r_{\mathrm{v}}^{\prime}+r_{1}^{\prime}+r_{\mathrm{i}}^{\prime}+r_{1}^{\prime(\mathrm{p})}+r_{\mathrm{i}}^{\prime(\mathrm{p})}\right)=0$.

Expanding the terms of this equation into relevant physical processes yields five master equations:

$$
\begin{aligned}
& \frac{\mathrm{d} r_{\mathrm{v}}^{\prime}}{\mathrm{d} z}=r_{\mathrm{v}} \frac{\mathrm{d} R_{\mathrm{v}}}{\mathrm{d} z}+R_{\mathrm{v}} \frac{\mathrm{d} r_{\mathrm{v}}}{\mathrm{d} z}, \\
& \frac{\mathrm{d} r_{1}^{\prime}}{\mathrm{d} z}=r_{1} \frac{\mathrm{d} R_{1}}{\mathrm{~d} z}+R_{1}\left(\left.\frac{\mathrm{d} r_{1}}{\mathrm{~d} z}\right|_{\mathrm{ajs}}+\left.\frac{\mathrm{d} r_{1}}{\mathrm{~d} z}\right|_{\mathrm{wbf}}+\left.\frac{\mathrm{d} r_{1}}{\mathrm{~d} z}\right|_{\mathrm{frz}}+\left.\frac{\mathrm{d} r_{1}}{\mathrm{~d} z}\right|_{\mathrm{acv}}\right), \\
& \frac{\mathrm{d} r_{\mathrm{i}}^{\prime}}{\mathrm{d} z}=R_{\mathrm{i}}^{(\mathrm{s})}\left(\left.\frac{\mathrm{d} r_{\mathrm{i}}}{\mathrm{d} z}\right|_{\mathrm{ajs}}-\left.\frac{\mathrm{d} r_{1}}{\mathrm{~d} z}\right|_{\mathrm{wbf}}\right) \\
& \frac{\mathrm{d} r_{1}^{\prime(\mathrm{p})}}{\mathrm{d} z}=-\left.R_{1} \frac{\mathrm{d} r_{1}}{\mathrm{~d} z}\right|_{\mathrm{acv}}, \\
& \frac{\mathrm{d} r_{\mathrm{i}}^{\prime(\mathrm{p})}}{\mathrm{d} z}=-\left.R_{\mathrm{i}}^{(\mathrm{p})} \frac{\mathrm{d} r_{\mathrm{i}}}{\mathrm{d} z}\right|_{\mathrm{acv}},
\end{aligned}
$$

which we now discuss in greater detail.

The first two Eqs. (24) and (25) simply reflect the definition of the isotopic ratios for vapour and liquid: $r_{\mathrm{v}}^{\prime}=r_{\mathrm{V}} R_{\mathrm{V}}$ and $r_{1}^{\prime}=r_{1} R_{1}$. The liquid mixing ratio $R_{1}$ here is predicated on an assumption that all cloud water has homogeneous composition $R_{1}=\alpha_{\mathrm{kl}} R_{\mathrm{V}}$. If droplets froze slowly relative to isotopic exchange timescales between liquid and vapour, we would need an additional term describing the extraction of further heavy water from the vapour phase as an ice germ 
grows within the droplet. However, droplet freezing can robustly be assumed to be fast relative to isotopic exchange timescales (see Supplement Sect. 2).

The third equation, Eq. (26), describes the tendency of heavy isotopologues in ice. The isotopic ratio at ice surface, $R_{\mathrm{i}}^{(\mathrm{s})}$, appears in the right hand side for the two processes that involve diffusional growth of ice crystals (growth following adjustment of vapour saturation and the WBF process). These two processes produce kinetic fractionation between vapour and ice surface $\left(R_{\mathrm{i}}^{(\mathrm{s})}=\alpha_{\mathrm{ki}} R_{\mathrm{v}}\right)$. The two remaining terms describe the source from droplet freezing and the sink from auto-conversion. Freezing has to be represented separately from the WBF process because it preserves the isotopic composition of the freezing droplet, whereas transition through the vapour phase in the WBF process involves fractionation.

The final two equations, Eqs. (27) and (28), describe the auto-conversion of liquid water and ice to deactivated/precipitated species. Deactivated liquid droplets carry the isotopic composition of the cloud water class at the time of deactivation. Deactivation of liquid droplets affect vapour composition by modifying the size of the liquid water reservoir that exchanges with vapour. In contrast, precipitation of ice in Eq. (26) has no effect on the water vapour isotopic composition, since ice did not exchange with vapour in the first place. Therefore the net isotopic content of precipitating ice $R_{\mathrm{i}}^{(\mathrm{p})}$, which depends on the ice crystal size distribution and individual crystal isotopic composition, may take any value without affecting our results, as seen below.

The isotopic composition of water vapour $R_{\mathrm{V}}$ can then be determined analytically by expanding Eq. (23) using Eqs. (24)-(28) and using the expressions for light water microphysical tendencies derived in Sect. 3.2.3. We neglect fractional changes in $\alpha_{\mathrm{kl}}$, compared to that in $R_{\mathrm{v}}$, implying that $\mathrm{d} R_{\mathrm{l}} / \mathrm{d} z \sim \alpha_{\mathrm{kl}} \mathrm{d} R_{\mathrm{V}} / \mathrm{d} z$. Carrying through the calculations yields the following expression:

$$
\begin{aligned}
\frac{\mathrm{d} \ln R_{\mathrm{v}}}{\mathrm{d} z}=\left[\left(\xi_{\mathrm{i}} \alpha_{\mathrm{ki}}\right.\right. & \left.+\left(1-\xi_{\mathrm{i}}\right) \alpha_{\mathrm{kl}}-1\right) \frac{\mathrm{d} r_{\mathrm{v}}}{\mathrm{d} z} \\
& \left.-b \varphi(T) r_{\mathrm{l}}\left(\alpha_{\mathrm{ki}}-\alpha_{\mathrm{kl}}\right)\right] \frac{1}{r_{\mathrm{v}}+\alpha_{\mathrm{kl}} r_{1}},
\end{aligned}
$$

The parameter $b$ is the fraction of liquid to ice conversion occurring via the WBF process (see Sect. 3.2.3) as opposed to via direct freezing. It is convenient to define a WBF parameter $\eta$ that measures the ratio between the amount of water vapour deposited as ice that results from droplet evaporation to that resulting from decreasing vapour pressure due to adiabatic cooling of the parcel:

$\eta=\frac{b \varphi(T) r_{1}}{-\mathrm{d} r_{\mathrm{v}} / \mathrm{d} z}$

Eq. (29) then reads

$\mathrm{d} \ln R_{\mathrm{v}} / \mathrm{d} z=\left[\Lambda\left(T, S_{\mathrm{i}}, \xi_{\mathrm{i}}, \eta\right)-1\right] \frac{\mathrm{d} r_{\mathrm{v}} / \mathrm{d} z}{r_{\mathrm{v}}+\alpha_{\mathrm{k} 1} r_{1}}$, where

$\Lambda\left(T, S_{\mathrm{i}}, \xi_{\mathrm{i}}, \eta\right)=\xi_{\mathrm{i}} \alpha_{\mathrm{ki}}+\left(1-\xi_{\mathrm{i}}\right) \alpha_{\mathrm{kl}}+\eta\left(\alpha_{\mathrm{ki}}-\alpha_{\mathrm{kl}}\right)$

is a generalised fractionation factor that depends on temperature, cloud saturation, the importance of ice deposition versus droplet condensation following changes in ambient saturation, and on the intensity of the WBF process. $\Lambda$ takes its name from the fact that it varies continuously from $\alpha_{1}$ to $\alpha_{\mathrm{i}}$ as a function of non-equilibrium conditions.

Equation (31) is equivalent to Eq. (18) of Federer et al. (1982) if we drop entrainment (i.e. set $\mu=0$ ) and diffusive isotopic exchange with rain (i.e. set $P_{\mathrm{vr}}^{\prime}=0$ ) in their representation; notice that $\left(1-\xi_{\mathrm{i}}-\eta\right) \mathrm{d} r_{\mathrm{v}} / \mathrm{d} z=P_{\mathrm{vc}}$ and $\left(\xi_{\mathrm{i}}+\eta\right) \mathrm{d} r_{\mathrm{v}} / \mathrm{d} z=P_{\mathrm{vi}}$, where $P_{\mathrm{vc}}$ and $P_{\mathrm{vi}}$ are, respectively, their production term for cloud water and cloud ice.

Equation (31) offers many deep insights on inspection. The generalised fractionation factor $\Lambda$ contains only the processes involving diffusive exchanges of isotopologues with vapour and excludes freezing and auto-conversion processes. The term $\xi_{\mathrm{i}} \alpha_{\mathrm{ki}}+\left(1-\xi_{\mathrm{i}}\right) \alpha_{\mathrm{kl}}-1$ in Eq. (32) corresponds to the net growth of droplets and ice crystals driven by adiabatic cooling, while $\eta\left(\alpha_{\mathrm{ki}}-\alpha_{\mathrm{kl}}\right)$ corresponds to the isotopic changes induced by the WBF process. The former term is always larger than 1 and leads to a depletion of heavy isotopologues in the vapour phase. In other words, net growth of droplets or ice crystals following parcel cooling results in the well-known progressive distillation of heavy isotopologues out of the vapour phase. The WBF term, on the other hand, can be of either sign, depending on the magnitude of liquid-ice disequilibrium (discussed at length in Sect. 4.3). If kinetic effects are strong, the fractionation factor over liquid may actually exceed that over ice: $\alpha_{\mathrm{kl}}>\alpha_{\mathrm{ki}}$. In these conditions, if a significant fraction of droplet freezing occurs via the WBF, then the WBF term may outweigh the net distillation term and actually lead to local isotopic enrichment of water vapour.

\subsection{Impact of glaciation on isotopic distillation}

The presence of liquid water reduces distillation compared to the case where liquid water is absent: cloud droplets retained within the parcel buffer vapour isotopic composition by exchanging isotopically with the vapour. This effect is represented by the component $\alpha_{\mathrm{kl}} r_{1}$ in the denominator of the unbracketed term in Eq. (31). In the case where all condensates are removed from the parcel and no liquid water is retained $\left(r_{1}=0\right)$, buffering vanishes and the overall expression for change in vapour isotopic composition reduces to a pure Rayleigh distillation process (Rayleigh and Ramsay, 1895; Dansgaard, 1964) with a modified fractionation factor $(\Lambda)$. Maximum buffering from re-equilibration between vapour and liquid occurs when $r_{1}$ is maximum, i.e. when auto-conversion efficiency is zero and all condensates are retained and can exchange with water vapour. This condition is termed the adiabatic scenario by Jouzel et al. (1975). The loss 
of liquid water on glaciation results in a well-known transition between liquid and ice regimes during parcel ascent (Federer et al., 1982; Moyer et al., 1996).

For illustrative purposes, we obtain an approximate solution in the ice and liquid regime by setting $\Lambda$ constant. This approximation is in most regions reasonable, since $r_{\mathrm{v}}$ may vary by four orders of magnitude during the ascent of a deep convective system to the tropopause, but $\Lambda-1$ varies up to a factor of 5. The approximate solution in the warm, liquidonly region under the adiabatic assumption is found by replacing $\Lambda$ (and $\alpha_{\mathrm{kl}}$ ) by a fixed fractionation factor $\Lambda_{0}$ and assuming $r_{\mathrm{v}}+r_{1}$ to be constant. Equation (31) can then be integrated to yield

$R_{\mathrm{v}}=\frac{R_{\mathrm{v} 0} r_{v 0}}{\Lambda_{0} r_{\mathrm{v} 0}-\left(\Lambda_{0}-1\right) r_{\mathrm{v}}}$,

where $R_{\mathrm{v} 0}$ and $r_{\mathrm{v} 0}$ are cloud base values of $R_{\mathrm{v}}$ and $r_{\mathrm{v}}$.

The approximate solution in the ice-only regime is found by setting $r_{1}$ to zero to yield the expression for Rayleigh distillation:

$R_{\mathrm{v}}=R_{\mathrm{v} 1}\left(\frac{r_{\mathrm{v}}}{r_{\mathrm{v} 1}}\right)^{\Lambda_{0}-1}$,

where $\left(R_{\mathrm{v} 1}, r_{\mathrm{v} 1}\right)$ is a reference point on the Rayleigh curve. These "adiabatic" and "Rayleigh" solutions are shown in Fig. 4 along with the full integrated solution of Eq. (31). The behaviour of the full solution is well reproduced other than in the coldest uppermost troposphere (where $\alpha_{\mathrm{ki}}$ departs significantly from $\Lambda_{0}$ ) and of course in the transition region between regimes.

As would be expected, the two approximate solutions yield very different asymptotic values in the limit where all vapour is removed from the air parcel $\left(r_{\mathrm{v}} \rightarrow 0\right)$. In the Rayleigh regime, loss of all vapour corresponds to complete distillation of heavy isotopologues out of the vapour phase: $R_{\mathrm{v}} \rightarrow 0$ when $r_{\mathrm{V}} \rightarrow 0$. In the adiabatic regime, $R_{\mathrm{V}}$ saturates at a finite value $R_{\mathrm{v} 0} / \Lambda_{0}$ when liquid water dominates total water. This value corresponds to the state of vapour in isotopic equilibrium with liquid water when the latter inherits the surface isotopic ratio of water vapour.

In the real world, rainout in the warm phase will limit the buffering effect provided by liquid water. In this case the adiabatic solution would overestimate the heavy isotopologue content during the initial stage of the ascent. Nevertheless, the presence of liquid water is a powerful factor in isotopic evolution. In the mixed-phase region, the location of the transition to the Rayleigh regime is governed by any inhibition of glaciation that allows supercooled water to persist and remain a significant fraction of total water.

\section{Sensitivity of vapour isotopic composition to cloud physics}

In this section, we use the framework developed above to explore the sensitivity of the isotopic composition of wa- ter vapour to cloud processes and parameters: supersaturation, retention of liquid water, and the nature of glaciation. In each set of experiments we vary a single parameter and keep others fixed. Isotopic profiles are determined by integrating Eq. (31) from surface to tropopause along the trajectory of a rising air parcel. A similar approach was followed by Federer et al. (1982) and Moyer et al. (1996). However, to our knowledge no further extensive study of sensitivity of isotopic profiles to microphysics in convective systems has been conducted.

Unless otherwise stated, the reference scenario (i.e. we vary one parameter at a time around this reference) from which the sensitivity studies are performed assumes the following:

- there is no auto-conversion to deactivated/precipitated species (i.e. $C_{1}=0$ )

- the WBF process plays no role $(b=\eta=0)$

- full glaciation occurs at $-31{ }^{\circ} \mathrm{C}$ (the glaciation parameter is $\gamma=3.5$; see Table 2)

- the value of saturation over ice is set by equilibrium saturation over liquid water in the mixed-phase zone and saturates at $147 \%$ for temperatures below $-40^{\circ} \mathrm{C}$ (i.e. the saturation parameter is $\zeta=1$ )

The model integration assumes conditions typical of the tropics. We take a cloud base at $1050 \mathrm{~m}$ with background temperature and pressure profiles from a multi-annual average of the ERA-Interim reanalysis (Dee et al., 2011) within the $20^{\circ} \mathrm{S}-20^{\circ} \mathrm{N}$ latitude band. The isotopic ratios are initialised at cloud base with values typical of the marine boundary layer for a relative humidity of $95 \%$ and under quiescent weather conditions: $\delta \mathrm{D}=-70 \% \circ$ and $\delta^{18} \mathrm{O}=-10 \% 0$ (Craig and Gordon, 1965; Lawrence et al., 2004). All other microphysical constants and parameters are given in the Appendix.

\subsection{Sensitivity to vapour saturation}

We first explore the effects of varying supersaturation in the absence of the WBF process $(\eta=0)$. Although we do not consider supersaturation over liquid in the liquid-only cloud regime, supersaturation over ice in the mixed-phase and iceonly regime can have strong isotopic effects (Dansgaard, 1964; Jouzel and Merlivat, 1984; Moyer et al., 1996). As $S_{\mathrm{i}}$ increases, the effective fractionation factor will decrease at any temperature, for both $\mathrm{HDO} / \mathrm{H}_{2} \mathrm{O}$ and $\mathrm{H}_{2}{ }^{18} \mathrm{O} / \mathrm{H}_{2} \mathrm{O}$, though the effects are stronger for $\mathrm{H}_{2}{ }^{18} \mathrm{O} / \mathrm{H}_{2} \mathrm{O}$ (see Sect. 2.3 for discussion of kinetic fractionation).

In our model, the specification of a constant saturation parameter $\zeta$ by definition produces some retained degree of supersaturation over ice after the cloud has glaciated and vapour pressure can drift away from liquid saturation. The effect of that supersaturation on $-(\Lambda-1)$ is shown in Figs. 5a 
(a)

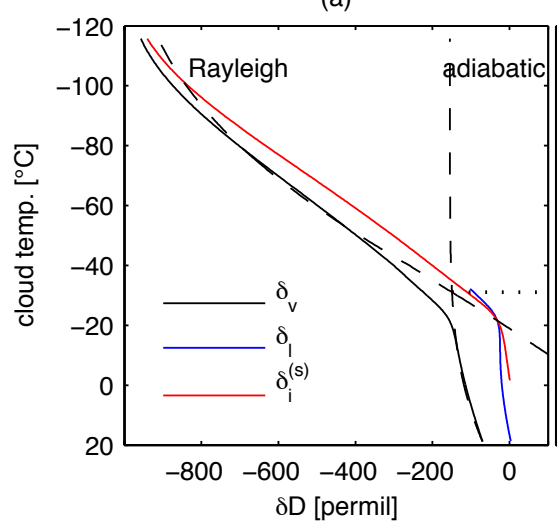

(b)

(c)

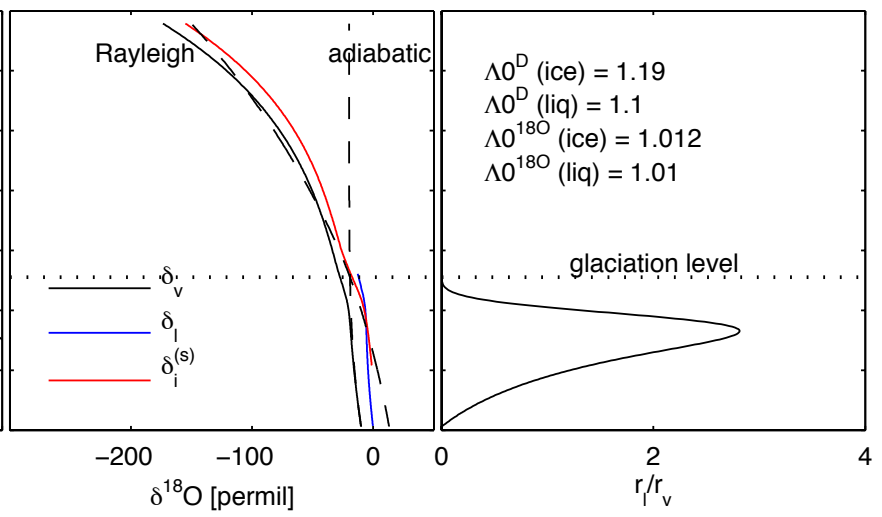

Fig. 4. (a and b) isotopic depletion of water vapour (solid black), (active) liquid water (solid blue) and ice surface layer (solid red) as a function of the temperature of a rising cloud parcel, computed from integrating Eq. (31), compared to the simplified adiabatic and Rayleigh solutions under constant generalised fractionation coefficient $\Lambda_{0}$ (dashed). The integration of Eq. (31) is performed as described in the default scenario of Sect. 4 and the values of $\Lambda_{0}$ for the simplified laws of Eqs. (33) (adiabatic) and (34) (Rayleigh) are given in the right panel. (a) is for $\mathrm{HDO} / \mathrm{H}_{2} \mathrm{O}$ and (b) is for $\mathrm{H}_{2}{ }^{18} \mathrm{O} / \mathrm{H}_{2} \mathrm{O}$. (c) Ratio of the (active) liquid to vapour mass mixing ratios $r_{1} / r_{\mathrm{V}}$. The glaciation level is defined where $r_{1}$ drops below $10^{-6} \mathrm{~kg} \mathrm{~kg}^{-1}$. (a, b) The isotopic ratio of active liquid water is computed as $R_{1}=\alpha_{\mathrm{kl}} R_{\mathrm{V}}$, and that of ice surface layer is computed as $R_{\mathrm{i}}^{(\mathrm{s})}=\alpha_{\mathrm{ki}} R_{\mathrm{V}}$ ( $\delta_{1}$ and $\delta_{\mathrm{i}}$ are the corresponding values in $\delta$-notation). Note that the transition from adiabatic to Rayleigh behaviour is less pronounced for oxygen 18 owing to smaller overall fractionation between vapour and condensed phase (the relative mass difference between isotopologues is smaller).
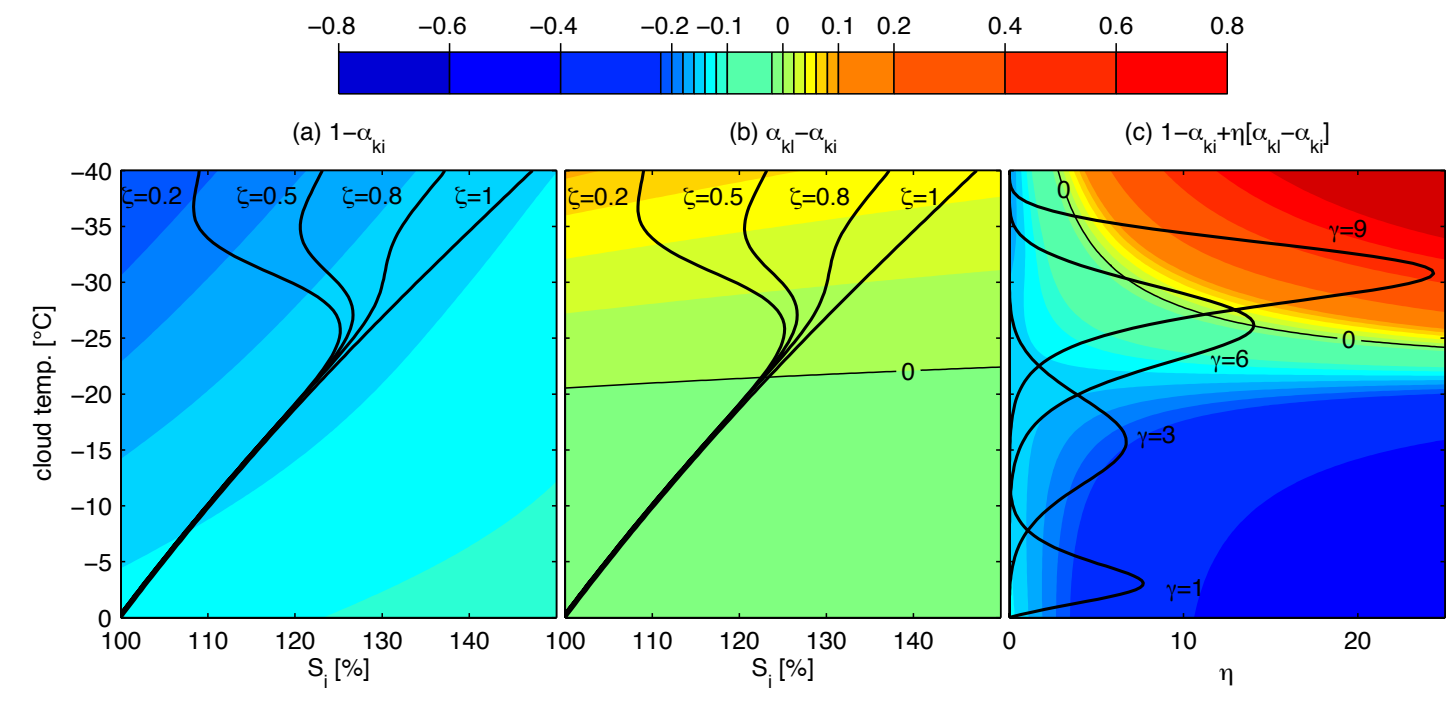

Fig. 5. Variations in the mixed-phase domain of $1-\Lambda=1-\alpha_{\mathrm{ki}}+\eta\left(\alpha_{\mathrm{kl}}-\alpha_{\mathrm{ki}}\right)$ and its components for the $\mathrm{HDO} / \mathrm{H}_{2} \mathrm{O}$ system $(\Lambda=$ generalised fractionation factor). $\xi_{\mathrm{i}}$ has been set to 1 , in coherence with the discussion in Sects. 4.1 and 4.3. (a) Sensitivity to saturation of $1-\alpha_{\mathrm{ki}}$ (corresponding to net adiabatic cooling of moisture); $\gamma$ is set to 9. (b) Sensitivity to saturation of $\alpha_{\mathrm{kl}}-\alpha_{\mathrm{ki}}$ (corresponding to droplet evaporation). The line in solid black marks the sign reversal. (a, b) Iso- $\zeta$ lines correspond to supersaturation over ice for each value of $\zeta$, as computed in the model. (c) Sensitivity of $1-\Lambda$ to the WBF parameter $\eta ; \zeta$ has been set to $1 . \eta$ measures the ratio of the source of vapour from droplet evaporation to that from net adiabatic cooling of moisture. Iso- $\gamma$ curves show the variations of $\eta$ for a rising cloud parcel as computed in the model for each value of the glaciation parameter $\gamma . \eta$ peaks at some cloud temperature which is somewhat higher than glaciation temperature. This is due to enhanced conversion of liquid to ice near glaciation, while evaporation eventually tails off as liquid water becomes depleted. For $\gamma=1$ and 3, the WBF process reinforces depletion. For $\gamma=6$, the WBF process enriches vapour with HDO so that the depletion is decreased compared to the case $\eta=0$. For $\gamma=9$, the WBF effect is strong enough to exceed the effect of net adiabatic moisture cooling and the overall effect is vapour enrichment in the range $-30^{\circ} \mathrm{C}$ to $-40^{\circ} \mathrm{C}$. 


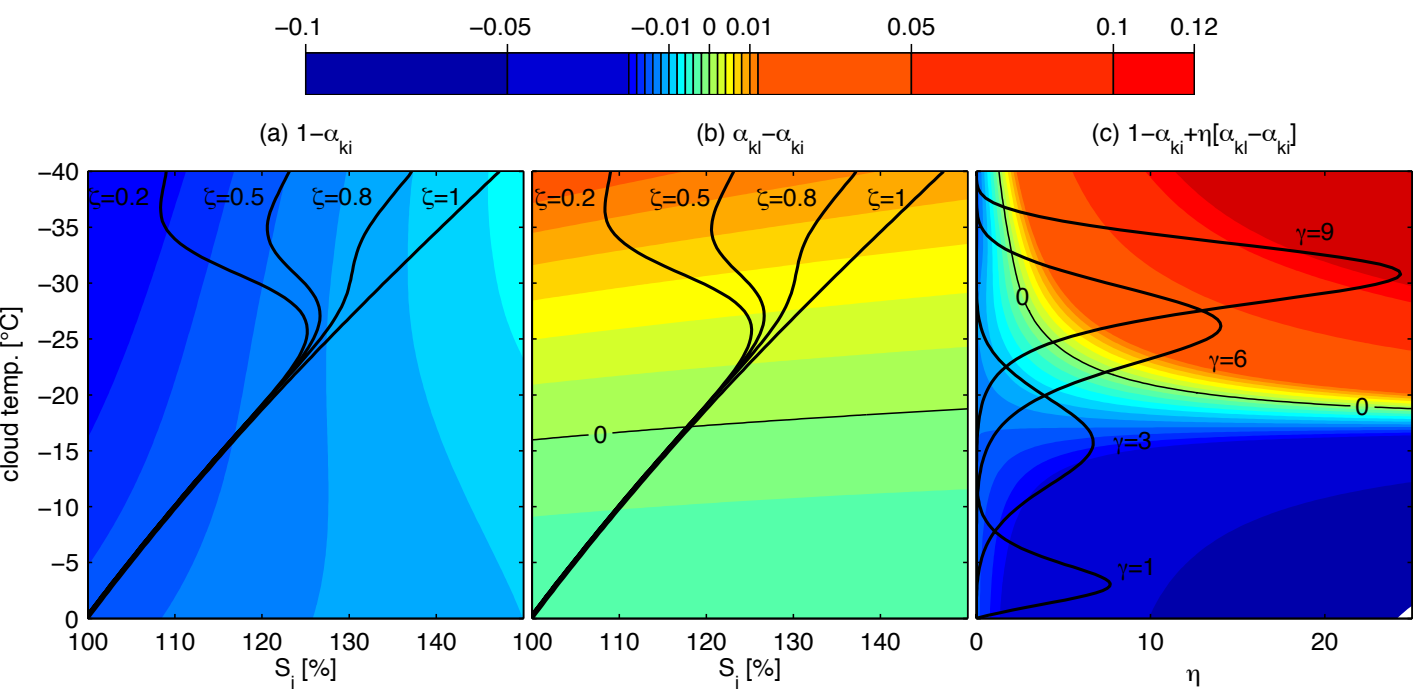

Fig. 6. Same as Fig. 5 but for the $\mathrm{H}_{2}{ }^{18} \mathrm{O} / \mathrm{H}_{2} \mathrm{O}$ system. $\mathrm{H}_{2}{ }^{18} \mathrm{O} / \mathrm{H}_{2} \mathrm{O}$ is more sensitive than $\mathrm{HDO} / \mathrm{H}_{2} \mathrm{O}$ to kinetic effects, which means stronger fractionation limitation with ice supersaturation (a) and stronger re-enrichment in $\mathrm{H}_{2}{ }^{18} \mathrm{O}$ with the WBF effect (b), with onset of the re-enrichment at higher cloud temperature. A larger portion of the positive domain of $1-\Lambda$ in (c) is sampled along the trajectories of $\eta$ than for $\mathrm{HDO} / \mathrm{H}_{2} \mathrm{O}$. Combining the effects of net moisture cooling and droplet evaporation, one can see that vapour is now re-enriched in heavy isotopologue when $\gamma=6$ in addition to $\gamma=9$, compared to the $\mathrm{HDO} / \mathrm{H}_{2} \mathrm{O}$ system.

and $6 \mathrm{a}$. For simplicity and readability, $\gamma$ has been set to 9 and $\xi_{\mathrm{i}}$ to 1 in those figures (thus effective fractionation is set to $\alpha_{\mathrm{ki}}$ ), which slightly overestimates $\Lambda$ in the liquidwater-dominated zone, but yields the expected value in the glaciated zone where scenarios are sensitive to $\zeta$. Choices of $\zeta$ from 0 to 1 produce final supersaturation over ice from $100 \%$ to $150 \%$. Within this range of $S_{\mathrm{i}}$, at $-40{ }^{\circ} \mathrm{C}$, $-(\Lambda-1)$ varies for $\mathrm{HDO} / \mathrm{H}_{2} \mathrm{O}$ by a factor of 1.5 , from -0.23 to -0.15 (Fig. 5a), and for $\mathrm{H}_{2}{ }^{18} \mathrm{O} / \mathrm{H}_{2} \mathrm{O}$ by a factor of 3 , from -0.03 to -0.01 (note from Eq. (31) that $-(\Lambda-1)$ is the relevant metric for comparison of isotopic effects rather than the effective fractionation factor $\Lambda)$. At temperatures lower than $-40^{\circ} \mathrm{C}$, relative variations of $-(\Lambda-1)=1-\alpha_{\mathrm{ki}}$ with saturation stay of the same order.

The resulting effects on isotopic profiles are shown in panels (a) and (d) of Fig. 7 ( $\xi_{\mathrm{i}}$ is now set back to $f_{\mathrm{i}}$, following Sect. 3.2.3). While isotopic changes in the glaciation region itself are small, supersaturations persist during the remaining ascent to the tropopause, and progressive distillation as water vapour deposits to ice means that supersaturation can produce substantial isotopic effects: supersaturations of 100 $150 \%$ ( $\zeta$ of $0-1$ ) produce isotopic profiles differing by up to $\sim 50 \%$ o for $\delta \mathrm{D}$ and $\sim 150 \%$ o for $\delta^{18} \mathrm{O}$. The curves in panel (a) of Fig. 7 actually converge at the coldest temperatures, not because of any saturation effect but because the large mass ratio $\mathrm{D} / \mathrm{H}$ produces such strong fractionations that by very cold temperatures, deuterium is fully stripped out of the vapour phase, that is, $\delta \mathrm{D} \rightarrow-1000 \%$, and the metric $\delta \mathrm{D}$ loses sensitivity to saturation.

The sensitivity of water isotopologues to supersaturation means that if numerical convective schemes are to realisti- cally reproduce isotopic profiles they must involve a careful parametrization of in-cloud supersaturation. Simplified parametrizations that depend only on temperature may not be appropriate in convective models. The appropriate physics for supersaturation in convective clouds involves a balance between the adiabatic cooling rate of moisture and the rate of vapour uptake due to growth of condensed phase (Squires (1952); Twomey (1959); Korolev and Mazin (2003); see also Appendix C). Higher updraft speeds, lower concentration of ice particles or smaller crystals will result in higher supersaturations over ice, which limits isotopic fractionation, especially for ${ }^{18} \mathrm{O}$.

Theory suggests that supersaturation in convective clouds is constrained to within a few percentage points of the value set by liquid saturation in liquid-water dominated zones and can be highly variable in the glaciated zone. The conditions of sustained liquid saturation in a mixed-phase updraft (necessary for vapour uptake on supercooled droplets) can be derived within the theoretical framework developed by Korolev and Mazin (2003) (updraft velocity must exceed $w_{\text {up }}^{\star}$; see Appendix C). For an ice number concentration of $5 \mathrm{~cm}^{-3}$ and a mean ice equivalent radius of $20 \mu \mathrm{m}$ (which are in the range of observations for maritime convection) (Lawson et al., 2010; Stith et al., 2002)), steady-state liquid saturation at $-20{ }^{\circ} \mathrm{C}$ (i.e. $22 \%$ supersaturation over ice) may be sustained in a vertical stream of at least $16 \mathrm{~m} \mathrm{~s}^{-1}$. If ice number concentration falls to lower values, liquid saturation is even more readily sustained. However, many modelling studies, including at mesoscale (Hoffmann et al., 1998; Schmidt et al., 2007; Lee et al., 2007; Yoshimura et al., 2008; Tindall et al., 2009; Risi et al., 2010; Kurita et al., 

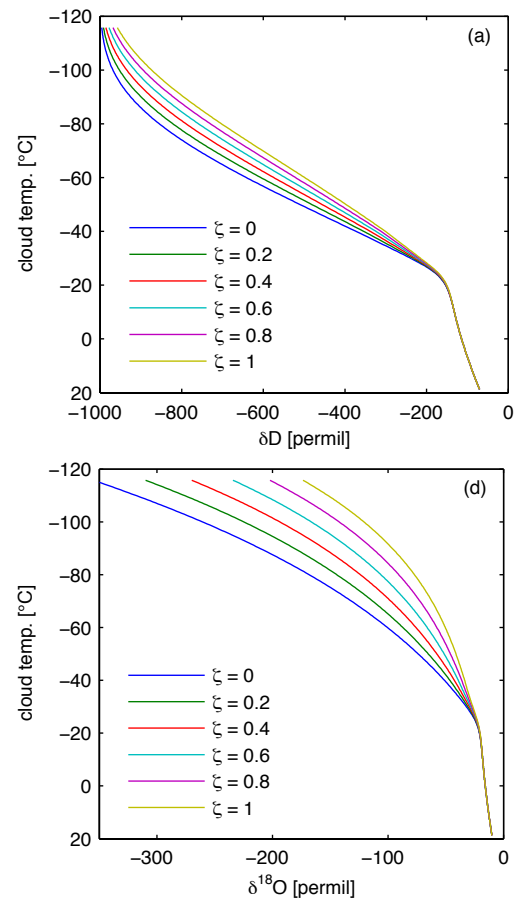
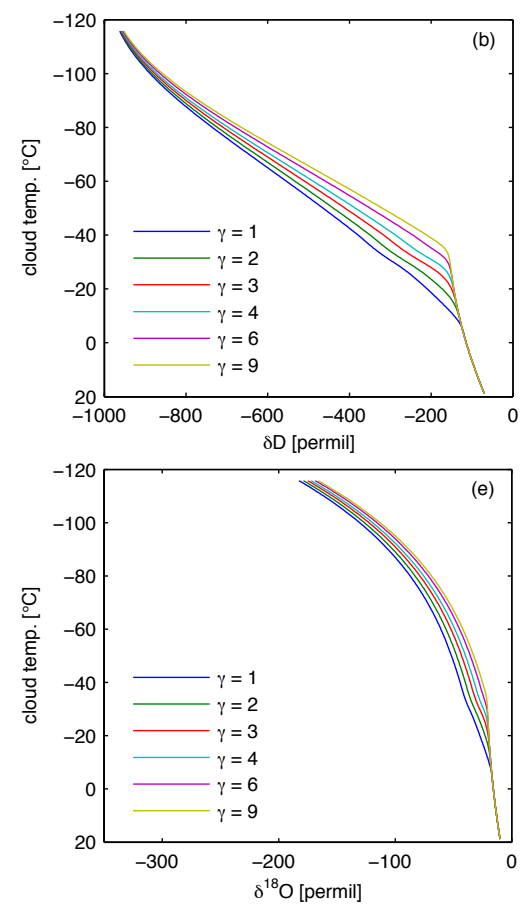
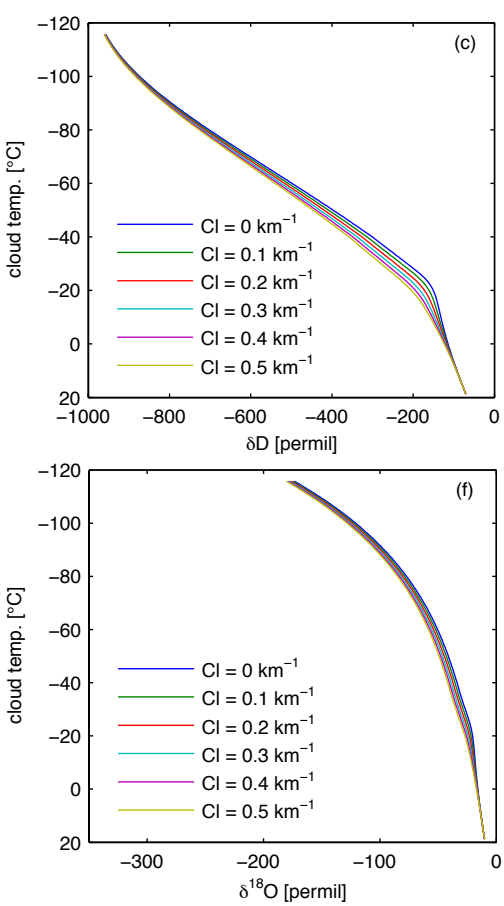

Fig. 7. Values of water vapour $\delta \mathrm{D}(\mathbf{a}-\mathbf{c})$ and $\delta^{18} \mathrm{O}(\mathbf{d}-\mathbf{f})$ along cloud parcel temperature. (a, d) Sensitivity to the saturation parameter $\zeta$. (b, e) Sensitivity to the glaciation parameter $\gamma$ (glaciation temperature decreasing as $\gamma$ increases, see Table 2). (c, f) Sensitivity to liquid water auto-conversion parameter $C_{1}$. Parameters not varied are taken from the default scenario of Sect. 4 .

2011), use a parametrisation of ice supersaturation of the form $S_{\mathrm{i}}=1-\lambda T\left[{ }^{\circ} \mathrm{C}\right]$ (initially derived by Jouzel and Merlivat, 1984, to represent supersaturation in inversion layers over Greenland and Antarctica). These parametrisations limit supersaturation over ice at $-20^{\circ} \mathrm{C}$ to $6-10 \%$, for the range of choices in $\lambda$ (between $0.003^{\circ} \mathrm{C}^{-1}$ and $0.005^{\circ} \mathrm{C}^{-1}$ according to Risi et al., 2012), less than half the value expected for vigorous convection (i.e. $22 \%$ over ice, set by saturation over liquid). The sensitivity of isotopic compositions to supersaturation means that this discrepancy is significant for models that track the isotopic composition of water vapour, and should be a focus of future study (see further discussion in Sect. 5).

\subsection{Sensitivity to (isotopically active) liquid water content}

Liquid water content in clouds is affected by entrainment rates, updraft velocities, precipitation efficiencies, particle size distribution and the relative dominance of warm rain versus ice processes (Cotton et al., 2011, chap. 8.12). The supercooled liquid water content (SLWC) persisting in the "mixed-phase zone" between 0 and $-40^{\circ} \mathrm{C}$ is then expected to be quite variable. Conditions that promote the retention of high SLWC down to the homogeneous freezing level are thought to exist in vigorous continental clouds with a shallow warm-phase zone where most liquid water is expected in the form of large concentrations of small droplets (Kumjian et al., 2012). Near-complete retention of liquid water has indeed been observed for such conditions: Rosenfeld and Woodley (2000) measured a near-adiabatic liquid water content of $1.8 \mathrm{~g} \mathrm{~m}^{-3}$ down to $-37.5^{\circ} \mathrm{C}$ in a case of vigorous continental convection over the USA state of Texas. The other extreme case of full glaciation at much warmer temperatures is also documented: Stith et al. (2004) found no liquid water at temperatures colder than $-17^{\circ} \mathrm{C}$ in cases of maritime convection over Kwajalein, Marshall Islands. The isotopic effects that arise from these variations in the size of the actively exchanging liquid water reservoir are expected to be strong. Moreover, in the case of continental convection just mentioned, a conservative assumption of $20 \mathrm{~m} \mathrm{~s}^{-1}$ for the updraught velocity and reported values of median volume diameter of supercooled droplets yields a median volume isotopic adjustment length scale of $14 \mathrm{~m}$ at $-10^{\circ} \mathrm{C}, 39 \mathrm{~m}$ at $-20^{\circ} \mathrm{C}$ and $200 \mathrm{~m}$ at $-35^{\circ} \mathrm{C}$ (see also Sect. 2.3). This suggests that a significant part of liquid water may not be considered to fully equilibrate with vapour at temperatures lower than $-20^{\circ} \mathrm{C}$, at least during the active stage of convection. In other words, the combined variability in the liquid water content and in the fraction of actively exchanging droplets is expected to significantly impact water vapour isotopic composition within convective systems.

We do not seek to accurately model the physics of removal of liquid water, as we are interested in the isotopic consequences of variations in the liquid reservoir size. In our 
model, the vertical profile of active liquid water is primarily governed by two parameters that control auto-conversion processes and the ability of supercooled droplets to survive at negative temperatures: $C_{1}$, the auto-conversion coefficient, and $\gamma$, which controls the conversion of liquid to ice and effectively sets the glaciation altitude.

Figure 7 (panels $b$ and e) shows that vapour isotopic composition is sensitive to the altitude of glaciation. Changing the glaciation altitude (via $\gamma$ ) with other parameters held fixed changes the level of transition from the adiabatic to the Rayleigh isotopic regimes. Trajectories where the cloud glaciates fully at lower altitudes (higher temperatures) produce more depleted vapour isotopic compositions in the middle and upper troposphere, since the strong Rayleigh fractionation over ice begins earlier. If supercooled water is retained to higher altitudes (lower temperature), vapour isotopic composition is relatively enhanced. The isotopic differences at some altitudes may be larger than $100 \%$ o for $\delta \mathrm{D}$.

The sensitivity of isotopic profiles to auto-conversion efficiency is also strong (Fig. 7, panels $\mathrm{c}$ and $\mathrm{f}$ ). In this case, we vary $C_{1}$ from 0 (adiabatic active water content) to $0.5 \mathrm{~km}^{-1}$. At the highest value of $C_{1}$, active liquid water content at $0^{\circ} \mathrm{C}$ level is reduced to $31 \%$ of its adiabatic value. When $C_{1}=0$, the transition between the adiabatic regime in which vapour exchanges with liquid cloud water to the Rayleigh regime is sharp. As active liquid water content decreases, its buffering effect is reduced and the transition between regimes becomes less sharp. In the limit of full auto-conversion, $r_{1}=0$ and isotopic evolution throughout cloud ascent occurs by pure Rayleigh distillation.

Moyer et al. (1996) described a similar dependency of cloud vapour isotopic composition to condensate retention, under the assumption that all droplets actively re-equilibrate, and showed the limiting cases of immediate condensate removal and full condensate retention. Federer et al. (1982) pointed out that their microphysical model exhibits an adiabatic behaviour when raindrops are excluded from consideration as a result of assuming a continental droplet spectrum. They also assumed that droplets are always in isotopic equilibrium with vapour. Our model results (Fig. 7) agree with previous work in showing that the isotopic consequences of retention of liquid water are strongest in the mid-troposphere. Once glaciation is complete, isotopic differences due to liquid water content are gradually eroded by continued distillation.

\subsection{Droplet evaporation in the mixed-phase region (WBF)}

In Sects. 4.1 and 4.2, glaciation was assumed to occur by freezing of liquid droplets, so that the phase change itself does not produce fractionation. If glaciation proceeds instead via the WBF process (liquid-vapour-ice), as previously shown, it produces fractionation. We explore these isotopic effects in our model by varying the parameter $b$, which gov- erns the fraction of glaciation that occurs via WBF, from $b=$ 0 (no WBF) to $b=1$ (all glaciation by WBF). The glaciation parameter $\gamma$ is set to a high value, 9, to move final glaciation to a high altitude, since isotopic effects of the WBF process are most obvious at low temperatures, as will be discussed below.

As seen in Fig. 8, the main isotopic effect produced by the WBF is an enhancement in heavy isotopologues of water vapour that occurs in the glaciation region. The enhancement occurs because effective fractionation over liquid becomes larger than effective fractionation over ice at small temperature, as was recognised by Ciais and Jouzel (1994) and Moyer et al. (1996). This effect is illustrated in Figs. 5b and $6 \mathrm{~b}$. The reason for this reversal is that as temperature decreases, kinetic isotopic effects decrease $\alpha_{\mathrm{ki}}$ and increase $\alpha_{\mathrm{k} 1}$, as a result of growing liquid-ice disequilibrium, until they cross. At this point, transferring water from liquid to vapour and then re-condensing it as ice produces enrichment of vapour, since freshly deposited ice is isotopically lighter than the supercooled droplets. However, net ice deposition and droplet growth following adiabatic cooling, corresponding to the term $1-\left(\xi_{\mathrm{i}} \alpha_{\mathrm{ki}}+\left(1-\xi_{\mathrm{i}}\right) \alpha_{\mathrm{kl}}\right)$ in $\Lambda$, always results in a depletion of vapour isotopic composition. The balance between these two counteracting processes produces the isotopic profiles seen in Fig. 8. The phenomenon of net isotopic enhancement occurs only at cold temperatures, when $\alpha_{\mathrm{ki}}<\alpha_{\mathrm{kl}}$ and droplet evaporation can supply enough vapour to outweigh the effects of adiabatic moisture cooling. In our representation, the enhancement scales with the importance of the WBF process in glaciation (i.e. $b$ ). Notice that Fig. 8 shows the upper bound of isotopic enrichment from WBF because of the assumption of no auto-conversion in the reference scenario (auto-conversion would reduce the reservoir of cloud liquid water available for evaporation).

While Fig. 8 shows isotopic profiles for only a single assumption of glaciation altitude $(\gamma=9)$, the occurrence and location of the isotopic enhancement in different glaciation conditions can be inferred from examining the generalised fractionation factor $\Lambda$. Figures $5 \mathrm{c}$ and $6 \mathrm{c}$ show $-(\Lambda-1)$, combining both WBF and the effects of adiabatic cooling over the entire mixed-phase region for a range of the WBF parameter $\eta$. The structure of dependence of generalised fractionation upon the altitude of glaciation is simplified by setting $\xi_{\mathrm{i}}=1$ in those figures, which makes the fractionation term accommodating adiabatic cooling $\left(\xi_{\mathrm{i}} \alpha_{\mathrm{ki}}+\left(1-\xi_{\mathrm{i}}\right) \alpha_{\mathrm{kl}}\right)$ independent of glaciation, but retains the dependence upon the glaciation parameter in $\eta$. That is, we set $-(\Lambda-1)=$ $1-\alpha_{\mathrm{ki}}-\eta\left(\alpha_{\mathrm{kl}}-\alpha_{\mathrm{ki}}\right)$. As discussed previously, $\eta$ measures the ratio of the source of vapour from droplet evaporation to that from net adiabatic cooling of moisture (it thus measures the magnitude of WBF). Variations of $\eta$ with cloud temperature are superimposed on the same panel, for rising parcels with several values of the glaciation parameter $\gamma(b$ is fixed to 1 in those simulations). The values of $\eta$ exhibit excursions which peak at temperatures somewhat warmer than the 

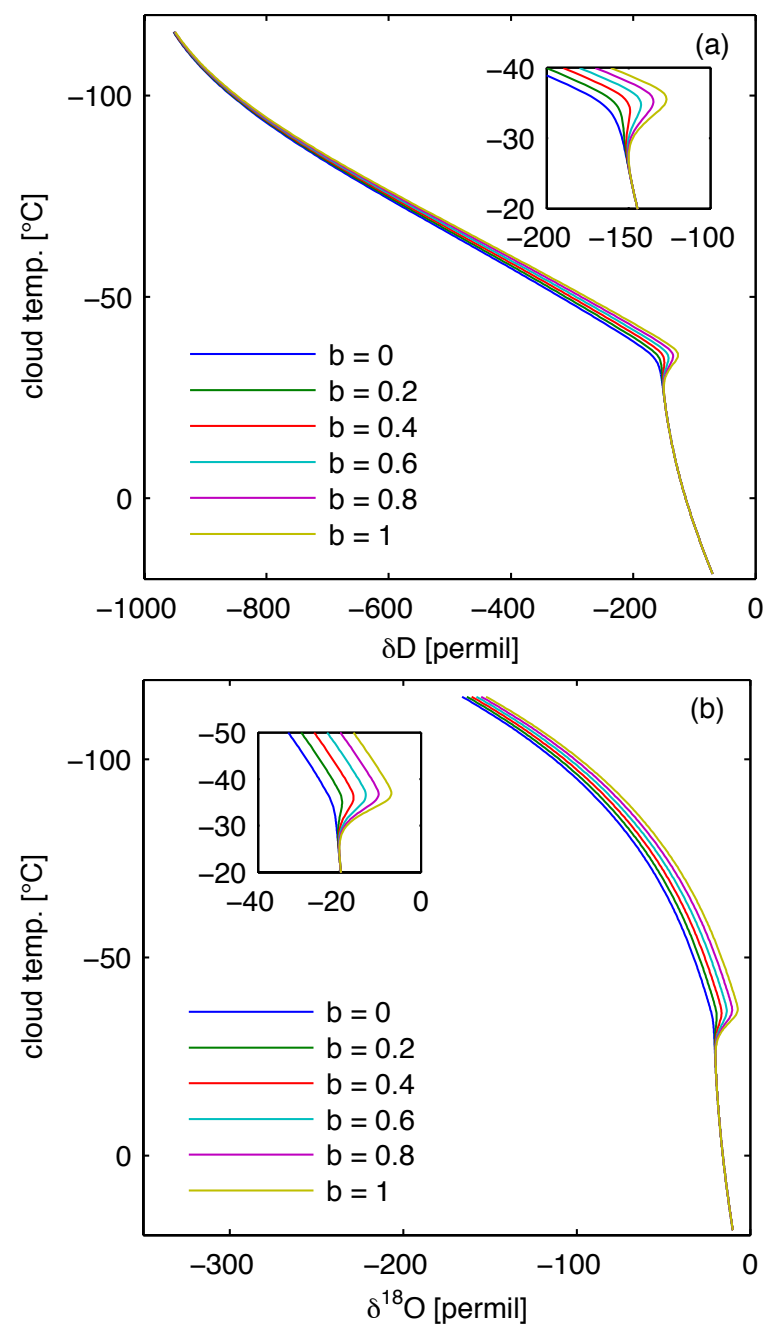

Fig. 8. (a) Sensitivity of $\delta \mathrm{D}$ along cloud parcel temperature to the WBF parameter $b$ with the glaciation parameter $\gamma=9$ (glaciation temperature $-38^{\circ} \mathrm{C}$ ). (b) Same as (a) for $\delta^{18} \mathrm{O}$. Other parameters are taken from the default scenario of Sect. 4 .

glaciation temperatures of the parcels and decreasing with increasing $\gamma$. This variation is due to enhanced conversion of liquid to ice near glaciation, while evaporation eventually tails off as liquid water becomes depleted. The generalised fractionation factor (or rather $-(\Lambda-1)$ here) is then determined according to the temperature and the excursion in $\eta$ along the trajectories of the parcels.

These results show that if glaciation is largely completed at low altitudes (warm temperatures), the WBF effect can only yield further isotopic depletion. Net enhancement of vapour isotopic composition via WBF occurs when $1-\Lambda>0$. This circumstance is reached only when sufficient liquid water is retained at cold temperatures $\left(\sim-30^{\circ} \mathrm{C}\right.$ or less $)$. The isotopic effect of the WBF process therefore depends on the average level to which supercooled droplets have managed to survive conversion to ice. Note that WBF enhancement of isotopic composition occurs more readily for $\mathrm{H}_{2}{ }^{18} \mathrm{O} / \mathrm{H}_{2} \mathrm{O}$ than for $\mathrm{HDO} / \mathrm{H}_{2} \mathrm{O}$, with onset at warmer temperatures. This effect is not surprising, since the WBF is driven by nonequilibrium processes that result in stronger kinetic fractionation effects for the system $\mathrm{H}_{2}{ }^{18} \mathrm{O} / \mathrm{H}_{2} \mathrm{O}$ than for $\mathrm{HDO} / \mathrm{H}_{2} \mathrm{O}$. We note that the simplification $\xi_{\mathrm{i}}=1$ in Figs. $5 \mathrm{c}$ and $6 \mathrm{c}$ slightly overestimates $1-\Lambda>0$ when $\eta=0$; the minimum $\eta$ for WBF enhancement would be slightly lower without that simplification.

Conditions where the WBF effect is important could be produced when strong convection loses buoyancy and enters its dissipating stage. If a significant amount of supercooled droplets have survived to low temperatures during the preceding active stage, then ice will begin to grow at the expense of droplet evaporation in residual vapour-limited uplifts at temperatures above $-40^{\circ} \mathrm{C}$. These ice crystals eventually serve as seeds for stratiform precipitation. Theory predicts also that the WBF process is more efficient than heterogeneous freezing in transforming supercooled liquid to ice at these low temperatures (Orville and Kopp, 1977, Fig. 3). Thus, we speculate that the transition from convective to stratiform physics, in cases of strong convection, may produce an isotopic enhancement in the $\sim-30^{\circ} \mathrm{C}$ to $-40^{\circ} \mathrm{C}$ region, especially for ${ }^{18} \mathrm{O}$.

Finally, note that models can only simulate WBF isotopic enhancement if they represent kinetic effects for both droplet evaporation and ice deposition within the mixed-phase zone. If kinetic effects are neglected for both processes, as in Federer et al. (1982), then no enhancement is possible.

\section{Deuterium oxygen-18 relationship}

It is common in geochemistry, when multiple isotopologue systems are available, to exploit the relationships between different isotopologues as tracers of relevant physical processes. These comparisons can both eliminate dependence on the concentration of the primary species and can elucidate subtle kinetic effects that affect isotopologues differently. With atmospheric water vapour, the very large change in concentration - four orders of magnitude from surface to tropopause - makes direct comparison of $\delta^{18} \mathrm{O}$ and $\delta \mathrm{D}$ especially useful, and it has been used since the inception of isotopic measurements (e.g. Craig, 1961a; Dansgaard, 1964; Merlivat and Jouzel, 1979).

In our model, we can readily combine the separate distillation equations ( $\mathrm{d} \ln R_{\mathrm{v}} / \mathrm{d} z$ ) for $\mathrm{HDO} / \mathrm{H}_{2} \mathrm{O}$ and $\mathrm{H}_{2}{ }^{18} \mathrm{O} / \mathrm{H}_{2} \mathrm{O}$ (see Eq. 31) in order to eliminate the dependence on water vapour concentration. Combining these equations yields the local slope of $\delta \mathrm{D}$ vs. $\delta^{18} \mathrm{O}$ in the vapour phase:

$$
\frac{\mathrm{d} \delta \mathrm{D}}{\mathrm{d} \delta^{18} \mathrm{O}}=\underbrace{\left(\frac{R_{0}^{18} \mathrm{O}}{R_{0}^{\mathrm{D}}}\right)\left(\frac{R_{\mathrm{v}}^{\mathrm{D}}}{R_{\mathrm{v}}^{18} \mathrm{O}}\right)}_{1}[\underbrace{\left[1+\frac{\alpha_{\mathrm{kl}}^{18}-\alpha_{\mathrm{kl}}^{\mathrm{D}}}{\frac{r_{\mathrm{v}}}{r_{1}}+\alpha_{\mathrm{kl}}^{\mathrm{D}}}\right]}_{2} \underbrace{\frac{\Lambda^{\mathrm{D}}-1}{\Lambda^{18 \mathrm{O}}-1},}_{3}
$$


where the superscript labels the isotopologue systems $\mathrm{HDO} / \mathrm{H}_{2} \mathrm{O}$ and $\mathrm{H}_{2}{ }^{18} \mathrm{O} / \mathrm{H}_{2} \mathrm{O}$.

Among the factors in the right-hand side of Eq. (35) that control the slope, the first two (term 1) are pure scaling terms. The third factor (term 2) contains the dependence upon liquid water content $r_{1}$. It is relatively invariant, being bound between 1 and $1+0.2\left(r_{\mathrm{v}} / r_{1}+1\right)^{-1}$ for temperature down to $-40^{\circ} \mathrm{C}$. Even in the most extreme case without liquid autoconversion, water vapour would constitute at least $20 \%$ of total water content in the lower troposphere $\left(r_{\mathrm{v}} / r_{1}>0.2\right)$, so that this factor does not exceed 1.16. Thus, while liquid water re-equilibration with vapour has strong effects on isotopic ratios, it is relatively unimportant to the $\delta \mathrm{D}-\delta^{18} \mathrm{O}$ slope. The main factor controlling the slope (term 3 ) arises from the different tendencies of fractionation in $\mathrm{HDO} / \mathrm{H}_{2} \mathrm{O}$ and $\mathrm{H}_{2}{ }^{18} \mathrm{O} / \mathrm{H}_{2} \mathrm{O}$ for rising parcels and depends on the local thermodynamical and microphysical conditions.

Although the $\delta \mathrm{D}-\delta{ }^{18} \mathrm{O}$ slope is nearly invariant to convective conditions at low altitudes, it becomes highly sensitive in the mixed-phase region and above (Fig. 9, which shows the slope given by Eq. (35) with extreme choices for vapour saturation and glaciation temperature). In the liquid-only regime of the lower troposphere and down to about $-20^{\circ} \mathrm{C}$ in the mixed-phase regime, no choice of parameters causes much dispersion and the value of the slope remains close to 8 , the slope of the meteoric water line originally defined from precipitation samples by Craig (1961b). At higher altitudes and lower temperature, the deviation from the meteoric water line is significant and the choice of cloud parameters becomes important. In conditions close to ice saturation, the slope lies below 8 , but at high supersaturations it can actually exceed 8.

Figure 10a shows how the differences in slope discussed above translate to differences between trajectories in $\delta \mathrm{D}-\delta^{18} \mathrm{O}$ space. It appears that the relative dispersion due to vapour saturation dominates the dispersion due to glaciation temperature. Greater separation with saturation is promoted at low temperatures while the separation due to glaciation temperature is bound by the converging slopes in Fig. 9. This dominance of sensitivity to supersaturation suggests that it may be possible to estimate its value from the joint measurement of $\delta \mathrm{D}$ and $\delta^{18} \mathrm{O}$, regardless of the knowledge of the glaciation temperature. Such possibility is hampered by the sensitivity of the slope to the WBF process, as seen in Fig. 10b (where WBF is measured from the WBF fraction $b$ of liquid to ice conversion). This sensitivity is concentrated in the temperature range $\sim-30^{\circ} \mathrm{C}$ to $-40^{\circ} \mathrm{C}$ where WBF enhancement takes place and results in successive sign reversals of the generalised fractionation coefficients (as seen in Figs. 5c and 6c). Additional information can, however, be provided by parcel temperature; isotherms in the $\delta \mathrm{D}-\delta^{18} \mathrm{O}$ space depend on glaciation temperature and WBF fraction.

The isotherms (see Figs. 10a and b) separate more with $\gamma$ and $b$ at warm temperatures where the iso- $\zeta$ curves merge than at low temperatures where the iso- $\zeta$ curves separate.

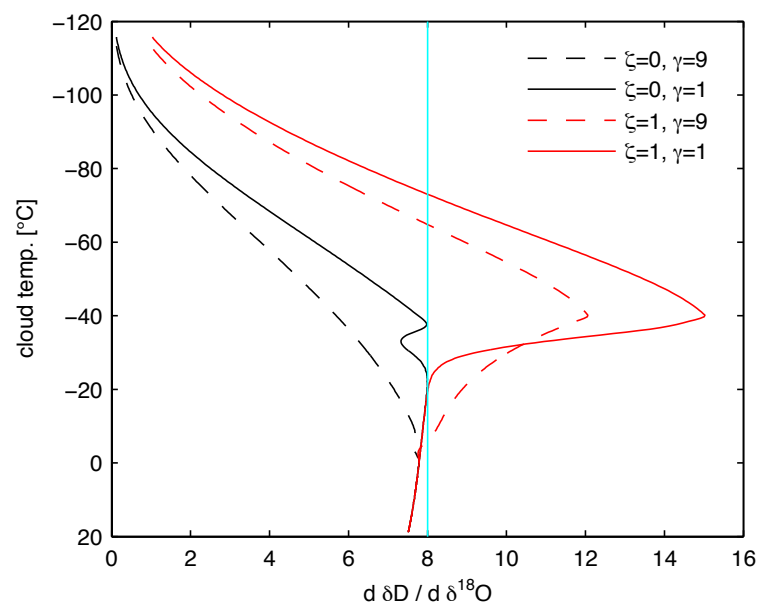

Fig. 9. Slope of $\delta \mathrm{D}$ versus $\delta^{18} \mathrm{O}$ as a function of cloud parcel temperature with extreme choices for vapour saturation $(\zeta=0$ and $\zeta=1$, corresponding to $100 \%$ and $147 \%$ final saturation over ice; see Table 2) and glaciation temperature $(\gamma=1$ and $\gamma=9$; see Table 2). No WBF effect is considered. The vertical line indicates the value 8 used in the definition of d-excess (when the slope of $\delta \mathrm{D}$ versus $\delta^{18} \mathrm{O}$ equals 8 , $\mathrm{d}$-excess is conserved).

Consequently, one expects that the simultaneous measurement of $\delta \mathrm{D}, \delta^{18} \mathrm{O}$ and $T$ provides a joint estimation of $b$ and $\gamma$ at warm temperature, leaving $\zeta$ fairly undetermined, whereas it provides an estimate of $\zeta$ but leaves $b$ and $\gamma$ fairly undetermined at low temperatures. These properties are exploited in the next section. Any additional independent measurement or hypothesis that links the parameters would reduce the uncertainty. For instance, in updrafts sufficiently strong to sustain vapour pressure in excess of liquid saturation $\left(w_{\text {up }}>w_{\text {up }}^{*}\right.$; see Appendix C), the conditions for droplet evaporation are not met and the WBF process can be discarded.

The variability in the $\delta \mathrm{D}$ versus $\delta^{18} \mathrm{O}$ relationship found in cold, glaciated regions of a rising convective system suggests that the commonly used metric of deuterium excess $(d)$, originally defined by Dansgaard (1964) as $d=\delta \mathrm{D}-8 \delta^{18} \mathrm{O}$ to account for kinetic effects in meteoric water formation and precipitation, may be highly sensitive to in-cloud processes. Any deviation from the value 8 in Fig. 9 is indicative of a positive or negative tendency in deuterium excess.

Profiles of deuterium excess along parcel trajectories exhibit both vertical structure and sensitivity to assumptions about cloud processes. Figure 11 shows the sensitivity of $d$ to saturation, glaciation parameter, and the WBF effect. From the boundary layer to about $-20^{\circ} \mathrm{C}, d$ is roughly constant at $d \approx 10 \%$ in all simulations, because the slope $\mathrm{d} \delta \mathrm{D} / \mathrm{d} \delta^{18} \mathrm{O}$ stays close to 8 (as shown in Fig. 9). In the midto upper troposphere $(11-15 \mathrm{~km})$, however, modelled deuterium excess shows wide variations, ranging from -200 to $+300 \%$. $d$ in this region is reduced by larger supersaturations, higher glaciation altitudes, and increased WBF, with 

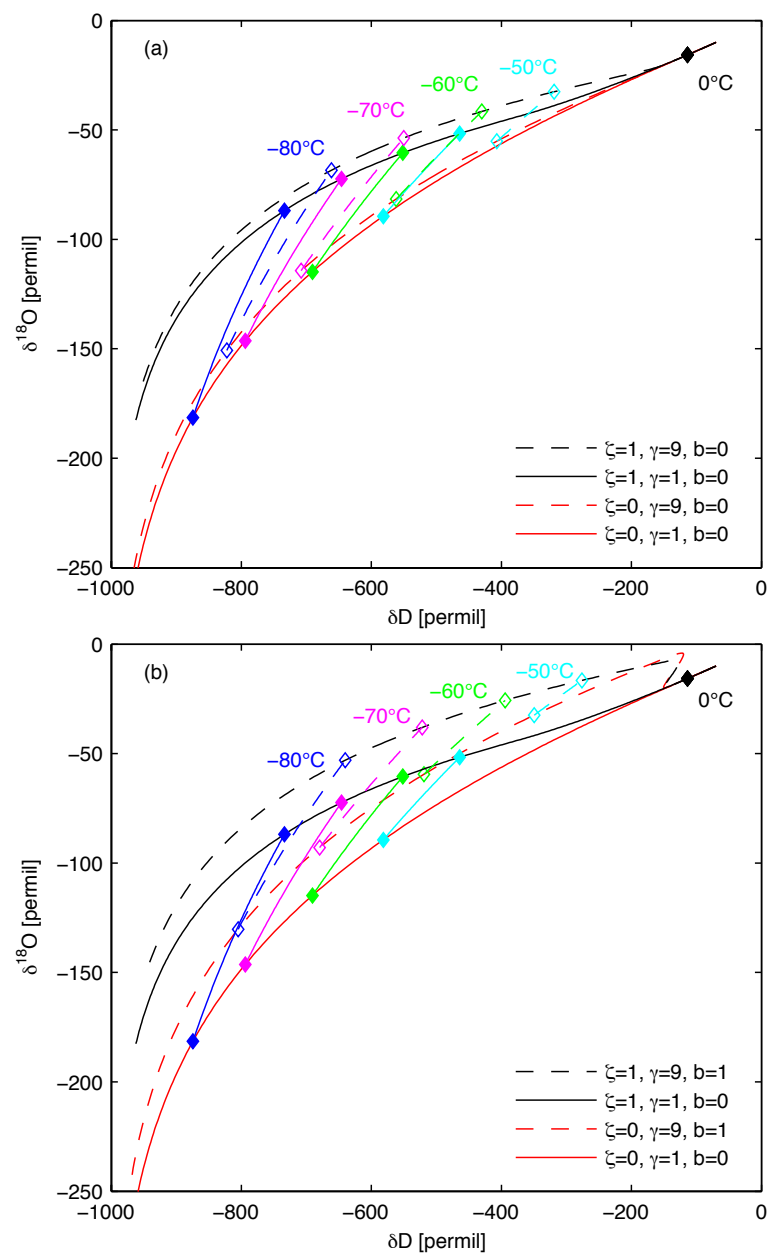

Fig. 10. (a) Sensitivity of the $\delta \mathrm{D}-\delta^{18} \mathrm{O}$ relationship to glaciation and saturation parameters $\gamma$ and $\zeta$. Glaciation proceeds as pure freezing $(b=0)$. (b) Same as (a) but glaciation proceeds as a pure WBF process $(b=1)$ when the glaciation parameter is $\gamma=9$. Isotherm curves at $-80^{\circ} \mathrm{C},-70^{\circ} \mathrm{C},-60^{\circ} \mathrm{C}$ and $-50{ }^{\circ} \mathrm{C}$ are shown for varying $\zeta$ from 0 to 1 under the following scenarios: $\gamma=1, b=0$ (solid lines, panels $\mathbf{a}$ and $\mathbf{b}$ ), $\gamma=9, b=0$ (dashed lines, panel a), $\gamma=9, b=1$ (dashed lines, panel $\mathbf{b})$.

some combinations driving $d$ negative, typically at convective detrainment levels. In the tropopause transition region (above $15 \mathrm{~km}$ ), modelled $d$ is positive in nearly all conditions but with variations of up to a thousand permil, depending on cloud processes.

The vertical structure and sensitivity in $d$ may make it a useful tracer of cloud processes, but care must be taken to understand the factors that affect it. Several recent modelling studies (Bony et al., 2008; Blossey et al., 2010; Kurita et al., 2011) have used $d$ as a tracer of upper tropospheric air subsiding to the surface, while using simplified parametrized physics of vapour saturation. In global models $S_{\mathrm{i}}=1-\lambda T\left[{ }^{\circ} \mathrm{C}\right]$ is often used (Hoffmann et al., 1998; Schmidt et al., 2007; Lee et al., 2007; Yoshimura et al., 2008;
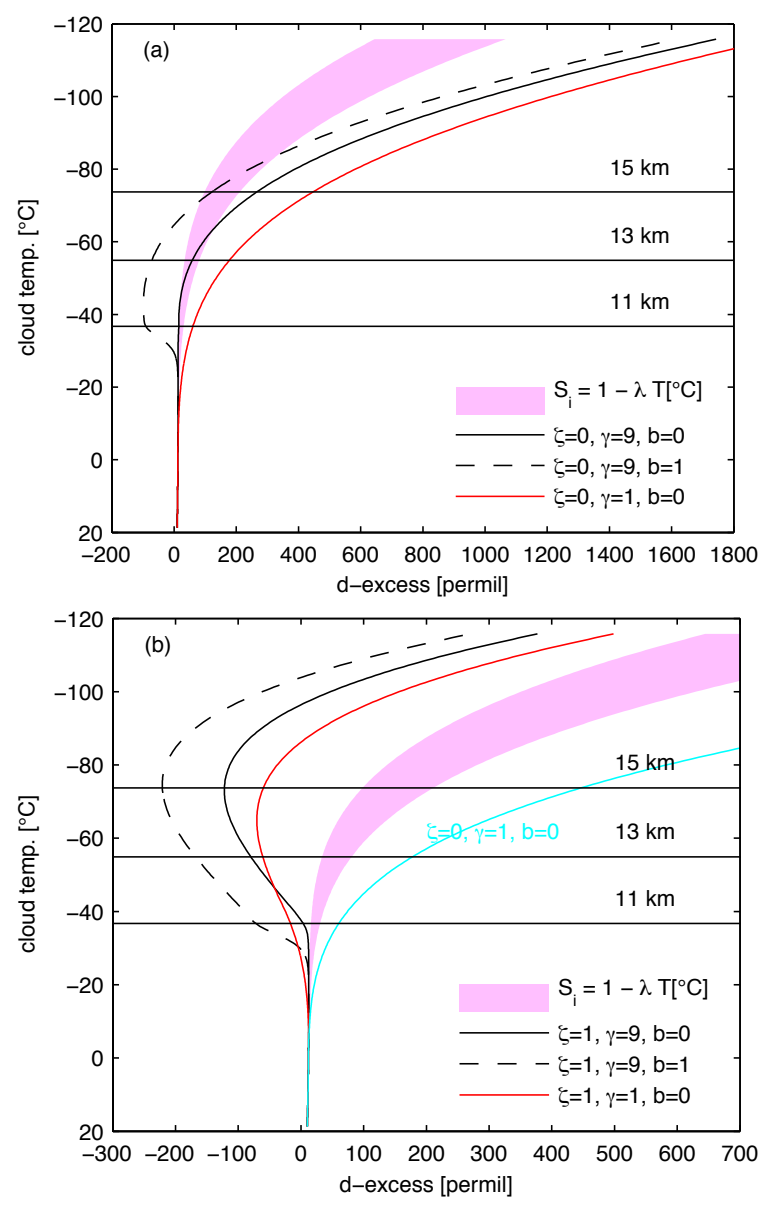

Fig. 11. (a) Deuterium excess values for conditions of equilibrium saturation over ice $(\zeta=0)$ and varying values of the glaciation and WBF parameters, $\gamma$ and $b$, as indicated in the panel. Magenta area: range of d-excess values when the saturation is parameterized as $S_{\mathrm{i}}=1-\lambda T\left[{ }^{\circ} \mathrm{C}\right]$ where $\lambda$ varies in the range $0.003{ }^{\circ} \mathrm{C}^{-1}$ $-0.005^{\circ} \mathrm{C}^{-1}$, and the glaciation temperature is $-15^{\circ} \mathrm{C}(\gamma=1.5)$. (b) Same as (a) except for conditions of equilibrium saturation over liquid water in the mixed-phase zone $(\zeta=1)$. The case $\zeta=b=0$ and $\gamma=1$ is reproduced from panel (a) for the sake of comparison.

Tindall et al., 2009; Risi et al., 2010; Kurita et al., 2011) as discussed in Sect. 4.1. Spanning the range of $\lambda$ used across these studies, assuming a glaciation temperature of $\sim-15^{\circ} \mathrm{C}$ and no WBF, yields d-excess in convective cores that increase monotonically with altitude to reach values of 20 $130 \%$ o between 12 and $14 \mathrm{~km}$ (see Fig. 11). These values are grossly consistent with our scenarios where $\zeta \sim 0.4-0.5$, which saturate at $18-23 \%$ over ice below $-40{ }^{\circ} \mathrm{C}$. However, as discussed throughout this paper, physical processes may well vary outside those assumptions, which would yield very different values of d-excess at low temperatures.

Our prediction is that low or negative values of d-excess could be found in and near convective clouds at detrainment levels given conditions of high supersaturation, high glaciation altitude, or a significant WBF effect. In particular, 
vapour-limited conditions that could take place in stratiform anvils and promote supercooled droplet evaporation should be marked by a shift of up to $-100 \%$ in the deuteriumexcess of vapour. We stress that a better understanding of the drivers of d-excess variations is important for the interpretation of field measurements.

\section{Towards a retrieval of physical parameters from water isotopologues}

The modelling framework presented here allows us to test quantitatively how combined observations of water vapour $\delta^{18} \mathrm{O}$ and $\delta \mathrm{D}$ at several altitudes can provide informations about in-cloud conditions, including vapour supersaturation and the profile of (isotopically active) cloud liquid water. Although the environment of a convective core means that it is unlikely that in situ measurements can be obtained there, high altitude aircraft measurements in anvil clouds seem to be able to sample convective outflow that is sufficiently recent that neither strong mixing with the environment nor evaporation of lofted ice has occurred. Such well resolved measurements give the hope to achieve observational data at cloud top (in the range 12 to $14 \mathrm{~km}$ typically). At the same time, it seems relatively easy to perform observations at cloud base (or in the boundary layer air being entrained). We therefore look for cases in which isotopic observations at these altitudes can provide information about cloud processes. We do not seek to be exhaustive as our main purpose is illustrative.

To evaluate whether this type of measurement campaign can provide insight into convective physics, we test the utility of these isotopic measurements in retrieving three arbitrarily chosen parameters of interest: $\zeta$, which measures vapour saturation; $r_{1}\left[-20^{\circ} \mathrm{C}\right]$, the abundance of supercooled water at $-20^{\circ} \mathrm{C}$; and $T_{\mathrm{g}}$, the temperature of full glaciation defined as $T_{\mathrm{g}}=T\left[r_{1}=10^{-6}\right]$. We combine the cloud base and cloud top measurements into two composite "observables" chosen to be particularly sensitive to cloud saturation and to cloud liquid water profile, respectively. The saturation-sensitive observable quantity is defined as $\Psi=\ln \left(\frac{R_{\mathrm{v}}^{18} \mathrm{O} \text { (top) }}{R_{\mathrm{v}}^{18} \text { (gnd) }}\right) / \ln \left(\frac{R_{\mathrm{V}}^{\mathrm{D}} \text { (top) }}{R_{\mathrm{v}}^{\mathrm{D}} \text { (gnd) }}\right)$ where "top" and "gnd" respectively denote cloud top and cloud base observations; the liquid-sensitive observable quantity is defined as $\Pi=$ $\ln \left(\frac{R_{\mathrm{V}}^{\mathrm{D}} \text { (top) }}{R_{\mathrm{v}}^{\mathrm{D}} \text { (gnd) }}\right)$, which contains information on the vertical profile of cloud liquid water.

Owing to the complexity of in-cloud isotopic physics, even within our model, there is no simple deterministic relation between these isotopic observables and cloud parameters; the problem is under-determined. We can, however, examine the statistical relationship between composite observables and parameters to be retrieved, taking into account the ranges of possible values for all unknown cloud parameters. We set up a Monte Carlo simulation, varying our control parameters $\zeta$,
$C_{1}, \gamma$, and $b$, as well as the values of vapour isotopic composition at cloud base $\delta_{0}^{\mathrm{D}}$ and $\delta_{0}^{18} \mathrm{O}$. These parameters are treated as independent random variables and sampled from uniform distributions $(\mathcal{U})$ over plausible ranges of values:

$$
\begin{aligned}
P(\zeta) & =\mathcal{U}([0,1]), \\
P\left(C_{1}\right) & =\mathcal{U}\left(\left[0 \mathrm{~km}^{-1}, 0.5 \mathrm{~km}^{-1}\right]\right), \\
P(\gamma) & =\mathcal{U}([1,9]), \\
P(b) & =\mathcal{U}([0,1]), \\
P\left(\delta_{0} \mathrm{D}\right) & =\mathcal{U}([-90 \% \text { o, }-70 \% 0]), \\
P\left(\delta_{0}{ }^{18} \mathrm{O}\right) & =\mathcal{U}([-15 \% \circ,-10 \% 0]) .
\end{aligned}
$$

Uniform distribution is the simplest possible choice for this study. If more realistic distributions were available, the process followed here would easily be adapted to incorporate that increase in knowledge. We generate $10^{6}$ simulations and then use a kernel-based method (Botev et al., 2010) to estimate the joint probability densities of composite observables $\Psi$ and $\Pi$ with relevant cloud parameters: $p(\zeta, \Psi), p\left(T_{\mathrm{g}}, \Pi\right)$ and $p\left(r_{1}\left[-20^{\circ} \mathrm{C}\right], \Pi\right)$.

Figure 12 shows the joint distributions estimated from that procedure at 12 and $14 \mathrm{~km}$. In many cases, a compact relation emerges, indicating that isotopic measurements provide robust tracers of cloud parameters. Relationships are generally stronger at one altitude than another. Supersaturation is more readily retrieved at higher altitudes, where the footprint of signals from the various processes involved in cloud glaciation has partially vanished, and parameters associated with cloud glaciation are, logically enough, more readily retrieved at lower altitudes, closer to the glaciation region. The saturation parameter $\zeta$ is essentially linear with $\Psi$ at both altitudes (panels a and d), but $\zeta$ is better resolved by $\Psi$ at $14 \mathrm{~km}$ than at $12 \mathrm{~km}$. Isotopic measurements at $12 \mathrm{~km}$, conversely, are better tracers of glaciation temperature $T_{\mathrm{g}}(\mathrm{b}$ and e) and liquid water content $r_{1}\left[-20^{\circ} \mathrm{C}\right]$ (c and f) than measurements performed at $14 \mathrm{~km}$. These results are consistent with inferences about the use of $\delta^{18} \mathrm{O}$ and $\delta \mathrm{D}$ measurements drawn in Sect. 5 .

A finer analysis shows that processes controlling liquid to ice transition (i.e. $\gamma, b$ ) and auto-conversion (i.e. $C_{1}$ ) compete to broaden the joint distributions $p\left(T_{\mathrm{g}}, \Pi\right)$ and $p\left(r_{1}\left[-20^{\circ} \mathrm{C}\right], \Pi\right)$. In practice, these joint statistics can be improved by incorporating a priori information on cloud processes (e.g. polarimetric radar observations, CAPE estimation), which is essentially equivalent to reducing the Monte Carlo sampling to a subset of cases. A full treatment of observations should also involve a Bayesian analysis that takes into account observational errors.

Although we suggest here new ways of exploring convective physics from isotopic measurements, more work is needed to assess how our conclusions apply to real world clouds, especially regarding the assumption of adiabaticity made throughout the paper. The extent of mixing between cumulus clouds and their environment is far from a settled 

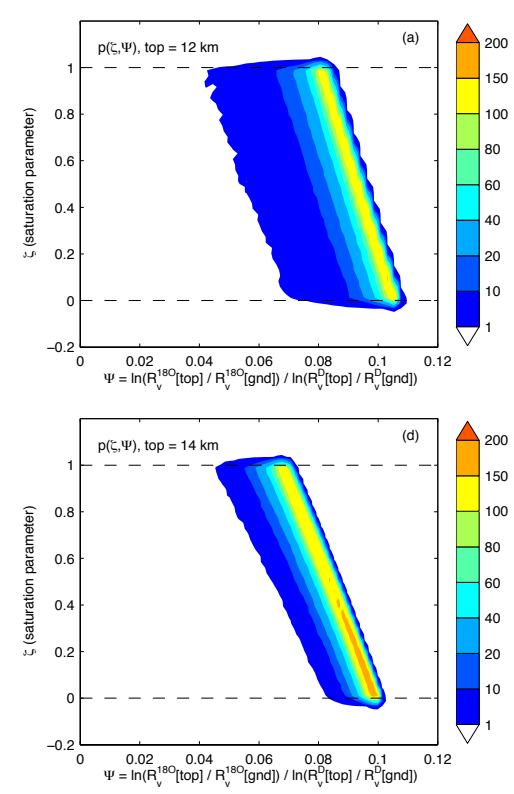
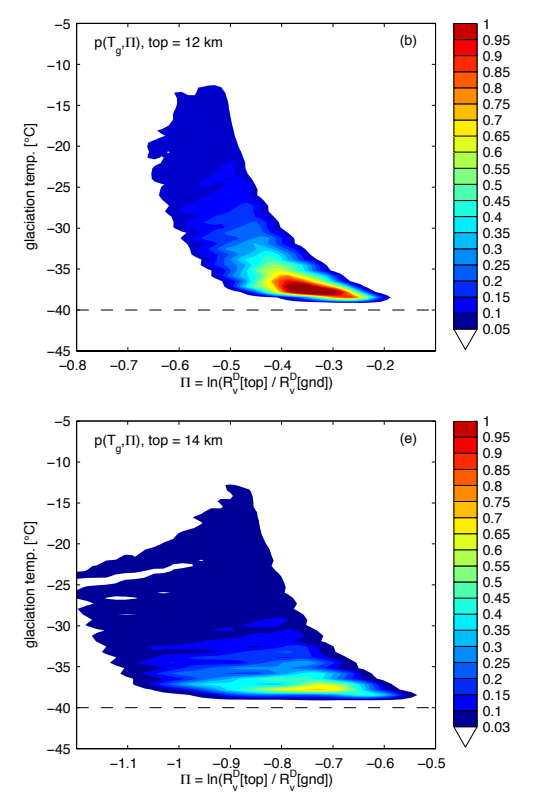
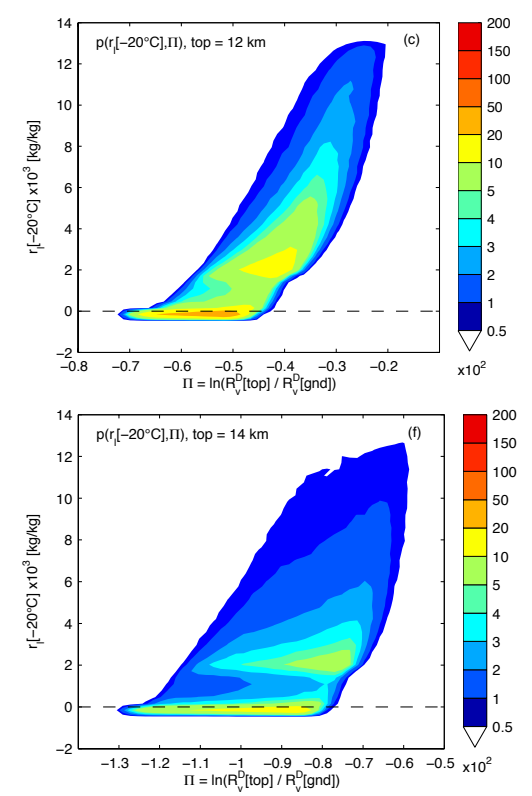

Fig. 12. First row: cloud top isotopic ratios $\left(R_{\mathrm{v}}^{\mathrm{D}}(\right.$ top $), R_{\mathrm{V}}^{18} \mathrm{O}($ top $\left.)\right)$ taken at $12 \mathrm{~km}$. (a): values of the joint probability density $p(\zeta$, $\Psi)$ as a function of the saturation parameter $\zeta$ and $\Psi=\ln \left(\frac{R_{\mathrm{v}}^{18} \mathrm{O}(\text { top })}{R_{\mathrm{v}}^{18} \mathrm{O}(\mathrm{gnd})}\right) / \ln \left(\frac{R_{\mathrm{v}}^{\mathrm{D}}(\text { top })}{R_{\mathrm{v}}^{\mathrm{D}}(\mathrm{gnd})}\right)$. (b) Values of the joint probability density $p\left(T_{\mathrm{g}}, \Pi\right)$ as a function of the glaciation temperature $T_{\mathrm{g}}$ and $\Pi=\ln \left(\frac{R_{\mathrm{v}}^{\mathrm{D}}(\text { top })}{R_{\mathrm{v}}^{\mathrm{D}}(\mathrm{gnd})}\right) \cdot$. (c) Values of the joint probability density $p\left(r_{1}\left[-20^{\circ} \mathrm{C}\right], \Pi\right)$ as a function of the supercooled liquid water content at $-20^{\circ} \mathrm{C} r_{1}\left[-20^{\circ} \mathrm{C}\right]$ and $\Pi$. Second row (d), (e) and (f): same as first row (a), (b) and (c) but for cloud top isotopic ratios taken at $14 \mathrm{~km} . R_{\mathrm{V}}^{\mathrm{D}}(\mathrm{gnd})$ and $R_{\mathrm{v}}^{18} \mathrm{O}(\mathrm{gnd})$ are cloud base isotopic ratios.

question. While the traditional thinking in convective studies (Riehl and Malkus, 1958) is that only non entraining or weakly entraining parcels can penetrate to the highest levels, modern LES/CRM studies find that the flux of undiluted air at upper tropospheric levels is negligible (Romps and Kuang, 2010; Sherwood et al., 2013). The latter studies usually focus on isolated cumulus clouds in their developing stage, so that their conclusions may not be transferable to storms in their fully developed stage or to more organised forms of convection. Therefore, it is not necessarily unrealistic to assume undiluted ascent as an initial working assumption when large mesoscale convective systems are considered. Further developments are then needed to estimate how entrainment impacts our conclusions, but these are beyond the scope of this paper. Our purpose here is to give evidence as to how a carefully designed observational campaign that measures isotopic composition of water vapour in air that has been processed by clouds can provide insights into previously hidden convective processes.

\section{Conclusions}

This work revisits the basic processes setting the isotopic composition of water vapour in a rising unmixed air parcel, with a consistent and physically-based treatment of microphysics and thermodynamics over vapour, liquid water and cloud ice. It is motivated by the current trend in the literature to investigate cloud processes from isotopic measurements (Fudeyasu et al., 2008; Lawrence and Gedzelman, 1996, 2003; Risi et al., 2008; Kurita et al., 2011; Berkelhammer et al., 2012) and the need to re-examine some widely used assumptions regarding convective physics in global models. By investigating the sensitivity of isotopic composition to relevant parameters of cloud physics, this work also suggests new ways to estimate these parameters from carefully designed measurements of isotopologues. We limit the scope of this study to updraft physics and its intrinsic variability, and for this reason consider the boundary layer conditions as fixed and neglect any processus related to evaporation of precipitations and entrainment.

We show that isotopic kinetic effects at evaporation/deposition are driven not only by the differential molecular diffusivity between light and heavy isotopologues, as is sometimes suggested, but also by the preferential uptake of heavy isotopologues at condensate surface. Both effects conspire to set up gradients in molecular abundance across a diffusive boundary layer surrounding condensate, which differ between heavy and light isotopologues. We also show that the magnitude of isotopic kinetic effects is reduced by thermal impedance to crystal growth/droplet evaporation in a way that vanishes with altitude. 
Model simulations replicate the well-known regime transition between warm, liquid-only clouds where vapour isotopic evolution is buffered to some extent by re-equilibration with liquid water, and cold, fully glaciated clouds in which isotopic evolution is essentially pure Rayleigh distillation, modified only by the kinetic effects associated with the growth of ice particles. The dominant convective variables affecting vapour isotopic composition are the profile of supercooled water in active equilibrium with vapour within the intervening mixed-phase regime (between $0{ }^{\circ} \mathrm{C}$ and $-40^{\circ} \mathrm{C}$ ), the supersaturation over ice in the ascending air parcel, which governs kinetic modifications to isotopic fractionation, and the route to cloud glaciation (through the Wegener-BergeronFindeisen WBF process versus freezing). These parameters are affected by the number density of cloud particles and the updraft speed of the rising air parcel. In particular, the size of the supercooled liquid water reservoir that can be considered in isotopic balance with vapour depends on droplets spectra and updraft strength. In the mixed-phase region, we show that glaciation by the WBF process, which is expected to occur in vapour limited conditions, may produce an isotopic enhancement provided supercooled droplets have survived to very low temperatures $\left(-30^{\circ} \mathrm{C}\right.$ to $\left.-40^{\circ} \mathrm{C}\right)$. This effect is stronger for the system $\mathrm{H}_{2}{ }^{18} \mathrm{O} / \mathrm{H}_{2} \mathrm{O}$ and, consequently, may produce a shift in d-excess of up to $-100 \%$. Such conditions may happen during transition from active convection to decaying stratiform stage.

Since severe turbulence, hail and icing conditions are ubiquitous within active convective cores, in situ sampling of such environments comes at a very high risk. Because water vapour within convective systems and their immediate surrounding has acquired its isotopic composition in updrafts, it may be possible to use isotopic measurements to probe convective physics remotely. We have described how measurements of $\delta \mathrm{D}$ and $\delta^{18} \mathrm{O}$ at cloud base and over restricted altitude regions at cloud top can be combined to estimate supersaturation and supercooled liquid water contents within updrafts. The fact that in-cloud measurements are not required greatly simplifies experimental requirements and can facilitate planning future measurement strategies. Cloud base measurements can be easily obtained from ground-based instruments and cloud top measurements would be possible from aircraft campaigns (Hanisco et al., 2007; Sayres et al., 2010) or even remotely by absorption in the mid-infrared (Nassar et al., 2007; Randel et al., 2012), active microwave limb sounding (Kursinski et al., 2004), or possibly by farinfrared thermal emission (Herbin et al., 2009). If measuring the isotopic composition of vapour at cloud top is sufficient, then a relatively tractable measurement program using existing techniques may permit diagnosing aspects of cloud dynamics from space.

\section{Appendix A}

\section{Diffusional growth rate of droplets and ice crystals}

We consider a single droplet or an ice crystal of mass $m$, growing by diffusion of water vapour to its surface. We further assume that the droplet or crystal has already grown from its nucleus and that its temperature is homogeneous. We assume the contribution of heavy isotopologues is small, so that $m$ corresponds to the mass of light water within the condensate. The rate of mass accretion according to stationary diffusion theory is then given by Pruppacher and Klett (1978) as

$$
\begin{aligned}
\frac{\mathrm{d} m}{\mathrm{~d} t} & =K_{\mathrm{v}} f_{\mathrm{v}} \int_{S} \vec{\nabla} \rho_{\mathrm{v}} \cdot \overrightarrow{d^{2} \sigma} \\
& =-4 \pi C K_{\mathrm{v}} f_{\mathrm{v}}\left(\rho_{\mathrm{v}}^{(\mathrm{s})}-\rho_{\mathrm{v}}^{(\infty)}\right),
\end{aligned}
$$

where (s) stands for the surface of the droplet or the ice crystal and $(\infty)$ for the far field environment, $C$ is the droplet radius or crystal capacitance (an effective radius for diffusional growth that depends only on the geometry of the crystal), $K_{\mathrm{v}}$ is the molecular diffusivity of light vapour and $f_{\mathrm{v}}$ is the ventilation coefficient for light vapour that describes enhancement of mass accretion over pure diffusive theory owing to the condensate fall relatively to the air. The light vapour density field $\rho_{\mathrm{v}}$ satisfies the stationary Laplace equation $\nabla^{2} \rho_{\mathrm{v}}=0$ with boundary conditions $\rho_{\mathrm{v}}=\rho_{\mathrm{v}}^{(\mathrm{s})}$ at the surface of the condensate and $\rho_{\mathrm{v}}=\rho_{\mathrm{v}}^{(\infty)}$ in the far field. Equation (A1) holds for both deposition, when $\rho_{\mathrm{v}}^{(\mathrm{s})}<\rho_{\mathrm{v}}^{(\infty)}$, and evaporation, when $\rho_{\mathrm{v}}^{(\mathrm{s})}>\rho_{\mathrm{v}}^{(\mathrm{s})}$.

We assume here a scale separation between submillimetric diffusive processes and hydrodynamics, so that the far field values of vapour concentration $\rho_{\mathrm{v}}^{(\infty)}$ and temperature $T^{(\infty)}$ are equivalent to the macroscopic values in the air parcel being modelled. This approximation might be questionable in highly turbulent regions of convective clouds (Lanotte et al., 2009).

We assume also that phase equilibrium applies at the surface of the droplet or the ice crystal. In this case surface vapour concentration corresponds to saturation at surface temperature and pressure: $\rho_{\mathrm{v}}^{(\mathrm{s})}=\rho_{\mathrm{sat}}^{1, \mathrm{i}}\left[T^{(\mathrm{s})}, p\right]$, where $T^{(\mathrm{s})}$ is the surface temperature of the condensate and "sat" stands for the equilibrium saturation value at the indicated temperature and pressure. This assumption on $\rho_{\mathrm{v}}^{(\mathrm{s})}$ breaks down for very small droplets (essentially inactivated aerosols) when surface curvature and salt concentration effects cannot be ignored, but those conditions can be neglected in isotopic models since total water content in particles this small is negligible compared to remaining vapour and so has negligible isotopic effect. Further comments on the growth of ice crystals are provided at the end of this section.

The accretion or evaporation represented by Eq. (A1) is associated with a corresponding release or intake of latent 
heat $\mathrm{d} Q / \mathrm{d} t=-L_{1, \mathrm{i}} \mathrm{d} m / \mathrm{d} t$ (where $L_{1, \mathrm{i}}$ is the latent heat of vaporisation or sublimation). Continuity of the heat flow at the surface of the particle requires that this heat source is balanced by the diffusive flux of heat between the particle and its environment. This balance holds because the rate of heat storage accommodating the variation of particle temperature as it rises within the cloud is negligible compared to the rate of latent heat release and that of diffusive heat export, as evidenced by the smallness of thermal relaxation times (Mason, 1956; see also Supplement Sect. 2 and Fig. B1). Heat diffusion can then be handled in the same way as vapour diffusion since the underlying physical processes are formally equivalent. Hence, we have

$$
\begin{aligned}
\frac{\mathrm{d} Q}{\mathrm{~d} t} & =-L_{1, \mathrm{i}} \frac{\mathrm{d} m}{\mathrm{~d} t} \\
& =k_{\mathrm{h}} f_{\mathrm{h}} \int_{S} \vec{\nabla} T \cdot \overrightarrow{d^{2} \sigma} \\
& =-4 \pi C k_{\mathrm{h}} f_{\mathrm{h}}\left(T^{(\mathrm{s})}-T^{(\infty)}\right) .
\end{aligned}
$$

The temperature field satisfies $\nabla^{2} T=0$ with boundary conditions $T=T^{(\mathrm{s})}$ at the surface of the condensate and $T=$ $T^{(\infty)}$ in the far field. $k_{\mathrm{h}}$ is the thermal conductivity of moist air and $f_{\mathrm{h}}$ is the thermal ventilation coefficient.

Replacing Eq. (A1) in Eq. (A2) yields

$k_{\mathrm{h}} f_{\mathrm{h}}\left(T^{(\mathrm{s})}-T^{(\infty)}\right)=-L_{1, \mathrm{i}} K_{\mathrm{v}} f_{\mathrm{v}}\left(\rho_{\mathrm{v}}^{(\mathrm{s})}-\rho_{\mathrm{v}}^{(\infty)}\right)$,

which shows that the surface temperature of the condensate is raised above the environmental temperature during deposition, or lowered below it during evaporation, as expected.

Since water vapour at the particle surface is assumed to be at saturation, $\rho_{\mathrm{v}}^{(\mathrm{s})}-\rho_{\mathrm{v}}^{(\infty)}$ can be expressed as a function of densities at saturation and then expanded to first order in $T^{(\mathrm{s})}-T^{(\infty)}$ by using the Clausius-Clapeyron relation, leading to

$$
\begin{aligned}
& \rho_{\mathrm{v}}^{(\mathrm{s})}-\rho_{\mathrm{v}}^{(\infty)} \sim \rho_{\mathrm{sat}}^{l, i(\infty)}\left(1-S_{\mathrm{l}, \mathrm{i}}\right. \\
& \left.+\frac{1}{T^{(\infty)}}\left(\frac{L_{1, \mathrm{i}}}{R_{\mathrm{v}}^{*} T^{(\infty)}}-1\right)\left(T^{(\mathrm{s})}-T^{(\infty)}\right)\right),
\end{aligned}
$$

where $\rho_{\text {sat }}^{1, \mathrm{i}(\infty)}$ is shorthand for $\rho_{\text {sat }}^{1, \mathrm{i}}\left[T^{(\infty)}, p\right]$ and $S_{\mathrm{l}, \mathrm{i}}=$ $\rho_{\mathrm{v}}^{(\infty)} / \rho_{\mathrm{sat}}^{1, \mathrm{i}(\infty)}$ is the relative humidity of the air parcel over liquid water or ice.

The rate of mass accretion for droplets or ice crystals can be then rewritten as a function of parcel temperature only by solving for $\rho_{\mathrm{v}}^{(\mathrm{s})}-\rho_{\mathrm{v}}^{(\infty)}$ from Eq. (A3) and Eq. (A4), and then replacing it in Eq. (A1) (Mason, 1971):

$$
\frac{\mathrm{d} m}{\mathrm{~d} t}=-4 \pi C f_{\mathrm{v}} K_{\mathrm{v}}\left(1-S_{1, \mathrm{i}}\right) A_{1, \mathrm{i}} \rho_{\mathrm{sat}}^{1, \mathrm{i}(\infty)},
$$

with

$$
A_{1, \mathrm{i}}=\left[1+\frac{f_{\mathrm{v}}}{f_{\mathrm{h}}} \frac{K_{\mathrm{v}} L_{1, \mathrm{i}} \rho_{\mathrm{sat}}^{1, \mathrm{i}(\infty)}}{k_{\mathrm{h}} T^{(\infty)}}\left(\frac{L_{1, \mathrm{i}}}{R_{\mathrm{v}}^{*} T^{(\infty)}}-1\right)\right]^{-1} .
$$

The $A_{1, \mathrm{i}}$ are transfer coefficients between vapour and condensate that represent reduced mass accretion (or loss) owing to the need to extract (or provide) latent heat of condensation (or evaporation) across the diffusive boundary layer.

The impeding effect of thermal diffusion on crystal growth varies with altitude in the cloud. From Eqs. (A3) and (A4), the temperature difference across the boundary layer may be obtained and arranged as follows:

$$
\begin{aligned}
& T^{(\mathrm{s})}-T^{(\infty)}=-\underbrace{\frac{L_{1, \mathrm{i}}}{c_{\mathrm{p}}}}_{1}\left(1-S_{1, \mathrm{i}}\right) \underbrace{\frac{f_{\mathrm{v}}}{\operatorname{Le} f_{\mathrm{h}}}}_{2} q_{\mathrm{sat}}^{1, \mathrm{i}(\infty)} \\
& \times[\underbrace{[1+\underbrace{\frac{L_{1, \mathrm{i}}}{c_{\mathrm{p}}}}_{1} \underbrace{\frac{f_{\mathrm{v}}}{\operatorname{Le} f_{\mathrm{h}}}}_{2} \underbrace{1}_{\underbrace{\frac{1}{T^{(\infty)}}}\left(\frac{L_{1, \mathrm{i}}}{R_{\mathrm{v}}^{*} T^{(\infty)}}-1\right)} q_{\mathrm{sat}}^{1, \mathrm{i}(\infty)}]^{-1}}_{A_{1, \mathrm{i}}},
\end{aligned}
$$

where $q_{\text {sat }}^{1, \mathrm{i}(\infty)}=\rho_{\text {sat }}^{1, \mathrm{i}(\infty)} / \rho^{(\infty)}$ is the saturation specific humidity with respect to liquid water or ice, measured in the far field, and the Lewis number $\mathrm{Le}=K_{\mathrm{h}} / K_{\mathrm{v}}$ measures the ratio between thermal and molecular diffusivity (thermal diffusivity $K_{\mathrm{h}}$ is defined by $k_{\mathrm{h}}=\rho^{(\infty)} c_{\mathrm{p}} K_{\mathrm{h}}$ ). It can be shown from the kinetic theory of gases that Le is a function of gas mixture composition only (i.e. it is independent of temperature and pressure), and that term 2 of Eq. (A7) is close to 1 (see Supplement Sect. 1). Term 1 is weakly dependent on temperature and the strong decrease of $q_{\mathrm{sat}}^{\mathrm{l,i}(\infty)}$ with decreasing temperature (see Appendix D1) dominates the temperature dependency of term 3 . Thus, thermal impedance to crystal growth depends on altitude mostly through $S_{1, \mathrm{i}}$ (it vanishes at exact saturation) and $q_{\mathrm{sat}}^{1, \mathrm{i}(\infty)}$. For the sake of illustration, consider a cloud parcel at $-20^{\circ} \mathrm{C}(8.5 \mathrm{~km}$ a.g.l. $)$ with $10 \%$ supersaturation over ice. In these conditions, our model (see Sect. 3) shows that growing crystals are heated $0.4{ }^{\circ} \mathrm{C}$ above $T^{(\infty)}$, evaporating droplets are cooled $0.4^{\circ} \mathrm{C}$ below $T^{(\infty)}$ and $A_{1, \mathrm{i}}$ is $\sim 0.65$, so the crystal growth is reduced. As the parcel rises within the cloud and its temperature drops, the temperatures at droplet surface approach that of the environment $\left(T^{(\mathrm{s})}-T^{(\infty)}\right.$ eventually vanishes) and $A_{1, \mathrm{i}}$ approaches unity, i.e. crystal growth is no longer impeded by heat diffusion. 


\section{Appendix B}

\section{Derivation of the kinetic fractionation factor and isotopic relaxation time for droplets and ice}

The kinetic modification to the fractionation factor can be derived by considering the accretion of heavy and light isotopologues separately. Since diffusion of all water isotopologues is governed by the same physics, the rate of accretion of a heavy water isotopologue onto a cloud droplet or crystal can be written analogously to that for light isotopes (cf. Eq. A1):

$$
\frac{\mathrm{d} m^{\prime}}{\mathrm{d} t}=-4 \pi C K_{\mathrm{v}}^{\prime} f_{\mathrm{v}}^{\prime}\left(\rho_{\mathrm{v}}^{\prime(\mathrm{s})}-\rho_{\mathrm{v}}^{\prime(\infty)}\right),
$$

where $m^{\prime}$ is the mass of the heavy isotopologue within the droplet, $\rho_{\mathrm{v}}^{\prime(\mathrm{s})}$ and $\rho_{\mathrm{v}}^{\prime(\infty)}$ are the densities of the heavy isotopologue vapour at the surface of the droplet and in the air parcel, $K_{\mathrm{v}}^{\prime}$ is molecular diffusivity of the heavy vapour, and $f_{\mathrm{v}}^{\prime}$ is the corresponding coefficient.

In the case of a droplet, equilibrium fractionation is assumed to apply at its surface, thus $R_{\mathrm{v}}^{(\mathrm{s})}=R_{1}^{(\mathrm{s})} / \alpha_{1}$, where $R_{1}^{(\mathrm{s})}$ is the isotopic ratio of liquid water at the droplet surface (as stated in Appendix A, this assumption is reasonable for droplets much larger than the size of the initial condensation nucleus). We can then express the vapour pressure of heavy water isotopologues as $\rho_{\mathrm{v}}^{\prime(\mathrm{s})}=R_{1}^{(\mathrm{s})} \rho_{\mathrm{v}}^{(\mathrm{s})} / \alpha_{1}$. If we then take $\rho_{\mathrm{v}}^{(\mathrm{s})}$ from Eq. (A4), Eq. (B1) becomes

$$
\begin{aligned}
\frac{\mathrm{d} m^{\prime}}{\mathrm{d} t}=-4 \pi C K_{\mathrm{v}}^{\prime} f_{\mathrm{v}}^{\prime}\left[S_{1}\left(\frac{R_{1}^{(\mathrm{s})}}{\alpha_{1}}-R_{\mathrm{v}}^{(\infty)}\right)\right. & \\
& \left.+A_{1}\left(1-S_{1}\right) \frac{R_{1}^{(\mathrm{s})}}{\alpha_{1}}\right] \rho_{\mathrm{sat}}^{1(\infty)} .
\end{aligned}
$$

The evolution of the isotopic ratio $R_{1}$ for the whole droplet can now be derived from Eqs. (A5) and (B2) by assuming a homogeneous isotopic composition within the droplet, a reasonable assumption given the fast self-diffusion of liquid water (Wang, 1951b). With this assumption, the surface isotopic composition holds for the whole droplet, that is, $R_{1}^{(\mathrm{s})}=R_{1}$ and $R_{1}=m^{\prime} / m$. It is also reasonable to further assume a spherical droplet of some radius $a$, in which case the effective radius $C$ becomes $a$ and the mass $m=\frac{4}{3} \pi a^{3} \rho_{\text {drop }}$ ). Then the tendency on droplet isotopic ratio becomes

$$
\begin{aligned}
& \frac{\mathrm{d} R_{1}}{\mathrm{~d} t}=\frac{1}{m}\left(\frac{\mathrm{d} m^{\prime}}{\mathrm{d} t}-R_{1} \frac{\mathrm{d} m}{\mathrm{~d} t}\right) \\
& =-\frac{3 \rho_{\mathrm{sat}}^{1(\infty)}}{a^{2} \rho_{\mathrm{drop}}}\left[-K_{\mathrm{v}} f_{\mathrm{v}} R_{\mathrm{l}} A_{1}\left(1-S_{1}\right)\right. \\
& \left.+K_{\mathrm{v}}^{\prime} f_{\mathrm{v}}^{\prime}\left(S_{1}\left(\frac{R_{1}}{\alpha_{1}}-R_{\mathrm{v}}^{(\infty)}\right)+A_{1}\left(1-S_{1}\right) \frac{R_{1}}{\alpha_{1}}\right)\right] .
\end{aligned}
$$
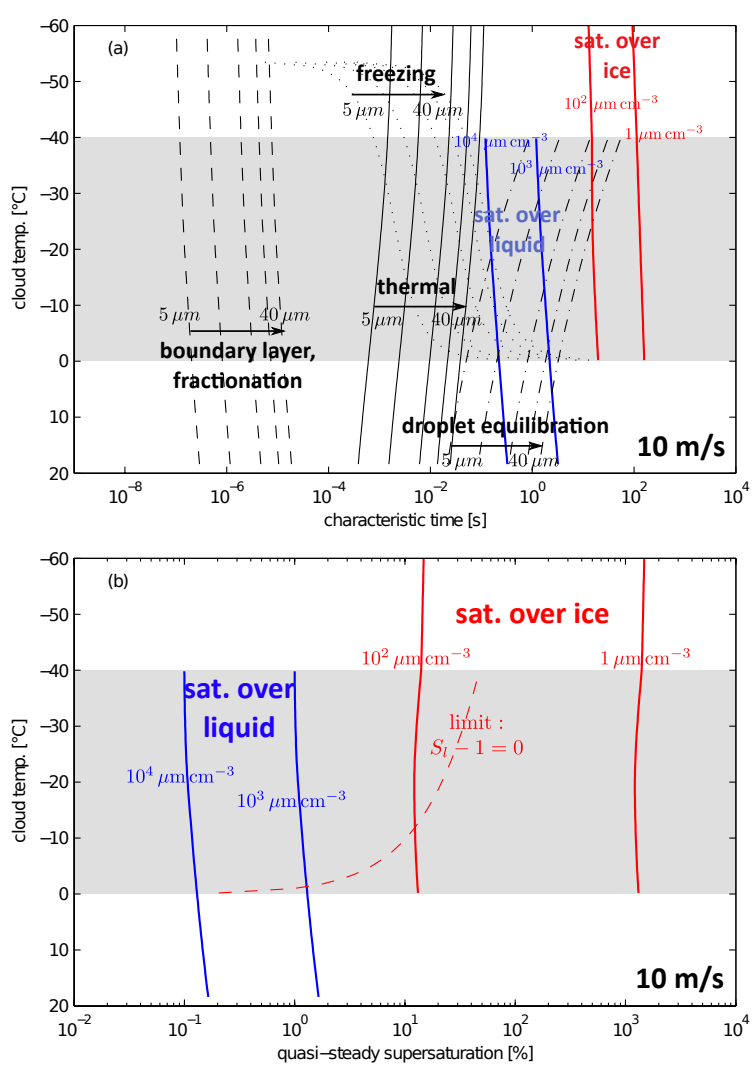

Fig. B1. (a) [dash-dotted black]: isotopic equilibration time $\tau_{\text {drop }}$ (Eq. (B5), Appendix B). [dotted black]: freezing time $t_{\mathrm{f}}$ (Eq. (6), Online Supplement). [solid black]: thermal equilibration time $t_{\mathrm{h}}$ (Eq. (8), Supplement). Computations assume droplets of radius: 5, $10,20,30$ and $40 \mu \mathrm{m}$. [solid blue]: times of phase relaxation over pure liquid water $\tau_{\mathrm{pl}}$ (Eq. (C2), Appendix C) assuming an updraft velocity of $10 \mathrm{~m} \mathrm{~s}^{-1}$ and for values of $N_{1} \bar{a}$ of $10^{3}$ and $10^{4} \mu \mathrm{m} \mathrm{cm}^{-3}$. [solid red]: times of phase relaxation over pure ice $\tau_{\text {pi }}$ (Eq. (C3), Appendix C) assuming an updraft velocity of $10 \mathrm{~ms}^{-1}$ and for values of $N_{\mathrm{i}} \overline{a_{\mathrm{i}}}$ of 1 and $100 \mu \mathrm{mcm}^{-3}$. [dashed black]: characteristic time to set-up a diffusive boundary layer around spherical particles of varying radii ( $5 \mu \mathrm{m}, 10 \mu \mathrm{m}, 20 \mu \mathrm{m}, 30 \mu \mathrm{m}, 40 \mu \mathrm{m})$, which is also the time necessary to set-up kinetic isotope fractionation between particle surface and far field environment. Computation follows Sect. 13.1.1 of Pruppacher and Klett (1978). (b) [solid blue]: Values of quasi-steady supersaturation over pure liquid water $S_{\mathrm{qs}}-1$ (Eq. (C2), Appendix C) assuming an updraft velocity of $10 \mathrm{~ms}^{-1}$ and for the same values of $N_{1} \bar{a}$ as in (a). [solid red]: Values of quasisteady supersaturation over pure ice $S_{\mathrm{qsi}}-1$ (Eq. (C3), Appendix C) assuming an updraft velocity of $10 \mathrm{~m} \mathrm{~s}^{-1}$ and for the same values of $N_{\mathrm{i}} \overline{a_{\mathrm{i}}}$ as in (a). [dashed red]: value of ice supersaturation set by equilibrium saturation over liquid water. $S_{\mathrm{qsi}}-1$ is unlikely to get above this value. (a-b) For both panels, temperature, pressure and vapour saturation used in the computations are taken along a reference integration of the cloud model as described in Sect. 4. 
Equation (B3) is equivalent to Eq. (5) of Jouzel et al. (1975), and to Eq. (20) of Gedzelman and Arnold (1994) if their $(1+b)$ is replaced by $A_{1}^{-1}$. Equation (B3) can be seen as an adjustment of droplet isotopic composition, if rewritten as

$$
\frac{\mathrm{d} R_{1}}{\mathrm{~d} t}=-\frac{R_{1}}{\tau_{\mathrm{drop}}}+\frac{3 \rho_{\mathrm{sat}}^{1(\infty)}}{a^{2} \rho_{\mathrm{drop}}} K_{\mathrm{v}}^{\prime} f_{\mathrm{v}}^{\prime} S_{1} R_{\mathrm{v}}^{(\infty)},
$$

The factor $\tau_{\text {drop }}$ is then an e-folding time of droplet isotopic relaxation to equilibrium with its environment:

$$
\begin{aligned}
& \tau_{\text {drop }}=\underbrace{\frac{a^{2} \rho_{\text {drop }} \alpha_{1}}{3 \rho_{\text {sat }}^{1(\infty)} K_{\mathrm{v}}^{\prime} f_{\mathrm{v}}^{\prime}}}_{1} \\
& \times \underbrace{\left[\left(S_{1}+A_{1}\left(1-S_{1}\right)\right)-\alpha_{1} \frac{K_{\mathrm{v}} f_{\mathrm{v}}}{K_{\mathrm{v}}^{\prime} f_{\mathrm{v}}^{\prime}} A_{1}\left(1-S_{1}\right)\right]^{-1}}_{2} .
\end{aligned}
$$

The degree of adjustment depends on droplet size, vapour saturation and altitude within the cloud. In a liquid-saturated environment (i.e. $S_{1}=1$ ), $\tau_{\text {drop }}$ reduces to the under-braced term 1 of Eq. (B5), which is also the relaxation time for stationary droplets, as defined by Jouzel et al. (1975) and Stewart (1975). In this case, the kinetic theory of gases under the rigid elastic spheres approximation (Chapman and Cowling, 1970) predicts that $\tau_{\text {drop }}$ behaves as $a^{2} /\left(q_{\text {sat }}^{l(\infty)} T^{1 / 2}\right)$ (neglecting variations of the fractionation coefficient with temperature). Decreasing temperature and saturation specific humidity at greater altitudes within the cloud slow down isotopic exchanges between droplets and vapour, as illustrated in Fig. $\mathrm{B} 1^{2}$. It must be added that supercooled droplets are likely to evaporate in a liquid-subsaturated environment (i.e. $S_{1}<1$ ), so that in subsaturated environments, diffusion of vapour out of the droplets (term 2 of Eq. B5) further lengthens isotopic relaxation times.

To provide some perspective on the question of droplet adjustment, note that the isotopic equilibration of droplets with the surrounding vapour depends on temperature and size, but also on the updraft speed. For instance, a supercooled droplet of radius $30 \mu \mathrm{m}$ has an isotopic relaxation time between $14 \mathrm{~s}$ and $20 \mathrm{~s}$ at $-30^{\circ} \mathrm{C}$, depending on whether vapour is at saturation over liquid water or ice. If carried upward in a fast updraft, the droplet can accumulate a significant isotopic imbalance with surrounding vapour. To understand how the validity of isotopic relaxation assumptions depends on updraft vertical speed $w_{\text {up }}$, consider that $w_{\text {up }} \tau_{\text {drop }}$ is the relevant vertical scale of isotopic adjustment. For instance, in order to relax over a maximum vertical scale of $10 \mathrm{~m}$ in a stream of $10 \mathrm{~m} \mathrm{~s}^{-1}$, a droplet must satisfy $\tau_{\text {drop }}<1 \mathrm{~s}$. As cloud temperature drops, this requirement is only satisfied by droplets

\footnotetext{
${ }^{2}$ Note that Jouzel et al. (1975) compute $\tau_{\text {drop }}$ at surface pressure, which yields values overestimated by up to $300 \%$.
}

of increasingly smaller radius: droplets should be no larger in radius than $20 \mu \mathrm{m}$ at $-4^{\circ} \mathrm{C}, 10 \mu \mathrm{m}$ at $-22^{\circ} \mathrm{C}$ and $5 \mu \mathrm{m}$ at $-36^{\circ} \mathrm{C}$ (as illustrated in Fig. B1). Faster updraft speeds would yield even smaller critical radii. It is thus expected that only a fraction of cloud liquid water fully re-equilibrates with surrounding vapour and that this portion decreases at lower temperatures (see also discussion in Sect. 4.1).

The cloud water droplets that adjust rapidly to their environment through their diffusive layer reach a stationary isotopic pseudo-equilibrium:

$$
R_{1}^{(\mathrm{eq})}=\frac{\alpha_{1} S_{1} R_{\mathrm{v}}^{(\infty)}}{\left(S_{1}+A_{1}\left(1-S_{1}\right)\right)-\alpha_{1} \frac{K_{\mathrm{v}} f_{\mathrm{v}}}{K_{\mathrm{v}} f_{\mathrm{v}}^{\prime}} A_{1}\left(1-S_{1}\right)} .
$$

Following Ciais and Jouzel (1994), this pseudo-equilibrium condition can be written as an effective kinetic fractionation factor between cloud water and vapour, defining $\alpha_{\mathrm{kl}}^{\text {(eq) }}=$ $R_{1}^{(\mathrm{eq})} / R_{\mathrm{v}}^{(\infty)}$. By introducing the effective saturation over liquid water $S_{1}^{\text {(eff) }}=\left[1-A_{1}\left(1-S_{1}^{-1}\right)\right]^{-1}$, as in Jouzel and Merlivat (1984) ${ }^{3}$, Eq. (B6) can be rearranged to give

$\alpha_{\mathrm{kl}}^{(\mathrm{eq})}=\frac{\alpha_{1}}{1+\left(\beta_{1}-1\right)\left(1-\left(S_{1}^{(\mathrm{eff})}\right)^{-1}\right)}$,

with $\beta_{1}=\alpha_{1} \frac{K_{\mathrm{v}}}{K_{\mathrm{v}}^{\prime}} \frac{f_{\mathrm{v}}}{f_{\mathrm{v}}^{\prime}}$.

The kinetic theory for ice is similar to that for cloud water with one critical difference: ice does not homogenise isotopically. The rate of accretion of heavy isotopologues is again given by

$$
\begin{aligned}
\frac{\mathrm{d} m^{\prime}}{\mathrm{d} t}=-4 \pi C D_{\mathrm{v}}^{\prime} f_{\mathrm{v}}^{\prime}\left[S_{\mathrm{i}}\left(\frac{R_{\mathrm{i}}^{(\mathrm{s})}}{\alpha_{\mathrm{i}}}-R_{\mathrm{v}}^{(\infty)}\right)\right. & \\
& \left.+A_{\mathrm{i}}\left(1-S_{\mathrm{i}}\right) \frac{R_{\mathrm{i}}^{(\mathrm{s})}}{\alpha_{\mathrm{i}}}\right] \rho_{\mathrm{sat}}^{\mathrm{i}(\infty),}
\end{aligned}
$$

which is identical to Eq. (B2) other than the use of indices i to denote ice rather than 1 . However, because the diffusivity within ice crystal lattice is slow - Kuhn and Thürkauf (1958) have measured a diffusivity of HDO in ice of only $10^{-14} \mathrm{~m}^{2} \mathrm{~s}^{-1}-$ isotopic equilibrium between vapour and a whole ice crystal will not occur over any reasonable timescale during the life cycle of a cloud. The mean isotopic ratio within an ice crystal, $R_{\mathrm{i}}^{(\mathrm{c})}=m^{\prime} / m$, then depends on the growth history of the crystal. Unlike in the liquid case, isotopic pseudo-equilibrium holds only between vapour and the most external layer of the crystal, and there is no transient to that state.

The condition of equilibrium at the ice surface yields

$R_{\mathrm{i}}^{(\mathrm{s})}=\frac{\mathrm{d} m^{\prime} / \mathrm{d} t}{\mathrm{~d} m / \mathrm{d} t}$.

\footnotetext{
${ }^{3}$ It appears that the definition of $A_{1}$ in this work is reversed from its initial expression in Jouzel et al. (1975).
} 
The instantaneous kinetic fractionation factor between ice surface and vapour within the air parcel $\alpha_{\mathrm{ki}}=R_{\mathrm{i}}^{(\mathrm{s})} / R_{\mathrm{v}}^{(\infty)}$ can then be readily derived upon replacing Eq. (B9) in Eq. (B8), using Eq. (A5) and re-arranging thusly:

$\alpha_{\mathrm{ki}}=\frac{\alpha_{\mathrm{i}}}{1+\left(\beta_{\mathrm{i}}-1\right)\left(1-\left(S_{\mathrm{i}}^{(\mathrm{eff})}\right)^{-1}\right)}$,

where $S_{\mathrm{i}}^{(\text {eff) }}=\left[1-A_{\mathrm{i}}\left(1-S_{\mathrm{i}}^{-1}\right)\right]^{-1}$ is the effective saturation over ice taken at the temperature of the air parcel and $\beta_{\mathrm{i}}=\alpha_{\mathrm{i}} \frac{K_{\mathrm{v}}}{K_{\mathrm{v}}^{\prime}} \frac{f_{\mathrm{v}}}{f_{\mathrm{v}}^{\prime}}$. Equation (B10) corresponds to Eq. (14) of Jouzel and Merlivat (1984). Note that the expression of $\alpha_{\mathrm{ki}}$ is formally equivalent to that of $\alpha_{\mathrm{kl}}^{(\mathrm{eq})}$ although there is no global equilibrium in this case.

Since $f_{\mathrm{v}} / f_{\mathrm{v}}^{\prime}$ and $f_{\mathrm{v}} / f_{\mathrm{h}}$ do not deviate from 1 by more, respectively, than $0.5 \%$ and $2 \%$ over all circumstances (see Supplement Sect. 1), we systematically set these ratios to 1 in our computations of kinetic fractionation factors.

\section{Appendix C}

\section{Water vapour supersaturation and phase relaxation time}

The supersaturation of water vapour in convective clouds depends on the speed of updraft $w_{\text {up }}$ and on the microphysical characteristics of droplets and ice particles. We summarise below the theory of supersaturation in clouds (restricted to unmixed evolutions) developed by Korolev and Mazin (2003).

From the conservation of total water and energy and the growth rates of droplets and ice crystals, the saturation of water vapour over liquid water $S_{l}=\rho_{\mathrm{v}} / \rho_{\text {sat }}^{1}$ within an air parcel evolves according to Eq. (9) of Korolev and Mazin (2003):

$$
\begin{aligned}
\frac{1}{S_{1}} \frac{\mathrm{d} S_{1}}{\mathrm{~d} t}=c_{0} w_{\text {up }}- & c_{2} B_{\mathrm{i}}^{*} N_{\mathrm{i}} \overline{a_{\mathrm{i}}} \\
& -\left(c_{1} B_{1} N_{1} \bar{a}+c_{2} B_{\mathrm{i}} N_{\mathrm{i}} \overline{a_{\mathrm{i}}}\right)\left(S_{1}-1\right),
\end{aligned}
$$

where $N_{1}$ and $N_{\mathrm{i}}$ are the number concentration of droplets and ice particles, $\bar{a}$ and $\overline{a_{\mathrm{i}}}$ are the average radii of the droplets and ice particles distributions (i.e. $\quad \bar{a}=\int N_{\mathrm{l}}(a) a d a / \int N_{\mathrm{l}}(a) d a \quad$ and $\left.\overline{a_{\mathrm{i}}}=\int N_{\mathrm{i}}\left(a_{\mathrm{i}}\right) a_{\mathrm{i}} d a_{\mathrm{i}} / \int N_{\mathrm{i}}\left(a_{\mathrm{i}}\right) d a_{\mathrm{i}}\right)$. The remaining coefficients are defined as $c_{0}=g\left(L_{1} R_{d}^{*} /\left(c_{\mathrm{p}} R_{\mathrm{v}}^{*} T\right)-1\right) /\left(R_{d}^{*} T\right)$, $c_{1}=1 / r_{\mathrm{v}}+L_{1}^{2} /\left(c_{\mathrm{p}} R_{\mathrm{v}}^{*} T^{2}\right), c_{2}=1 / r_{\mathrm{v}}+L_{1} L_{\mathrm{i}} /\left(c_{\mathrm{p}} R_{\mathrm{v}}^{*} T^{2}\right), B_{1}=$ $4 \pi K_{\mathrm{v}} A_{\mathrm{l}} \rho_{\mathrm{sat}}^{1} \rho^{-1}, B_{\mathrm{i}}=4 \pi K_{\mathrm{v}} A_{\mathrm{i}} \rho_{\mathrm{sat}}^{\mathrm{i}} \rho^{-1}\left(C / a_{\mathrm{i}}\right)\left(e_{\mathrm{sat}}^{1} / e_{\mathrm{sat}}^{\mathrm{i}}\right)$ and $B_{\mathrm{i}}^{*}=4 \pi K_{\mathrm{v}} A_{\mathrm{i}} \rho_{\mathrm{sat}}^{\mathrm{i}} \rho^{-1}\left(C / a_{\mathrm{i}}\right)\left(e_{\mathrm{sat}}^{1} / e_{\mathrm{sat}}^{\mathrm{i}}-1\right)$. Eq. (C1) is derived under the quasi-hydrostatic approximation and therefore is questionable for very large updraft velocity.

Equation $(\mathrm{C} 1)$ is the basis for predicting the evolution of vapour saturation in convective clouds. In order to integrate it, one must know the dependence of the quantities $N_{1} \bar{a}$ and $N_{\mathrm{i}} \overline{a_{\mathrm{i}}}$ upon diffusional growth and new nuclei activation, which is not feasible in our model.
Equation (C1) still offers several insights upon inspection. Assuming that changes in the quantities $N_{1} \bar{a}$ and $N_{\mathrm{i}} \overline{a_{\mathrm{i}}}$ can be neglected (this rules out new nuclei activation and demands that integration of Eq. (C1) be performed over a time period no longer than the time of phase adjustment, to be defined below), Eq. (C1) describes adjustment of $S_{1}$ to a quasi-steady saturation $S_{\mathrm{qsl}}$ over a characteristic time referred to as the time of phase relaxation $\tau_{\mathrm{pl}}$ by Korolev and Mazin (2003).

We first consider phase relaxation over pure liquid water and over pure ice separately. In the former case, setting $N_{\mathrm{i}}=0$ in Eq. (C1) gives the expression for the quasi-steady saturation over liquid water $S_{\mathrm{qsl}}$ and the time of phase relaxation over liquid water $\tau_{\mathrm{pl}}$ (Eqs. (16) and (17) of Korolev and Mazin, 2003):

$S_{\mathrm{qsl}}=1+\frac{c_{0} w_{\mathrm{up}}}{c_{1} B_{1} N_{1} \bar{a}} \quad ; \quad \tau_{\mathrm{pl}}=\frac{1}{c_{0} w_{\mathrm{up}}+c_{1} B_{1} N_{1} \bar{a}}$.

Similarly, setting $N_{1}=0$ and using the fact that $S_{\mathrm{i}}=$ $\left(e_{\mathrm{sat}}^{1} / e_{\mathrm{sat}}^{\mathrm{i}}\right) S_{\mathrm{l}}$, Eq. (C1) may be rewritten to yield the quasisteady value of saturation over ice $S_{\mathrm{qsi}}$ and the time of phase relaxation over ice $\tau_{\text {pi }}$ (Eqs. (20) and (21) of Korolev and Mazin, 2003):

$S_{\mathrm{qsi}}=1+\frac{c_{0} w_{\mathrm{up}}}{c_{3} B_{\mathrm{i} 0} N_{\mathrm{i}} \overline{a_{\mathrm{i}}}} \quad ; \quad \tau_{\mathrm{pi}}=\frac{1}{c_{0} w_{\mathrm{up}}+c_{3} B_{\mathrm{i} 0} N_{\mathrm{i}} \overline{a_{\mathrm{i}}}}$,

where the new coefficients are defined as $c_{3}=1 / r_{\mathrm{v}}+$ $L_{\mathrm{i}}^{2} /\left(c_{\mathrm{p}} R_{\mathrm{v}}^{*} T^{2}\right)$ and $B_{\mathrm{i} 0}=4 \pi K_{\mathrm{v}} A_{\mathrm{i}} \rho_{\mathrm{sat}}^{\mathrm{i}} \rho^{-1}\left(C / a_{\mathrm{i}}\right)$.

One sees that the departure from saturation of vapour over pure liquid water or ice tends to be proportional to the speed of updraft $w_{\text {up }}$ and inversely proportional to $N_{1} \bar{a}$ or $N_{\mathrm{i}} \overline{a_{\mathrm{i}}}$. Profiles of $S_{\mathrm{qsl}}-1, S_{\mathrm{qsi}}-1, \tau_{\mathrm{pl}}$ and $\tau_{\mathrm{pi}}$ are displayed in Fig. B1, for an updraft velocity of $10 \mathrm{~m} \mathrm{~s}^{-1}$ and typical values of $N_{\mathrm{l}} \bar{a}$ or $N_{\mathrm{i}} \overline{a_{\mathrm{i}}}$ found in liquid water and ice clouds. Because number concentrations of droplets are much higher than those of ice crystals, departures from liquid saturation do not exceed a few percentage points (a fact already noticed by Warner, 1968) and the time of phase relaxation is sufficiently fast to support the use of saturation adjustment over liquid in most models. Figure B1 shows that $S_{\mathrm{qsl}}-1$ and $\tau_{\mathrm{pl}}$ reach up to $1.5 \%$ and $3 \mathrm{~s}$ for $N_{1} \bar{a}=10^{3} \mu \mathrm{mcm}^{-3}$, dropping to $0.3 \%$ and $0.3 \mathrm{~s}$ for $N_{1} \bar{a}=10^{4} \mu \mathrm{mcm}^{-3}$. On the contrary, large departures from ice saturation and long phase adjustment times are expected for vapour over pure ice. $S_{\mathrm{qsi}}-1$ and $\tau_{\mathrm{pi}}$ are respectively in the range $12-14 \%$ and $13-19 \mathrm{~s}$ for $N_{\mathrm{i}} \overline{a_{\mathrm{i}}}=10^{2} \mu \mathrm{mcm}^{-3}$, reaching $1200-1400 \%$ and $95-155 \mathrm{~s}$ for $N_{\mathrm{i}} \overline{a_{\mathrm{i}}}=1 \mu \mathrm{m} \mathrm{cm}^{-3}$. However, for $T>-40^{\circ} \mathrm{C}$, supersaturation over ice is unlikely to get above the value set by equilibrium saturation over liquid water since activation of cloud condensation nuclei will happen in large numbers past that limit.

In the mixed-phase zone, when liquid water and ice coexist, $S_{\mathrm{qsl}}$ and $\tau_{\mathrm{pl}}$ read as (Eqs. (12) and (13) of Korolev and 
Mazin, 2003):

$$
\begin{aligned}
& S_{\mathrm{qsl}}=1+\frac{c_{0} w_{\mathrm{up}}-c_{2} B_{\mathrm{i}}^{*} N_{\mathrm{i}} \overline{a_{\mathrm{i}}}}{c_{1} B_{1} N_{1} \bar{a}+c_{2} B_{\mathrm{i}} N_{\mathrm{i}} \overline{a_{\mathrm{i}}}} ; \\
& \tau_{\mathrm{pl}}=\frac{1}{c_{0} w_{\mathrm{up}}+c_{1} B_{1} N_{1} \bar{a}+\left(c_{2} B_{\mathrm{i}}+c_{2} B_{\mathrm{i}}^{*}\right) N_{\mathrm{i}} \overline{a_{\mathrm{i}}}} .
\end{aligned}
$$

The disequilibrium between liquid water and ice would alone tend to adjust vapour saturation to an intermediate value between saturation over ice and saturation over liquid, only a few percentage points below liquid saturation as long as $N_{\mathrm{i}} \overline{a_{\mathrm{i}}} \ll N_{\mathrm{l}} \bar{a}$. At the same time, uplift acts to increase vapour saturation and drives $S_{\mathrm{qsl}}$ above 1 when vertical velocity exceeds $w_{\mathrm{up}}^{*}=c_{2} B_{\mathrm{i}}^{*} N_{\mathrm{i}} \overline{a_{\mathrm{i}}} / c_{0}$, as shown by Korolev and Mazin (2003). Under such conditions of strong updraft, water uptake occurs mostly on droplets until glaciation is sufficiently advanced that ice crystals exert control on saturation (i.e. $N_{\mathrm{i}} \overline{a_{\mathrm{i}}}$ is large enough, cf. Fig. (8) of Korolev and Mazin, 2003) and promote droplet evaporation, or until the limit of homogeneous freezing is reached.

In summary, the following picture of vapour saturation and diffusional growth processes in convective clouds emerges from Korolev and Mazin (2003):

- above $0{ }^{\circ} \mathrm{C}$, vapour saturation instantaneously adjusts to within up to a few percentage points of the equilibrium value over liquid water.

- between $0{ }^{\circ} \mathrm{C}$ and $-40^{\circ} \mathrm{C}$, as long as glaciation is not advanced, and provided conditions of strong updraft $\left(w_{\text {up }}>w_{\text {up }}^{*}\right)$, droplets take up all the available vapour and still limit supersaturation over liquid water to up to few percentage points.

- as glaciation proceeds, vapour saturation is increasingly controlled by ice crystals. Quasi-steady values of vapour saturation then range from saturation over ice to saturation over liquid (and possibly more when $T<$ $-40^{\circ} \mathrm{C}$ ), depending on updraft velocity and on $N_{\mathrm{i}} \overline{a_{\mathrm{i}}}$, with corresponding values of phase relaxation times ranging from tens of seconds to several minutes. Vapour saturation in that part of the cloud is expected to vary with the phase in the cloud life cycle.

\section{Appendix D}

\section{Thermodynamic and isotopic quantities}

\section{D1 Thermodynamic expressions}

We summarise here the standard thermodynamic expressions and constants used in this study.
Values of thermodynamic specific capacities and gas constants:

$$
\begin{aligned}
R_{\mathrm{v}}^{*} & =461 \mathrm{~J} \mathrm{~kg}^{-1} \mathrm{~K}^{-1}, \\
R_{d}^{*} & =287 \mathrm{~J} \mathrm{~kg}^{-1} \mathrm{~K}^{-1}, \\
c_{\mathrm{pv}} & =1885 \mathrm{~J} \mathrm{~kg}^{-1} \mathrm{~K}^{-1}, \\
c_{1} & =4186 \mathrm{~J} \mathrm{~kg}^{-1} \mathrm{~K}^{-1}, \\
c_{\mathrm{i}} & =2106 \mathrm{~J} \mathrm{~kg}^{-1} \mathrm{~K}^{-1},
\end{aligned}
$$

with $\epsilon=R_{d}^{*} / R_{\mathrm{v}}^{*}=0.622$.

Latent heats:

$L_{1(0)}=2.501 \times 10^{6} \mathrm{~J} \mathrm{~kg}^{-1}$,

$L_{1}=L_{1(0)}-\left(c_{1}-c_{\mathrm{pv}}\right)(T-273.15)$,

$L_{\mathrm{i}(0)}=2.836 \times 10^{6} \mathrm{~J} \mathrm{~kg}^{-1}$,

$L_{\mathrm{i}}=L_{\mathrm{i}(0)}-\left(c_{\mathrm{i}}-c_{\mathrm{pv}}\right)(T-273.15)$.

Saturation vapour pressure over liquid, after Murphy and Koop (2005) (unit Pa):

$$
\begin{aligned}
& e_{\text {sat }}^{1}=\exp \left(54.842763-\frac{6763.22}{T}-4.210 \ln (T)\right. \\
& +0.000367 T+\tanh (0.0415(T-218.8)) \\
& \left.\times\left(53.878-\frac{1331.22}{T}-944523 \ln (T)+0.014025 T\right)\right) .
\end{aligned}
$$

This expression is given as accurate within $0.05 \%$ between $123 \mathrm{~K}$ and $332 \mathrm{~K}$.

Saturation vapour pressure over ice, after Murphy and Koop (2005) (unit Pa):

$$
\begin{aligned}
e_{\mathrm{sat}}^{\mathrm{i}}=\exp (9.550426 & -\frac{5723.265}{T} \\
+ & 3.53068 \ln (T)-0.00728332 T) .
\end{aligned}
$$

Ice density is fixed at $\rho_{\text {ice }}=0.9 \times 10^{3} \mathrm{~kg} \mathrm{~m}^{-3}$, which corresponds to pure water composition without any included air.

Note that the expression of $\theta_{\mathrm{il}}$ given in Eq. (7) is strictly valid only for fixed thermodynamic capacities while Eqs. (D1) and (D2) take into account the variation of the thermodynamic capacities with temperature. This small inconsistency has no practical effect for temperature computation, but allows more accurate expression of vapour sub/supersaturation in kinetic fractionation factors.

\section{D2 Reference isotopic ratio}

The reference isotopic ratio of deuterium for VSMOW is provided in the literature (Hagemann et al., 1970) as a ratio of abundances of deuterium to hydrogen $[\mathrm{D}] /[\mathrm{H}]$ and 
takes the value $1.5576 \pm 0.0005 \times 10^{-4}$. In this study, we consider the ratio of mass of $\mathrm{HDO}$ to $\mathrm{H}_{2} \mathrm{O}$, which involves a multiplication by a factor two and by the ratio of molecular mass of HDO to $\mathrm{H}_{2} \mathrm{O}$, i.e. 19/18. Hence, we have $R_{0}\left[\mathrm{HDO} / \mathrm{H}_{2} \mathrm{O}\right]=3.2891 \times 10^{-4}$. In the same way, the VSMOW reference isotopic ratio of oxygen-18, as found in the literature, is transformed to $R_{0}\left[\mathrm{H}_{2}{ }^{18} \mathrm{O} / \mathrm{H}_{2} \mathrm{O}\right]=22.28 \times$ $10^{-4}$ in our study.

\section{D3 Equilibrium fractionation factors}

The equilibrium fractionation factors depend only on temperature and have been measured in the laboratory for $\mathrm{HDO} / \mathrm{H}_{2} \mathrm{O}$ by Merlivat and Nief (1967) who provide the following semi-empirical expressions, based on measurements made between $-11^{\circ} \mathrm{C}$ and $5.5^{\circ} \mathrm{C}$ for liquid-vapour phase transition and between $-33^{\circ} \mathrm{C}$ and $-6^{\circ} \mathrm{C}$ for ice-vapour phase transition:

$\alpha_{1}\left(\mathrm{HDO} / \mathrm{H}_{2} \mathrm{O}\right)=\exp \left(\frac{15013}{T^{2}}-0.1\right)$,

$\alpha_{\mathrm{i}}\left(\mathrm{HDO} / \mathrm{H}_{2} \mathrm{O}\right)=\exp \left(\frac{16289}{T^{2}}-0.0945\right)$.

The corresponding expressions for $\mathrm{H}_{2}{ }^{18} \mathrm{O} / \mathrm{H}_{2} \mathrm{O}$ have been obtained by Majoube (1971) and Majoube (1970), yielding

$$
\begin{aligned}
& \alpha_{1}\left(\mathrm{H}_{2}{ }^{18} \mathrm{O} / \mathrm{H}_{2} \mathrm{O}\right)=\exp \left(\frac{1137}{T^{2}}-\frac{0.4156}{T}-0.0020667\right), \\
& \alpha_{\mathrm{i}}\left(\mathrm{H}_{2}{ }^{18} \mathrm{O} / \mathrm{H}_{2} \mathrm{O}\right)=\exp \left(\frac{11.839}{T}-0.028224\right) .
\end{aligned}
$$

\section{D4 Thermal conductivity}

The thermal conductivity of moist air is calculated according to Eqs. (13-16), (13-17) and (13-18) of Pruppacher and Klett (1978) using Mason and Saxena (1958) theory.

For dry air and water vapour, thermal conductivities are, respectively,

$k_{a}=4.3783 \times 10^{-3}+7.1128 \times 10^{-5} T \mathrm{~J} \mathrm{~m}^{-1} \mathrm{~s}^{-1} \mathrm{~K}^{-1}$,

$k_{\mathrm{v}}=-7.0417 \times 10^{-3}+8.368 \times 10^{-5} T \mathrm{Jm}^{-1} \mathrm{~s}^{-1} \mathrm{~K}^{-1}$.

The thermal conductivity of moist air is then $k_{\mathrm{h}}=$ $k_{a}\left(1-\left(\gamma_{1}-\gamma_{2} \frac{k_{\mathrm{v}}}{k_{a}}\right) \frac{r_{\mathrm{v}}}{r_{\mathrm{v}}+\epsilon}\right)$ with $\gamma_{1}=1.17$ and $\gamma_{2}=1.02$.

\section{D5 Molecular diffusivity}

The ratio of heavy to light vapour molecular diffusivity in air has been measured by Merlivat (1978) for $\mathrm{HDO} / \mathrm{H}_{2} \mathrm{O}$ and $\mathrm{H}_{2}{ }^{18} \mathrm{O} / \mathrm{H}_{2} \mathrm{O}$. These measurements have been done at $21^{\circ} \mathrm{C}$ and atmospheric pressure in a nitrogen atmosphere, and extended to air using the kinetic theory of gas. The ratios are

$$
\begin{aligned}
K_{\mathrm{v}}\left(\mathrm{H}_{2} \mathrm{O}\right) / K_{\mathrm{v}}^{\prime}(\mathrm{HDO}) & =1.0251, \\
K_{\mathrm{v}}\left(\mathrm{H}_{2} \mathrm{O}\right) / K_{\mathrm{v}}^{\prime}\left(\mathrm{H}_{2}{ }^{18} \mathrm{O}\right) & =1.0289 .
\end{aligned}
$$

The rigid elastic sphere approximation from gas kinetic theory predicts that these ratios are independent of temperature and pressure (Merlivat, 1978).

The molecular diffusivity of light vapour in air has been measured by Hall and Pruppacher (1976), yielding $K_{\mathrm{v}}=$ $0.211 \times 10^{-4}\left(\frac{1013.25}{p}\right)\left(\frac{T}{273.15}\right)^{1.94} \mathrm{~m}^{2} \mathrm{~s}^{-1}$ where $p$ is in $\mathrm{hPa}$ and $T$ in $\mathrm{K}$.

The diffusivity of water molecules within the crystal lattice of hexagonal ice is about $10^{-14} \mathrm{~m}^{2} \mathrm{~s}^{-1}$ (Kuhn and Thürkauf, 1958), and self-diffusivity of liquid water is about $10^{-9} \mathrm{~m}^{2} \mathrm{~s}^{-1}$ (Wang, 1951a).

\section{Supplementary material related to this article is available online at: http://www.atmos-chem-phys.net/13/ 7903/2013/acp-13-7903-2013-supplement.pdf.}

Acknowledgements. This work was supported in part by grants from INSU and from the NSF International Collaboration in Chemistry program (grant no. 1026830). M. Bolot acknowledges fellowships from Ecole Normale Supérieure and Université Pierre et Marie Curie. The authors thank Jim Anderson for hosting M. Bolot during the initiation of this work and Jean Jouzel, Jun-Ichi Yano, Hector Teitelbaum and one anonymous reviewer for helpful discussions. They are grateful to Peter Blossey for his thorough review that has significantly improved the quality and presentation of the manuscript.

Edited by: F. Fierli

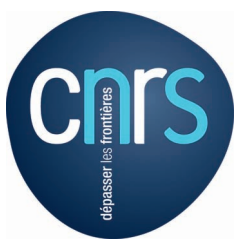

The publication of this article is financed by CNRS-INSU.

\section{References}

Bergeron, T.: On the physics of clouds and precipitation, in: Procès Verbaux de l'Association de Météorologie, International Union of Geodesy and Geophysics, 156-178, 1935.

Berkelhammer, M., Risi, C., Kurita, N., and Noone, D. C.: The moisture source sequence for the Madden-Julian oscillation as derived from satellite retrievals of $\mathrm{HDO}$ and $\mathrm{H}_{2} \mathrm{O}$, J. Geophys. Res., 117, D03106, doi:10.1029/2011JD016803, 2012.

Bigeleisen, J.: Statistical mechanics of isotope effects on the thermodynamic properties of condensed systems, J. Chem. Phys., 34, 1485-1493, doi:10.1063/1.1701033, 1961.

Blossey, P. N., Kuang, Z., and Romps, D. M.: Isotopic composition of water in the tropical tropopause layer in cloud-resolving simulations of an idealized tropical circulation, J. Geophys. Res., 115, D24309, doi:10.1029/2010JD014554, 2010.

Bony, S., Risi, C., and Vimeux, F.: Influence of convective processes on the isotopic composition $\left(\delta^{18} \mathrm{O}\right.$ and 
$\delta \mathrm{D})$ of precipitation and water vapor in the tropics: 1 . Radiative-convective equilibrium and tropical ocean-global atmosphere-coupled ocean-atmosphere response experiment (TOGA-COARE) simulations, J. Geophys. Res., 113, D19305, doi:10.1029/2008JD009942, 2008.

Botev, Z. I., Grotowski, J. F., and Kroese, D. P.: Kernel density estimation via diffusion, The Annals of Statistics, 38, 2916-2957, doi:10.1214/10-AOS799, 2010.

Bryan, G. H. and Fritsch, J. M.: A reevaluation of ice-liquid water potential temperature, Mon. Weather Rev., 132, 2421-2431, doi:10.1175/1520-0493(2004)132<2421:AROIWP>2.0.CO;2, 2004.

Chapman, S. and Cowling, T. G.: The Mathematical Theory of Non Uniform Gases, Cambridge Mathematical Library, Cambridge Univ. Press, Cambridge, UK, 1970.

Ciais, P. and Jouzel, J.: Deuterium and oxygen 18 in precipitation: isotopic model, including mixed cloud processes, J. Geophys. Res., 99, 16793-16803, doi:10.1029/94JD00412, 1994.

Cotton, W. R., Bryan, G. H., and van den Heever, S. C.: Storm and cloud dynamics, vol. 99 of International Geophysics Series, Academic Press, 2nd Edn., 2011.

Couhert, A., Schneider, T., Li, J., Waliser, D. E., and Tompkins, A. M.: The maintenance of the relative humidity of the subtropical free troposphere, J. Climate, 23, 390-403, doi:10.1175/2009JCLI2952.1, 2010.

Craig, H.: Isotopic variations in meteoric waters, Science, 133, 1702-1703, doi:10.1126/science.133.3465.1702, 1961a.

Craig, H.: Standard for reporting concentrations of deuterium and oxygen-18 in natural waters, Science, 133, 1833-1834, doi:10.1126/science.133.3467.1833, 1961 b.

Craig, H. and Gordon, L. I.: Deuterium and oxygen-18 variations in the ocean and the marine atmosphere, in: Proceedings of a Conference on Stable Isotopes in Oceanographic Studies and Paleotemperatures, edited by: Tongiorgi, E., Spoleto, Italy, 9-130, 1965.

Dansgaard, W.: Stable isotops in precipitation, Tellus, 16, 436-468, doi:10.1111/j.2153-3490.1964.tb00181.x, 1964.

Dee, D. P., Uppala, S. M., Simmons, A. J., Berrisford, P., Poli, P., Kobayashi, S., Andrae, U., Balmaseda, M. A., Balsamo, G., Bauer, P., Bechtold, P., Beljaars, A. C. M., van de Berg, L., Bidlot, J., Bormann, N., Delsol, C., Dragani, R., Fuentes, M., Geer, A. J., Haimberger, L., Healy, S. B., Hersbach, H., Hólm, E. V., Isaksen, L., Kållberg, P., Köhler, M., Matricardi, M., McNally, A. P., Monge-Sanz, B. M., Morcrette, J.-J., Park, B.K., Peubey, C., de Rosnay, P., Tavolato, C., Thépaut, J.-N., and Vitart, F.: The ERA-Interim reanalysis: configuration and performance of the data assimilation system, Q. J. Roy. Meteorol. Soc., 137, 553-597, doi:10.1002/qj.828, 2011.

DePaolo, D. J.: Surface kinetic model for isotopic and trace element fractionation during precipitation of calcite from aqueous solutions, Geochim. Cosmochim. Ac., 75, 1039-1056, 2011.

Federer, B., Brichet, N., and Jouzel, J.: Stable isotopes in hailstones. Part 1: The isotopic cloud model, J. Atmos. Sci., 39, 1323-1335, doi:10.1175/1520-0469(1982)039<1323:SIIHPI > 2.0.CO;2, 1982.

Fierro, A. O., Simpson, J., Lemone, M. A., Straka, J. M., and Smull, B. F.: On how hot towers fuel the hadley cell: an observational and modeling study of line-organized convection in the equatorial trough from TOGA COARE, J. Atmos. Sci., 66, 2730,
doi:10.1175/2009JAS3017.1, 2009.

Folkins, I. and Martin, R. V.: The vertical structure of tropical convection and its impact on the budgets of water vapor and ozone, J. Atmos. Sci., 62, 1560-1573, doi:10.1175/JAS3407.1, 2005.

Fudeyasu, H., Ichiyanagi, K., Sugimoto, A., Yoshimura, K., Ueta, A., Yamanaka, M. D., and Ozawa, K.: Isotope ratios of precipitation and water vapor observed in Typhoon Shanshan, J. Geophys. Res., 113, D12113, doi:10.1029/2007JD009313, 2008.

Galewsky, J., Sobel, A., and Held, I.:Diagnosis of Subtropical Humidity Dynamics Using Tracers of Last Saturation, J. Atmos. Sci., 62, 3353-3367, doi:10.1175/JAS3533.1, 2005.

Gedzelman, S. D. and Arnold, R.: Modeling the isotopic composition of precipitation, J. Geophys. Res., 99, 10455-10472, doi:10.1029/93JD03518, 1994.

Gedzelman, S. D. and Lawrence, J. R.: The isotopic composition of cyclonic precipitation., J. Appl. Meteor., 21, 1385-1404 doi:10.1175/1520-0450(1982)021<1385:TICOCP > 2.0.CO;2, 1982.

Gonfiantini, R.: Standards for stable isotope measurements in natural compounds, Nature, 271, 534-536, doi:10.1038/271534a0, 1978.

Hagemann, R., Nief, G., and Roth, E.: Absolute isotopic scale for deuterium analysis of natural waters. Absolute $\mathrm{D} / \mathrm{H}$ ratio for SMOW, Tellus, 22, 712-715, doi:10.1111/j.21533490.1970.tb00540.x, 1970.

Hall, W. D. and Pruppacher, H. R.: The survival of ice particles falling from cirrus clouds in subsaturated air, J. Atmos. Sci., 33, 1995-2006, doi:10.1175/15200469(1976)033<1995:TSOIPF>2.0.CO;2, 1976.

Hanisco, T. F., Moyer, E. J., Weinstock, E. M., St. Clair, J. M., Sayres, D. S., Smith, J. B., Lockwood, R., Anderson, J. G., Dessler, A. E., Keutsch, F. N., Spackman, J. R., Read, W. G., and Bui, T. P.: Observations of deep convective influence on stratospheric water vapor and its isotopic composition, Geophys. Res. Lett., 34, L04814, doi:10.1029/2006GL027899, 2007.

Herbin, H., Hurtmans, D., Clerbaux, C., Clarisse, L., and Coheur, P.-F.: $\mathrm{H}_{2}{ }^{16} \mathrm{O}$ and HDO measurements with IASI/MetOp, Atmos. Chem. Phys., 9, 9433-9447, doi:10.5194/acp-9-9433-2009, 2009.

Herzfeld, K. F. and Teller, E.: The vapor pressure of isotopes, Phys. Rev., 54, 912-915, doi:10.1103/PhysRev.54.912, 1938.

Hoffmann, G., Werner, M., and Heimann, M.: Water isotope module of the ECHAM atmospheric general circulation model: a study on timescales from days to several years, J. Geophys. Res., 103, 16871-16896, doi:10.1029/98JD00423, 1998.

Houze, R. A. J.: Cloud Dynamics, vol. 53 of International Geophysics Series, Academic Press, San Diego, 1993.

Johnson, D. A. and Hallett, J.: Freezing and shattering of supercooled water drops, Q. J. Roy. Meteorol. Soc., 94, 468-482, doi:10.1002/qj.49709440204, 1968.

Joussaume, S., Sadourny, R., and Jouzel, J.: A general circulation model of water isotope cycles in the atmosphere, Nature, 311, 24-29, doi:10.1038/311024a0, 1984

Jouzel, J. and Merlivat, L.: Deuterium and oxygen 18 in precipitation: modeling of the isotopic effects during snow formation, J. Geophys. Res., 89, 11749-11758, doi:10.1029/JD089iD07p11749, 1984. 
Jouzel, J., Merlivat, L., and Roth, E.: Isotopic study of hail, J. Geophys. Res., 80, 5015-5030, doi:10.1029/JC080i036p05015, 1975.

Jouzel, J., Russell, G. L., Suozzo, R. J., Koster, R. D., White, J. W. C. and Broecker, W. S.: Simulations of the HDO and $\mathrm{H}_{2}{ }^{18} \mathrm{O}$ atmospheric cycles using the NASA/GISS general circulation model: The seasonal cycle for presentday conditions, J. Geophys. Res., 92, 14739-14760, doi:10.1029/JD092iD12p14739,1987.

Kirkpatrick, C., McCaul, E. W., and Cohen, C.: Variability of updraft and downdraft characteristics in a large parameter space study of convective storms, Mon. Weather Rev., 137, 1550, doi:10.1175/2008MWR2703.1, 2009.

Korolev, A. V.: Limitations of the Wegener Bergeron Findeisen mechanism in the evolution of mixed-phase clouds, J. Atmos. Sci., 64, 3372-3375, doi:10.1175/JAS4035.1, 2007.

Korolev, A. and Isaac, G. A.: Relative Humidity in Liquid, Mixed-Phase, and Ice Clouds, J. Atmos. Sci., 63, 2865-2880, doi:10.1175/JAS3784.1, 2006.

Korolev, A. V. and Mazin, I. P.: Supersaturation of water vapor in clouds, J. Atmos. Sci., 60, 2957-2974, doi:10.1175/15200469(2003)060<2957:SOWVIC>2.0.CO;2, 2003.

Kuang, Z., Toon, G. C., Wennberg, P. O., and Yung, Y. L.: Measured $\mathrm{HDO} / \mathrm{H}_{2} \mathrm{O}$ ratios across the tropical tropopause, Geophys. Res. Lett., 30, 1372, doi:10.1029/2003GL017023, 2003.

Kuhn, W. and Thürkauf, M.: Isotopentrennung beim Gefrieren von Wasser und Diffusionskonstanten von $\mathrm{D}$ und ${ }^{18} \mathrm{O}$ im Eis. Mit Diskussion der Möglichkeit einer Multiplikation der beim Gefrieren auftretenden Isotopentrennung in einer Haarnadelgegenstromvorrichtung, Helv. Chim. Acta, 41, 938-971, doi:10.1002/hlca.19580410408, 1958.

Kumjian, M. R., Ganson, S. M., and Ryzhkov, A. V.: Freezing of Raindrops in Deep Convective Updrafts: A Microphysical and Polarimetric Model,J. Atmos. Sci., 69, 3471-3490, doi:10.1175/JAS-D-12-067.1, 2012.

Kurita, N., Noone, D., Risi, C., Schmidt, G. A., Yamada, H., and Yoneyama, K.: Intraseasonal isotopic variation associated with the Madden-Julian oscillation, J. Geophys. Res., 116, D24101, doi:10.1029/2010JD015209, 2011.

Kuroda, T.: Rate determining processes of growth of ice crystals from the vapour phase. I: Theoretical consideration, J. Meteor. Soc. Japan, 62, 552-562, 1984.

Kursinski, E. R., Feng, D., Flittner, D., Hajj, G., Herman, B., Romberg, F., Syndergaard, S., Ward, D., and Yunck, T.: An active microwave limb sounder for profiling water vapour, ozone, temperature, geopotential, clouds, isotopes and stratospheric winds, in: Occulations for Probing Atmosphere and Climate (OPAC-1), Springer-Verlag, Berlin, 2004.

Lanotte, A. S., Seminara, A., and Toschi, F.: Cloud droplet growth by condensation in homogeneous isotropic turbulence, J. Atmos. Sci., 66, 1685-1697, doi:10.1175/2008JAS2864.1, 2009.

Lawrence, J. R. and Gedzelman, S. D.: Low stable isotope ratios of tropical cyclone rains, Geophys. Res. Lett., 23, 527-530, doi:10.1029/96GL00425, 1996.

Lawrence, J. R. and Gedzelman, S. D.: Tropical ice core isotopes: do they reflect changes in storm activity?, Geophys. Res. Lett., 30, 1072, doi:10.1029/2002GL015906, 2003.

Lawrence, J. R., Gedzelman, S. D., Dexheimer, D., Cho, H., Carrie, G. D., Gasparini, R., Anderson, C. R., Bowman, K. P., and Biggerstaff, M. I.: Stable isotopic composition of water vapor in the tropics, J. Geophys. Res., 109, D06115, doi:10.1029/2003JD004046, 2004.

Lawson, R. P., Jensen, E., Mitchell, D. L., Baker, B., Mo, Q., and Pilson, B.: Microphysical and radiative properties of tropical clouds investigated in TC4 and NAMMA, J. Geophys. Res., 115, D00J08, doi:10.1029/2009JD013017, 2010.

Lee, J.-E., Fung, I., DePaolo, D. J., and Henning, C. C.: Analysis of the global distribution of water isotopes using the NCAR atmospheric general circulation model, J. Geophys. Res., 112, D16306, doi:10.1029/2006JD007657, 2007.

Lee, J.-E., Pierrehumbert, R., Swann, A., and Lintner, B. R.: Sensitivity of stable water isotopic values to convective parameterization schemes, Geophys. Res. Lett., 362, L23801, doi:10.1029/2009GL040880, 2009.

LeMone, M. A. and Zipser, E. J.: Cumulonimbus vertical velocity events in GATE. Part 1: Diameter, intensity and mass flux, J. Atmos. Sci., 37, 2444-2457, doi:10.1175/15200469(1980)037<2444:CVVEIG > 2.0.CO;2, 1980.

Majoube, M.: Fractionation factor of ${ }^{18} \mathrm{O}$ between water vapour and ice, Nature, 226, 1242, doi:10.1038/2261242a0, 1970.

Majoube, M.: Fractionnement en oxygène 18 et en deutérium entre l'eau et sa vapeur., J. Chim. Phys. Physicochim. Biol., 10, 14231436, 1971.

Mason, B. J.: On the melting of hailstones, Q. J. Roy. Meteorol. Soc., 82, 209-216, doi:10.1002/qj.49708235207, 1956.

Mason, B. J.: The Physics of Clouds, Oxfod Monogr. Meterol., Clarendon, Oxford, 1971.

Mason, E. A. and Saxena, S. C.: Approximate formula for the thermal conductivity of gas mixtures, Phys. Fluids, 1, 361-369, doi:10.1063/1.1724352, 1958.

Merlivat, L.: Molecular diffusivities of $\mathrm{H}_{2}^{16} \mathrm{O}, \mathrm{HD}^{16} \mathrm{O}$, and $\mathrm{H}_{2}^{18} \mathrm{O}$ in gases, J. Chem. Phys., 69, 2864-2871, doi:10.1063/1.436884, 1978.

Merlivat, L. and Jouzel, J.: Global climatic interpretation of the deuterium-oxygen 18 relationship for precipitation, J. Geophys. Res., 84, 5029-5033, doi:10.1029/JC084iC08p05029, 1979.

Merlivat, L. and Nief, G.: Fractionnement isotopique lors des changements d'état solide-vapeur et liquide-vapeur de l'eau à des températures inférieures à $0^{\circ} \mathrm{C}$, Tellus, 19, 122-127, doi:10.1111/j.2153-3490.1967.tb01465.x, 1967.

Moyer, E. J., Irion, F. W., Yung, Y. L., and Gunson, M. R.: ATMOS stratospheric deuterated water and implications for tropospherestratosphere transport, Geophys. Res. Lett., 23, 2385-2388, doi:10.1029/96GL01489, 1996.

Murphy, D. M. and Koop, T.: Revue of the vapour pressures of ice and supercooled water for atmospheric applications, Q. J. Roy. Meteorol. Soc., 131, 1539-1565, doi:10.1256/qj.04.94, 2005.

Nassar, R., Bernath, P. F., Boone, C. D., Gettelman, A., McLeod, S. D., and Rinsland, C. P.: Variability in $\mathrm{HDO} / \mathrm{H}_{2} \mathrm{O}$ abundance ratios in the tropical tropopause layer, J. Geophys Res., 112, D21305, doi:10.1029/2007JD008417, 2007.

Nelson, J.: Theory of isotopic fractionation on facetted ice crystals, Atmos. Chem. Phys., 11, 11351-11360, doi:10.5194/acp11-11351-2011, 2011.

Orville, H. D. and Kopp, F. J.: Numerical simulation of the life history of a hailstorm., J. Atmos. Sci., 34, 1596-1618, doi:10.1175/1520-0469(1977)034<1596:NSOTLH > 2.0.CO;2, 1977. 
Pierrehumbert, R. T. and Roca, R.: Evidence for control of atlantic subtropical humidity by large scale advection, Geophys. Res. Lett., 25, 4537-4540, doi:10.1029/1998GL900203, 1998.

Pruppacher, H. R. and Klett, J. D.: Microphysics of Clouds and Precipitation, D. Reidel, Norwell, Mass. USA, 1978.

Randel, W. J., Moyer, E., Park, M., Jensen, E., Bernath, P., Walker, K., and Boone, C.: Global variations of HDO and $\mathrm{HDO} / \mathrm{H}_{2} \mathrm{O}$ ratios in the upper troposphere and lower stratosphere derived from ACE-FTS satellite measurements, J. Geophys. Res., 117, D06303, doi:10.1029/2011JD016632, 2012.

Rayleigh, L. and Ramsay, W.: Argon, a new constituent of the atmosphere, Philos. T. Roy. Soc. Lond. A, 186, 187-241, doi:10.1098/rsta.1895.0006, 1895.

Riehl, H. and Malkus, J. S.: On the heat balance in the equatorial trough zone, Geophysica, 6, 503-537, 1958.

Risi, C., Bony, S., Vimeux, F., Descroix, L., Ibrahim, B., Lebreton, E., Mamadou, I., and Sultan, B.: What controls the isotopic composition of the African monsoon precipitation? Insights from event-based precipitation collected during the 2006 AMMA field campaign, Geophys. Res. Lett., 35, L24808, doi:10.1029/2008GL035920, 2008.

Risi, C., Bony, S., Vimeux, F., and Jouzel, J.: Water-stable isotopes in the LMDZ4 general circulation model: model evaluation for present-day and past climates and applications to climatic interpretations of tropical isotopic records, J. Geophys. Res., 115, D12118, doi:10.1029/2009JD013255, 2010.

Risi, C., Noone, D., Worden, J., Frankenberg, C., Stiller, G., Kiefer, M., Funke, B., Walker, K., Bernath, P., Schneider, M., Bony, S., Lee, J., Brown, D., and Sturm, C.: Process-evaluation of tropospheric humidity simulated by general circulation models using water vapor isotopic observations: 2 . Using isotopic diagnostics to understand the mid and upper tropospheric moist bias in the tropics and subtropics, J. Geophys. Res., 117, D05304, doi:10.1029/2011JD016623, 2012.

Romps, D. M., and Kuang, Z.: Do undiluted convective plumes exist in the upper tropical troposphere?, J. Atmos. Sci., 67, 468-484, doi:10.1175/2009JAS3184.1, 2010.

Rosenfeld, D. and Woodley, W. L.: Deep convective clouds with sustained supercooled liquid water down to $-37.5^{\circ} \mathrm{C}$, Nature, 405, 440-442, doi:10.1038/35013030, 2000.

Sayres, D. S., Moyer, E. J., Hanisco, T. F., St. Clair, J. M., Keutsch, F. N., O'Brien, A., Allen, N. T., Lapson, L., Demusz, J. N., Rivero, M., Martin, T., Greenberg, M., Tuozzolo, C., Engel, G. S., Kroll, J. H., Paul, J. B., and Anderson, J. G.: A new cavity based absorption instrument for detection of water isotopologues in the upper troposphere and lower stratosphere, Rev. of Sci. Inst., 80, 044102, doi:10.1063/1.3117349, 2009.

Sayres, D. S., Pfister, L., Hanisco, T. F., Moyer, E. J., Smith, J. B., St. Clair, J. M., O’Brien, A. S., Witinski, M. F., Legg, M., and Anderson, J. G.: Influence of convection on the water isotopic composition of the tropical tropopause layer and tropical stratosphere, J. Geophys. Res., 115, D00J20, doi:10.1029/2009JD013100, 2010.

Schmidt, G. A., Hoffmann, G., Shindell, D. T., and Hu, Y.: Modeling atmospheric stable water isotopes and the potential for constraining cloud processes and stratospheretroposphere water exchange, J. Geophys. Res., 110, D21314, doi:10.1029/2005JD005790, 2005.
Schmidt, G. A., LeGrande, A. N., and Hoffmann, G.: Water isotope expressions of intrinsic and forced variability in a coupled ocean-atmosphere model, J. Geophys. Res., 112, D10103, doi:10.1029/2006JD007781, 2007.

Sherwood, S. C., Hernández-Deckers, D., Colin, M. and Robinson, F.: Slippery thermals and the cumulus entrainment paradox, J. Atmos. Sci., 70, 2426-2442, doi:10.1175/JAS-D-120220.1, 2013.

Smith, J. A., Ackerman, A. S., Jensen, E. J., and Toon, O. B.: Role of deep convection in establishing the isotopic composition of water vapor in the tropical transition layer, Geophys. Res. Lett., 330, L06812, doi:10.1029/2005GL024078, 2006.

Squires, P.: The growth of cloud drops by condensation. I. General characteristics, Aust. J. Sci. Res. A, 5, 59-86, 1952.

Steinwagner, J., Milz, M., von Clarmann, T., Glatthor, N., Grabowski, U., Höpfner, M., Stiller, G. P., and Röckmann, T.: HDO measurements with MIPAS, Atmos. Chem. Phys., 7, 26012615, doi:10.5194/acp-7-2601-2007, 2007.

Stewart, M. K.: Stable isotope fractionation due to evaporation and isotopic exchange of falling waterdrops: applications to atmospheric processes and evaporation of lakes, J. Geophys. Res., 80, 1133-1146, doi:10.1029/JC080i009p01133, 1975.

Stichler, W., Gonfiantini, R., and Rozanski, K.: Reference and intercomparison materials for stable isotopes of light elements, IAEA-TECDOC 825, IAEA, Vienna, Austria, 1995.

Stith, J. L., Dye, J. E., Bansemer, A., Heymsfield, A. J., Grainger, C. A., Petersen, W. A., and Cifelli, R.: Microphysical observations of tropical clouds, J. Appl. Meteorol., 41, 97-117, doi:10.1175/1520-0450(2002)041<0097:MOOTC > 2.0.CO;2, 2002.

Stith, J. L., Haggerty, J. A., Heymsfield, A., and Grainger, C. A.: Microphysical characteristics of tropical updrafts in clean conditions, J. Appl. Meteorol., 43, 779-794, doi:10.1175/2104.1, 2004.

Tindall, J. C., Valdes, P. J., and Sime, L. C.: Stable water isotopes in HadCM3: isotopic signature of El Niño-Southern Oscillation and the tropical amount effect, J. Geophys. Res., 114, D04111, doi:10.1029/2008JD010825, 2009.

Tripoli, G. J. and Cotton, W. R.: The use of ice-liquid water potential temperature as a thermodynamic variable in deep atmospheric models, Mon. Weather Rev., 109, 1094-1102, doi:10.1175/15200493(1981)109<1094:TUOLLW>2.0.CO;2, 1981.

Twomey, S.: The nuclei of natural cloud formation. Part II: The supersaturation in natural clouds and the variation of cloud droplet concentration, Geofys. Pura e Appl., 43, 243-249, 1959.

Urey, H.: The thermodynamics of isotopic substances, J. Chem. Soc., 1947, 562-581, doi:10.1039/JR9470000562, 1947.

Van Hook, W. A.: Vapor pressures of the isotopic waters and ices, J. Phys. Chem., 72, 1234-1244, doi:10.1021/j100850a028, 1968.

Wang, J. H.: Self-diffusion and structure of liquid water. I. Measurement of self-diffusion of liquid water with deuterium as tracer, J. Amer. Chem. Soc., 73, 510-513, doi:10.1021/ja01146a002, $1951 \mathrm{a}$.

Wang, J. H.: Self-diffusion and structure of liquid water. II. Measurement of self-diffusion of liquid water with ${ }^{18} \mathrm{O}$ as tracer, J. Amer. Chem. Soc., 73, 4181-4183, doi:10.1021/ja01153a039, $1951 b$. 
Warner, J.: The supersaturation in natural clouds, J. Rech. Atmos., 3, 233-237, 1968.

Wegener, A.: Thermodynamik der Atmosphäre, J. A. Barth, Leipzig, 1911.

Worden, J., Noone, D., Galewsky, J., Bailey, A., Bowman, K., Brown, D., Hurley, J., Kulawik, S., Lee, J., and Strong, M.: Estimate of bias in Aura TES $\mathrm{HDO} / \mathrm{H}_{2} \mathrm{O}$ profiles from comparison of TES and in situ $\mathrm{HDO} / \mathrm{H}_{2} \mathrm{O}$ measurements at the Mauna Loa observatory, Atmos. Chem. Phys., 11, 4491-4503, doi:10.5194/acp-11-4491-2011, 2011.
Wright, J. S., Sobel, A. H., and Schmidt, G. A.: Influence of condensate evaporation on water vapor and its stable isotopes in a GCM, Geophys. Res. Lett., 361, L12804, doi:10.1029/2009GL038091, 2009.

Yoshimura, K., Kanamitsu, M., Noone, D., and Oki, T.: Historical isotope simulation using reanalysis atmospheric data, J. Geophys. Res., 113, D19108, doi:10.1029/2008JD010074, 2008. 